\title{
Preclinical Evaluation of Pharmacotherapies for Treatment of Cocaine and Opioid Abuse Using Drug Self-Administration Procedures
}

Nancy K. Mello, Ph.D., and S. Stevens Negus, Ph.D.

Drug abuse is a major public health problem, and the relationship between intravenous drug abuse and AIDS underscores the need for more effective treatment medications. Animal models of drug self-administration are useful to systematically evaluate new treatment medications and predict clinical efficacy. This review summarizes the status of preclinical evaluations of medications for treatment of cocaine and opiate abuse. The basic drug self-administration methodology and the rationale for experimental designs and outcome criteria are described. Studies of the effects of dopamine or opioid receptor agonists and antagonists as well as medications used clinically for other indications on drug selfadministration are critically examined. Where possible, the degree of concordance between clinical and preclinical studies of drug abuse treatment medications is discussed. We conclude that drug self-administration models are valuable for preclinical assessment of medication efficacy, and we recommend some strategies to further improve evaluation procedures. The discovery of more effective medications for substance abuse treatment should be facilitated by recent advances in behavioral science, pharmacology, neurobiology and medicinal chemistry. [Neuropsychopharmacology 14:375-424, 1996]
KEY WORDS: Cocaine treatment; Heroin treatment; Opioids; Substance abuse; Drug self-administration; Substance abuse treatment

Opioid abuse and cocaine abuse are major public health problems (NIDA 1995), and the development of more effective medications for drug abuse treatment is a continuing challenge. Recently, a number of factors have converged to make drug abuse treatment a highly visible national priority. The cocaine epidemic of the $1980 \mathrm{~s}$

This paper is based on a review presented at the 1993 Plenary Session of the American College of Neuropsychopharmacology. The Plenary Session was entitled "The Development of New Drugs for the Treatment of Alcohol and Cocaine Dependence: The Scientific Challenges." Preparation of this review was supported in part by grants no. DA00101, DA04059, and DA02519 from the National Institute on Drug Abuse, NIH.

From the Alcohol and Drug Abuse Research Center, McLean Hospital, Belmont, MA.

Address correspondence to Dr. Nancy K. Mello, Alcohol and Drug Abuse Research Center, McLean Hospital, 115 Mill Street, Belmont, MA 02178.

Received July 23, 1995; revised November 28, 1995; accepted December 4, 1995.
(Adams and Durell 1984; Kozel and Adams 1986) was paralleled by an increased use of cocaine by opioid-dependent and methadone-maintained patients (Kosten et al. 1986, 1987; Cushman 1988; Condelli et al. 1991). Methadone, the traditional treatment for opioid abuse (Dole 1988), has not been as effective in reducing concurrent cocaine abuse (Kosten et al. 1986, 1987, 1989a). Some patients begin or increase cocaine abuse during methadone treatment (Cushman 1988; Chaisson et al. 1989; Condelli et al. 1991; Dunteman et al. 1992). There is no uniformly effective pharmacological treatment for cocaine abuse per se, and concurrent abuse of both cocaine and opioids presents an even greater challenge for the development of treatment medications (Rawson et al. 1991; Halikas et al. 1993; Tutton and Crayton 1993; Mendelson and Mello 1996).

The urgent need to develop new pharmacotherapies is prompted in part by the link between intravenous use of cocaine and heroin and the spread of AIDS. Intravenous drug abuse and needle sharing have been estimated to account for over 30 percent of all AIDS cases and over 50 percent of AIDS cases in women (National 
Commission 1991; CDC 1993). Intravenous cocaine and heroin abuse also may accentuate the risk for AIDS, because each has direct immunosuppressive effects (Donahoe and Falek 1988; Pillai et al. 1991). One approach to AIDS prevention is more effective drug abuse treatment. Pharmacotherapies can provide treatment for larger numbers of patients than would be possible with nonpharmacological approaches and can also enhance more traditional treatment methods such as counseling and rehabilitation. These arguments were summarized in a congressional staff report entitled "Pharmacotherapy: A Strategy for the 90s" developed by a committee chaired by Senator J. R. Biden (1989). This report focused attention on the importance of developing improved pharmacotherapies for drug abuse treatment and led to the establishment of the Medications Development Division at the National Institute on Drug Abuse, National Institutes of Health.

With the impetus of congressional sanction and the specter of an accelerating epidemic of AIDS associated with intravenous drug abuse, scientific interest in pharmacotherapies for drug abuse treatment has increased. Investigators from a broad spectrum of disciplines are now concerned with the development and evaluation of new drug abuse treatment medications, and this gathering momentum was reflected by the Plenary Session of the American College of Neuropsychopharmacology, of which this review was a part. Of course, recognition of the value of pharmacotherapies for drug abuse treatment is not new. The basic arguments were clearly articulated by Dole and Nyswander (1965) in the mid-1960s and federally endorsed in the 1973 National Strategy for Drug Abuse Prevention published by the White House Special Action Office for Drug Abuse Prevention. Unfortunately, medical approaches to drug abuse treatment were often met by a series of quasimoralistic objections as well as arguments for enhanced law enforcement and interdiction of drug supplies. Advocacy for drug supply reduction strategies has persisted undiminished since the early 1900s and continues to command the greatest allocation of federal resources devoted to reducing drug abuse (Musto 1973). This political emphasis has often obscured the real benefits of methadone treatment for opioid dependence while exaggerating its limitations.

The emerging consensus that more effective pharmacotherapies may reduce drug abuse and risk for AIDS has stimulated interest in using preclinical models to evaluate potential medications for drug abuse treatment (Mello 1991, 1992; Balster et al. 1992; Spealman 1992; Woolverton and Kleven 1992). Animals will reliably self-administer most drugs that are abused by man, and it is reasonable to anticipate that medications that decrease drug self-administration should be more clinically effective than medications that do not change or increase drug self-administration. Moreover, animal drug self-administration models offer some methodological advantages for the systematic evaluation of new medications. Unlike clinical trials, compliance with the treatment regimen is ensured, and there is no confounding influence of unreported polydrug abuse. The effects of a new treatment medication on an ongoing pattern of drug self-administration can be evaluated quantitatively under controlled experimental conditions. Accurate baseline measures of the daily dose and patterns of drug self-administration can be determined before, during, and after administration of the treatment medication, whereas in clinical studies the drug abuse history and the usual pattern of drug use are often unknown. It is also possible to monitor medication safety during exposure to the abused drugs and to detect any adverse side effects that compromise the health of the animal. Finally, uncontrolled social factors such as expectancy or placebo effects and peer pressure cannot complicate the interpretation of data obtained in animal models. Moreover, targeted preclinical trials are more cost-effective than extensive clinical trials.

This review describes the use of animal models of drug self-administration to evaluate potential medications for treatment of cocaine, opioid, and polydrug abuse involving concurrent cocaine and opioid abuse. We have selected these three forms of substance abuse because of their prevalence and medical and social virulence (Kreek 1987; DAWN 1993; Mendelson and Mello 1994; NIDA 1995). We have focused on the drug self-administration model because it has been studied extensively across a number of laboratories in several species and appears to have clinical relevance. Where possible, we have compared preclinical data with clinical evaluations of established pharmacotherapies for drug abuse treatment, but many medications examined in preclinical studies have not been approved for clinical testing. The validation of preclinical models for evaluation of drug abuse treatment medications requires an ongoing assessment of the concordance between preclinical studies and outpatient studies. These interrelated processes of validation and prediction are illustrated schematically in Figure 1.

Drug self-administration models are especially valuable for evaluation of medications that substitute for or antagonize the effects of cocaine and heroin. These medication strategies do not depend on any particular conceptualization of the pathogenesis of drug abuse, and the effects of antagonists and agonists on drug self-administration can be interpreted in terms of pharmacological interactions with the target drug of abuse. However, in addition to pharmacological antagonists and agonists, a wide range of medications approved for other indications are often used clinically in substance abuse treatment. For example, antidepressants such as desipramine and fluoxetine have been used clinically for the treatment of abuse of cocaine alone and com- 


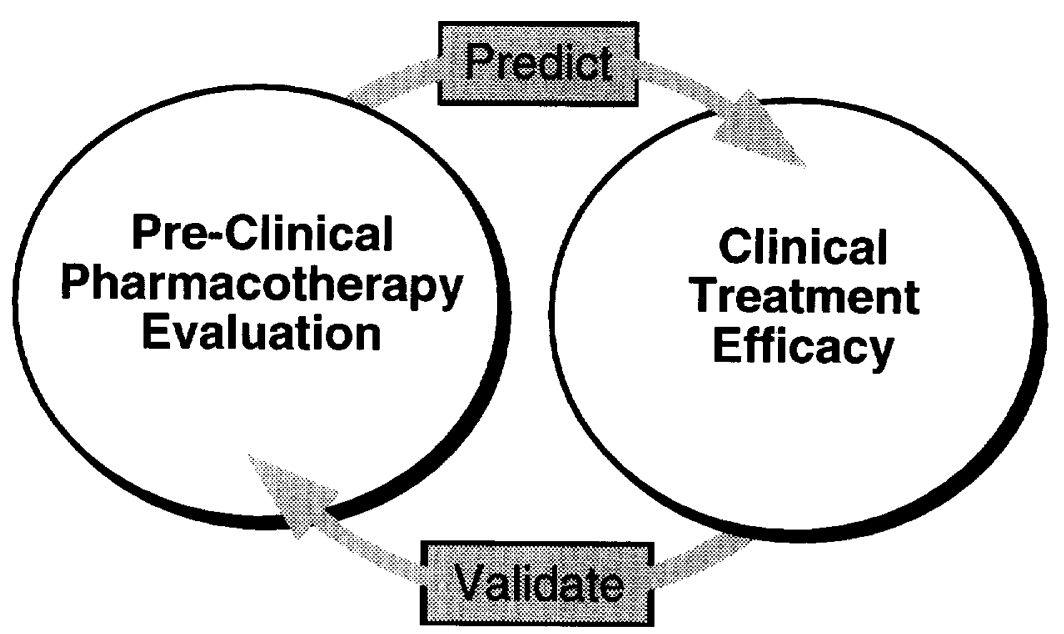

Figure 1. Cross validation of preclinical and clinical models. Validation of the effectiveness of animal models for preclinical evaluation of drug abuse treatment medications requires assessing the degree of concordance between preclinical studies and outpatient clinical studies. Eventually, the preclinical model should enable users to predict the potential effectiveness of new pharmacotherapies. This interactive process of cross-validation and prediction is essential for refinement of the preclinical model. From Mello NK (1992): Behavioral Strategies for the Evaluation of New Pharmacotherapies for Drug Abuse Treatment. NIDA Research Monograph 119. Washington, DC: Government Printing Office, pp 150-154. bined cocaine and opioid dependence (Gawin and Kleber 1984; Tutton and Crayton 1993; Mendelson and Mello 1996). Insofar as a coexisting psychiatric disorder may contribute to the initiation and perpetuation of drug abuse, this strategy has potential clinical usefulness. Antidepressant medications also have been examined in preclinical models of cocaine self-administration, and these studies will be reviewed. A variety of other medications ranging from anticonvulsants to ibogaine also have been examined in animal models of cocaine and opioid self-administration, and we discuss the implications of these studies for medication development. Finally, a number of the studies described in this review were designed to analyze the pharmacological mechanisms underlying the reinforcing effects of abused drugs rather than to evaluate the effects of potential treatment medications. Despite a different emphasis, results from these studies of drug interactions often are very relevant to issues of treatment medication development.

This review is divided into four sections. The first section describes the basic methods used to conduct drug self-administration studies and the types of data obtained. In this context, we examine the underlying assumptions and the advantages and limitations of various study designs for evaluating treatment medications. The rationale for several criteria used to determine treatment medication efficacy are critically examined. The next two sections review illustrative preclinical studies of the effects of drugs on the self-administration of cocaine, opioids, and cocaine/opioid combinations. We have attempted to provide a comprehensive, although not exhaustive, summary of the basic preclinical literature in tabular form. These tables summarize studies that examined drug effects on cocaine self-administration (Tables 1-4) and opioid self-administration (Tables 5 and 6). Four categories of medication effects on cocaine self-administration are summarized: dopamine antagonists (Table 1); dopamine agonists and partial agonists (Table 2); opioid antagonists, agonists, and mixed agonist-antagonists (Table 3); and medications approved for other indications (Table 4). Two categories of medication effects on opioid self-administration are summarized in tabular form: opioid antagonists (Table 5), and opioid agonists and mixed agonist-antagonists (Table 6). The effects of a diverse group of nonopioid drugs on opioid self-administration are described in the text. The implications of findings from this emerging database for the design of optimal preclinical studies for pharmacotherapy evaluation are discussed in the final section of this review.

\section{PRECLINICAL MODELS OF INTRAVENOUS DRUG SELF-ADMINISTRATION}

\section{Drug Self-Administration: Basic Procedures}

During the 1960s, several independent groups reported the first studies showing that monkeys and rats surgically implanted with an intravenous catheter would self-administer a wide range of opioids, stimulants, and alcohol (Weeks 1962; Thompson and Schuster 1964; Yanagita et al. 1965; Deneau et al. 1969). The procedures currently used for drug self-administration studies are similar across laboratories. A chronic intravenous catheter is surgically implanted into an accessible vein (usually a jugular or femoral vein) to permit infusion of a drug solution. During drug self-administration sessions, the subject acquires drug injections by emitting some discrete response, such as pressing a response key or a lever on an operant panel. The number and pattern of responses required for each injection are specified by the schedule of reinforcement, and the availability of drug injections under this schedule of reinforcement is 
usually signaled by a stimulus, such as the illumination of a stimulus light on or above the response key. Parameters such as the schedule of reinforcement, the volume and duration of each injection, the duration and frequency of drug self-administration sessions, and the stimulus conditions in effect during drug self-administration sessions are controlled by computers. In addition, alternative reinforcers such as food may be made available. The dependent variables in drug self-administration studies are usually the number of injections delivered or the rate of responding during each drug self-administration session.

It is now well-established that animals will self-administer most drugs that are abused by man, and there are many similarities in patterns of animal and human drug self-administration (Mello 1979; Griffiths et al. 1980; Brady and Lukas 1984). For example, drug selfadministration procedures have been used to predict the abuse liability of novel compounds (Schuster and Johanson 1974; Thompson and Unna 1977; Brady et al. 1987), and there has been consistently good concordance between clinical and preclinical assessments of the reinforcing effects of drugs (Griffiths and Balster 1979; Brady and Lukas 1984; Balster 1991). Similarly, insofar as the goal of pharmacotherapy is to reduce drug self-administration, this drug self-administration model also should be useful for the evaluation of new treatment medications (Mello 1992).

Drug self-administration studies have consistently obtained an inverted U-shaped dose-effect curve relating the dose of drug delivered in each injection (the unit dose) to some metric of drug self-administration behavior, such as response rate or the number of injections delivered. There is an extensive literature indicating that cocaine and opioid self-administration dose-effect curves display the typical inverted U-shaped dose-effect curves

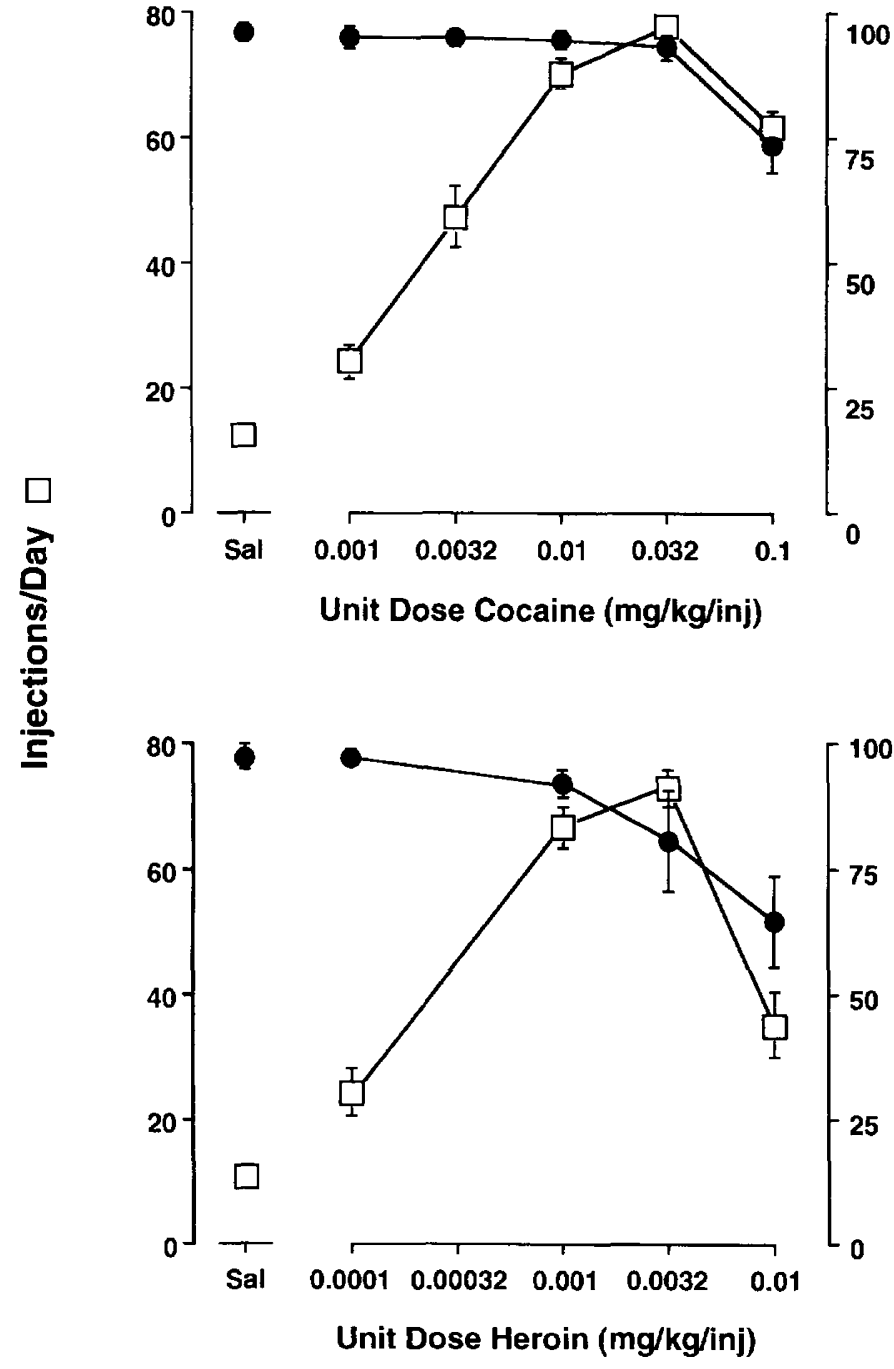

Figure 2. Number of injections/day or food pellets/day delivered to rhesus monkeys when different unit doses of cocaine or heroin were available during drug self-administration sessions. Abscissae: Unit dose cocaine in $\mathrm{mg} / \mathrm{kg} / \mathrm{inj}$ (log scale) available during drug self-administration sessions. Left Ordinates: Number injections delivered per day (open squares). Right Ordinates: Number $1 \mathrm{gm}$ food pellets delivered per day (filled circles). Points above "Sal" show data from days when saline was available during drug sessions. Monkeys responded for food and drugs under a second-order FR 4 (VR16:S) schedule. Four food sessions were run daily from 6:00 to 7:00 A.M., 11:00 A.M. to noon, 3:00 to 4:00 P.M., and 7:00 to 8:00 P.M. During each food session, monkeys could earn up to 25 pellets, for a maximum of 100 pellets per day. Four drug sessions were run daily from 7:00 to 8:00 A.M., noon to 1:00 P.M., 4:00 to 5:00 P.M., and 8:00 to 9:00 P.M. During each drug session, monkeys could earn up to 20 injections, for a maximum of 80 injections per day. The monkeys were initially trained to self-administer a maintenance dose of 0.01 or $0.032 \mathrm{mg} / \mathrm{kg} /$ injection of cocaine and saline, and each unit dose of cocaine or heroin was substituted for the maintenance dose for 5 to 10 consecutive days and until responding for injections stabilized. Stability was defined as 3 consecutive days during which the number of injections/day was within $10 \%$ of the mean number of injections per day. Each point shows mean data from the last 3 days of each condition in 11 monkeys (top panel) or three monkeys (bottom panel). Brackets show the SE. Adapted from Negus SS; Mello NK; Lukas SE; Mendelson JH (1995a): Diurnal patterns of cocaine and heroin self-administered in rhesus monkeys responding under a schedule of multiple daily sessions. Behav Pharmacol. 6:763-775. 
under most conditions (Brady and Lukas 1984; Woods et al. 1987). Similar dose-effect curves also were measured for simultaneous self-administration of cocaine and heroin combinations in a primate model of polydrug abuse (Mello et al. 1995). Controlled clinical studies have usually found that increasing drug doses are associated with increasing levels of drug self-administration corresponding to the ascending limb of the dose-effect curve in preclinical studies (see Griffiths et al. 1980 for review; Lamb et al. 1991). Detailed exploration of the effects of high doses has often been limited by considerations of subject safety in clinical research. In practice, the drug abuser seldom knows the purity or the dose of the drug purchased, and the empirical doseeffect curve may span a range from a mild subjective high to a potentially lethal overdose.

An example of a dose-effect curve for cocaine and heroin self-administration by rhesus monkeys is shown in Figure 2. The cocaine dose-effect curve is characterized by an ascending limb $(0.001-0.01 \mathrm{mg} / \mathrm{kg} /$ inj. $)$, a peak (0.01-0.032 mg/kg/inj.) and a descending limb [0.032-0.1 mg $/ \mathrm{kg} / \mathrm{inj}$. (see Figure 2, top panel)]. Along the ascending limb, increasing unit doses of cocaine result in an increase in the number of injections delivered until some peak number of injections per day is obtained. Along the descending limb, further increases in the unit doses of cocaine result in decreases in the number of drug injections. A similar dose-effect curve is shown for heroin self-administration (Figure 2, lower panel). The peak of the heroin dose-effect curve is at a unit dose of $0.0032 \mathrm{mg} / \mathrm{kg} /$ inj., and the number of injections decreases at higher unit doses. The shape of these dose-effect curves reflects an interaction between the self-administered drug's reinforcing effects, which tend to increase response rates, and other effects (such as sedation and stereotypies), which limit rates of operant responding. Thus, along the ascending limb, reinforcing effects predominate and response rates increase, whereas along the descending limb, rate-decreasing effects predominate and response rates decrease. In contrast, food-maintained responding remains quite stable during the ascending limb of the cocaine and the heroin dose-effect curve and decreases during the descending limb of the dose-effect curve.

The slopes of the ascending and descending limbs, the magnitude and width of the peak, and the position of the curve along the abscissa can vary as a function of several parameters, including the schedule of reinforcement, the drug available for self-administration, and the behavioral history of the subject. An example of how the cocaine dose-effect curve in rats can vary as a function of schedule parameters such as the fixed ratio requirement and the postinjection timeouts is shown in Figure 3 . Notice that lengthening the postinjection timeout from 20 seconds to 2 minutes changed the position of the ascending limb, peak, and descending limb of the cocaine dose-effect curve. Thus, when postreinforcement timeouts were brief, rats could rapidly self-administer many cocaine injections and a low unit dose was at the peak of the dose-effect curve. When successive cocaine injections were separated by at least $2 \mathrm{~min}$ utes, higher unit doses were required to maintain responding. These data illustrate that the schedule of reinforcement is an important determinant of baseline drug dose-effect curves.

\section{Evaluation of Medication Efficacy}

Study Designs. The basic study design used for preclinical evaluation of a potential pharmacotherapy is similar to a single-blind, crossover trial in clinical re-

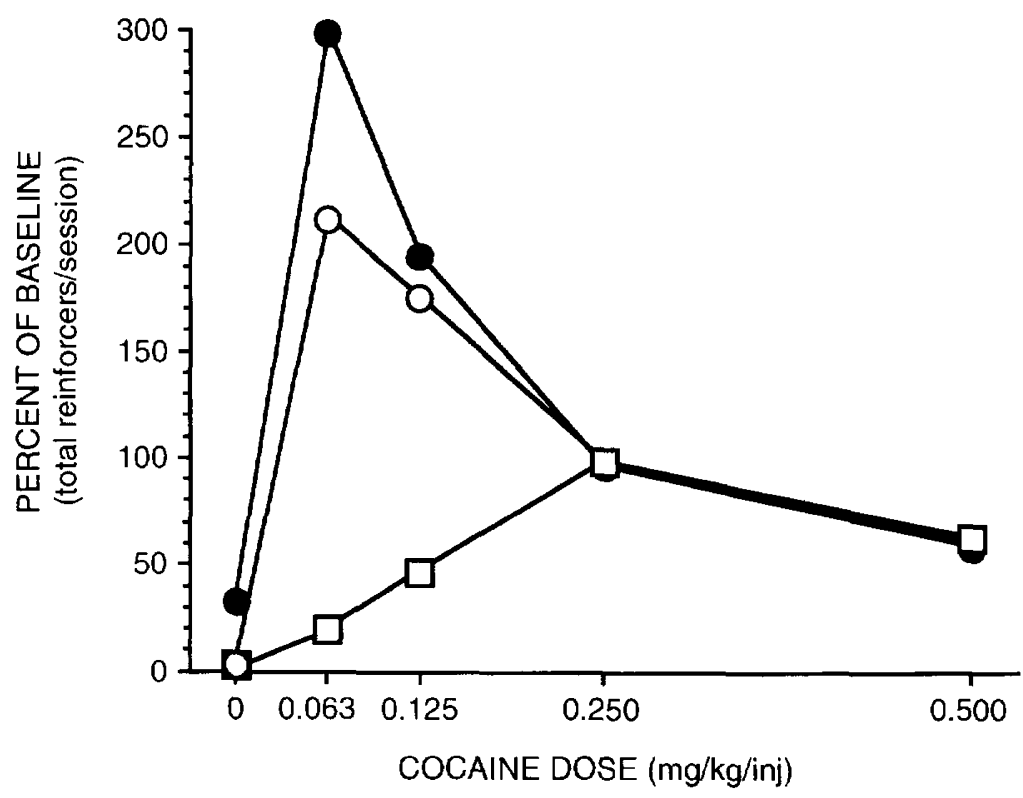

Figure 3. The effect of schedule requirements and postinjection timeout duration on the cocaine self-administration dose-effect curve. Saline and different unit doses of cocaine are shown on the abscissa. The percent of baseline control responding (total cocaine injections per 3-hour session) is shown on the left ordinate. Cocaine selfadministration maintained on a FR 5 to 20 -sec timeout (closed circles) and a FR 15 to 20 -sec timeout (open circles) represents the average of eight and four rats, respectively. Cocaine selfadministration maintained on a FR 15 to 2-minute timeout (open squares) was determined in six or eight rats. Adapted and reprinted with permission from Caine SB and Koob GF (1994): Effects of dopamine $D_{1}$ and $\mathrm{D}_{2}$ antagonists on cocaine self-administration under different schedules of reinforcement in the rat. J Pharmacol Exp Ther 270(1):209-218. 
Possible Effects of Pharmacotherapy $(\square \wedge \mathbf{\Delta}$ ) on a Drug Dose-Response Curve $(O)$

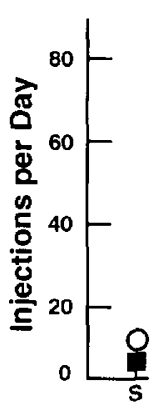

Antagonisma

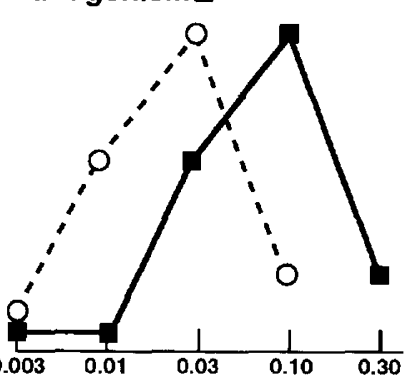

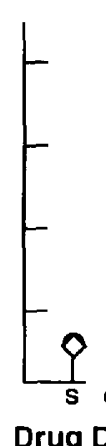

Depression
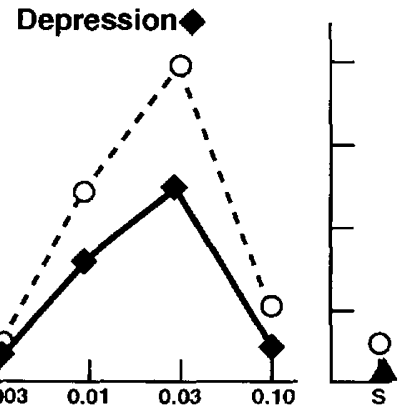

Enhancement $\boldsymbol{A}$

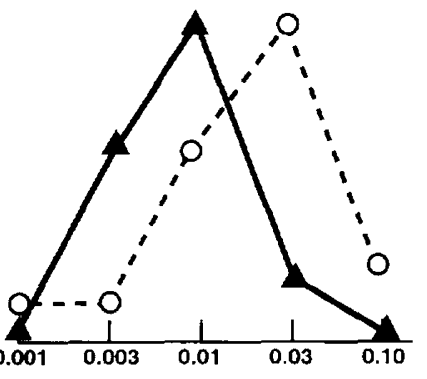

Figure 4. Medication effects on drug dose-response curve. Drug injections per day are shown on the ordinate and the drug dose per injection is shown on the abscissa of each panel. Injections per day during saline-maintained responding are shown above $S$ on each abscissa. Open circles, drug dose-effect curve during saline control treatment; Solid squares, left panel, antagonism of the drug's reinforcing effects and rightward shift in the drug dose-response curve. Solid diamonds, center panel, depression of drug-maintained responding with no shift in the dose-response curve. Solid triangles, right panel, enhancement of the drug's reinforcing effects and leftward shift in the drug dose-response curve.

search. First, baseline drug self-administration patterns are examined during placebo treatment with saline or a vehicle control solution. Once drug self-administration patterns are stable, the treatment medication is substituted for saline placebo treatment on a single occasion or for several days. Placebo-control treatment is then resumed, and the rate at which drug self-administration returns to baseline control levels is measured. This sequence may be repeated several times using different doses of the treatment drug or different treatment drugs. It is important to study several doses of the treatment medication to determine the range of doses over which it is maximally effective.

Medication Effects on Drug Dose-Effect Curves. Usually, the effects of the treatment medications are first evaluated on a dose of the abused drug that maintains high levels of drug self-administration, that is, a reinforcing dose on the ascending limb or the peak of the drug dose-effect curve. If a treatment drug reduces self-administration of a reinforcing dose of the abused drug, this is one indication of potential treatment efficacy. However, a treatment drug may have different effects at higher and lower doses of the abused drug, so a complete dose-effect curve should also be examined. Three possible effects of a treatment medication on a theoretical cocaine dose-response curve are shown in Figure 4.

Antagonism. If the dose-response curve for cocaine is shifted to the right during treatment, this suggests that the medication is antagonizing the reinforcing effects of cocaine. Higher doses of cocaine are required to maintain the same level of responding previously maintained by a lower dose of cocaine (Figure 4, left panel).

Depression. A second possibility is that the position of the cocaine dose-effect curve may remain the same, but there is an overall reduction in responding (Figure 4 , center panel).

Enhancement. Alternatively, the cocaine dose-response curve may be shifted to the left during treatment. If lower doses of cocaine now maintain the same level of responding as during saline control treatment, these data suggest that the treatment medication is enhancing cocaine's reinforcing effects (Figure 4, right panel).

It is important to note that both leftward and rightward shifts in the dose-effect curve decrease self-administration of some unit doses, but simultaneously increase self-administration of other unit doses. Leftward or rightward shifts, then, represent a change in the potency of the self-administered drug. Only a downward shift in the dose-effect curve involves a decrease in the self-administration of all unit doses. From a treatment perspective, medications that shift the cocaine or heroin dose-effect curve downward may have the most general therapeutic utility, because drug-taking behavior decreases across a broad range of unit doses. Medications that simply alter the potency of the self-administered drug and shift the dose-effect curve to the right may be less satisfactory. It is apparent in Figure 4 (left panel) that despite a rightward shift in the dose-effect curve, the drug available for self-administration retains its ability to maintain high rates of drug-taking behavior and drug users may compensate for the change in potency by changing the amount of drug used per occasion or the rate of drug self-administration. This phenomenon is illustrated in many of the studies we review, in which treatment medication effects were evaluated against a single unit dose of the self-administered drug located on the descending limb of the dose-effect curve. In these studies, an increase in drug self-administration 
often is taken as evidence that the underlying dose-effect curve has shifted to the right and that the treatment medication has antagonized the reinforcing effects of the self-administered drug. Although an increase in drug self-administration may be interpreted as evidence for antagonism, it is not a desirable goal for medications that are to be used in the clinical treatment of drug abuse.

Duration of Treatment. Treatment medications can be given in single acute doses or chronically over days or weeks. Pragmatic considerations, such as very limited quantities of a new medication, may dictate the use of an acute rather than a chronic treatment paradigm. However, most medications are used clinically on a chronic basis, and some pharmacotherapies require a long exposure before treatment effects are evident (Gawin and Ellinwood 1988; Gawin 1991). In preclinical studies, repeated daily exposures to the medication may be necessary to detect a suppressant effect on drug self-administration. Chronic treatment offers several important methodological advantages over acute treatment for preclinical evaluations. During chronic treatment, it is possible to measure the persistence of treatment medication effects and to determine whether an initial decrease in drug self-administration remains constant over time. If a decrease in drug self-administration is only transient, this could indicate that tolerance developed to the treatment drug effect. For example, chronic administration of a treatment medication for as little as 8 to 10 days sometimes is sufficient to reveal tolerance development in rhesus monkeys (Woolverton and Virus 1989; Kleven and Woolverton 1990b; Gold and Balster 1992; Negus et al. 1995b). In contrast, testing single acute doses may lead to an erroneous conclusion of no effect or may yield false positives because an initial decrease in drug self-administration may not be sustained.

Treatment Outcome Measures. The dependent measures used to assess treatment medication efficacy usually are the number of drug injections taken during a period of drug availability and the rate of operant responding for drug injections. As we have seen in Figures 2 and 3, both behavioral measures are critically influenced by the schedule of reinforcement, the drug dose per injection, and the cumulative dose acquired over a session. The importance of the schedule of reinforcement in determining drug self-administration has been extensively reviewed elsewhere, and discussion of the many complex schedule permutations and the effects on operant behavior is beyond the scope of this review (see Ferster and Skinner 1957; Dews 1958, 1981; Kelleher and Morse 1968; Byrd 1981 for review). The basic building blocks of complex schedules are ratio schedules where the animal is reinforced after emitting some number of responses, and interval schedules where the first response after a specified interval has passed results in reinforcement. One fundamental difference between fixed-ratio and fixed-interval schedules is the degree of control that the animal has over the frequency of drug injections. For example, in a fixed-ratio (FR) schedule of reinforcement, the interval between successive drug injections is controlled by the animal's rate of response, and response rate and number of injections are likely to be highly correlated. In contrast, on a fixed-interval (FI) schedule, the frequency of injections is primarily determined by the reinforcement schedule, not by response rates. The duration of the postreinforcement timeout also influences the frequency of drug injections (see Figure 3).

Most investigators have relied exclusively on only one dependent variable and have not studied the correlation between rate of operant responding and number of drug injections. The issue is complicated by the fact that drugs usually have a direct effect on rates of responding that is cumulative during the drug self-administration session. Moreover, drugs from different pharmacological classes may have different effects on response rates. For example, stimulants such as cocaine may increase rates of responding initially, whereas opioids may decrease rates of responding. Although both measures have limitations, the number of injections has a consistent definition from laboratory to laboratory whereas the definition of response rates may vary. There is disagreement as to whether overall response rate (including postreinforcement pauses), running rate (time from the first response to acquisition of each reinforcer), or derivative measures (such as inter-response times distributions) provide the most sensitive index of operant response rates (Skjoldager et al. 1991). Although response rate data during medication treatment are often presented as percent of control rates, these definitional and procedural differences complicate comparisons between laboratories. As research on preclinical evaluation of treatment medications evolves, it is likely that more attention will be directed toward integrating information from these two dependent variables.

The number of drug injections is a sensitive measure of medication efficacy (Mello et al. 1989, 1990b, 1992) and shows good concordance with clinical trials (Mello et al. 1990b, 1993c; Mello 1991). However, most laboratories limit the total number of drug injections available per session to minimize the possibility of drug overdose. This safety precaution could impose an artificial ceiling effect that would prevent detection of a medication-induced enhancement of drug self-administration (Mello et al. 1990b). Because the effectiveness of chronic treatment is defined in terms of a selective decrease in drug self-administration, limiting the number of drug injections is seldom a serious problem. Unlimited access to some drugs has led to severe toxicity in rhesus monkeys (Aigner and Balster 1978) so there is no practical alternative to restricted drug access. 


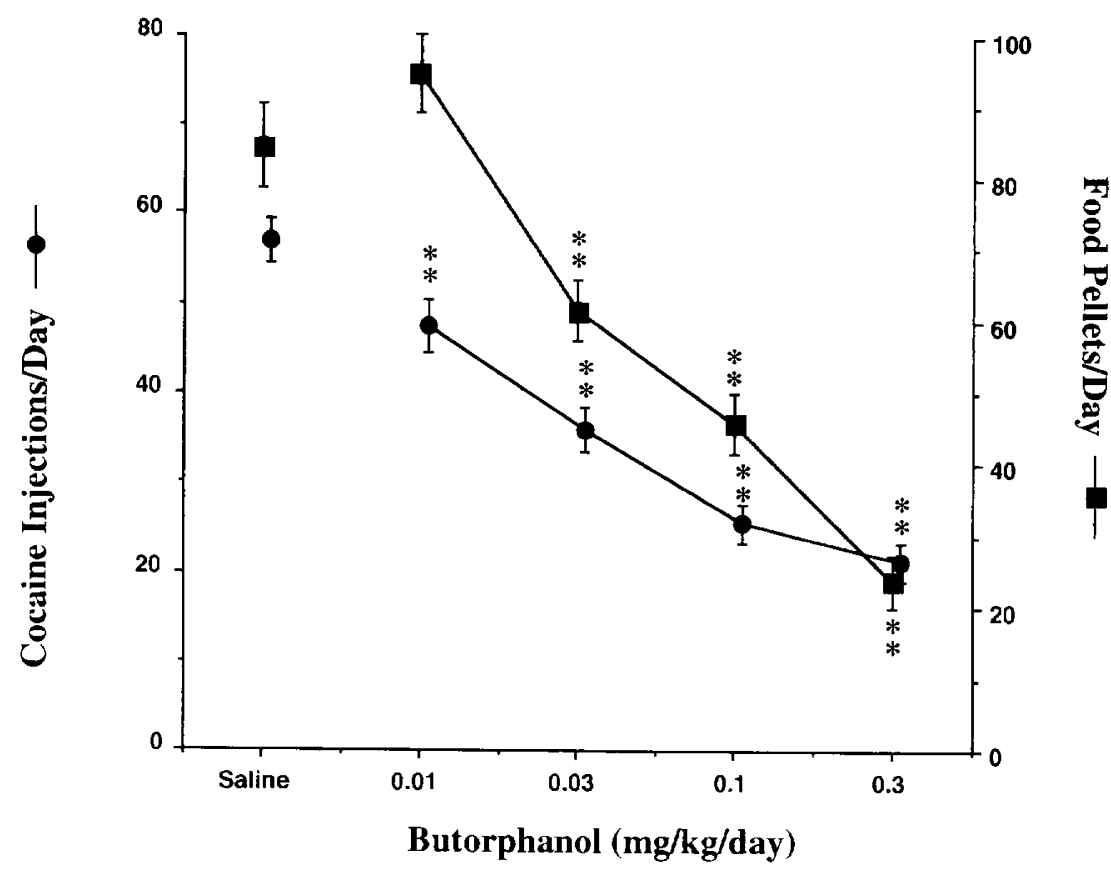

Figure 5. Butorphanol effects on cocaine and food self-administration. Nonselective effects of treatment with an opioid mixed agonist-antagonist analgesic, butorphanol, on cocaine and food self-administration by rhesus monkeys. The effects of daily treatment with saline or butorphanol $(0.01$ to $0.30 \mathrm{mg} /$ $\mathrm{kg} /$ day) on cocaine (solid circles) and food self-administration (solid squares) are shown. Saline treatment and each dose of butorphanol were studied for 10 days. Each data point is the average ( $\pm \mathrm{SE}$ ) of five subjects except for butorphanol $(0.3 \mathrm{mg} / \mathrm{kg})$, which is an average of four subjects. The statistical significance of each change from the saline treatment baseline is indicated by asterisks (**, $p<0.01$ ). From Mello NK; Kamien JB; Lukas SE; Drieze J; Mendelson JH (1993d): The effects of nalbuphine and butorphanol treatment on cocaine and food self-administration by rhesus monkeys. Neuropsychopharmacology 8:45-55. Reprinted with permission.

\section{Selectivity of Treatment Effects on Drug Self-Administration}

During preclinical evaluation of medication effects on drug-taking behavior, the principal focus is on the ability of the medication to change drug self-administration. However, preclinical studies also provide an opportunity to examine a medication's adverse consequences that may limit its clinical usefulness. In drug self-administration studies, the adverse effects of a medication usually are inferred from its effects on behaviors other than self-administration of the target drug of abuse. For example, the effects of a medication on unconditioned behaviors such as posture or locomotor activity as well as adverse effects such as convulsions or extreme sedation can be observed and recorded.

The extent to which a treatment medication selectively reduces drug self-administration is another important consideration. If the treatment medication reduces drug self-administration to a greater extent or for a longer time than it reduces behavior maintained by another reinforcer, this would suggest that the treatment drug has selective effects on drug self-administration. Alternatively, if the treatment drug is sedating, this could result in a parallel dose-dependent decrease in the self-administration of both a drug and a nondrug reinforcer such as food. An example of both a selective and a nonselective decrease in cocaine self-administration during daily treatment with an opioid mixed agonist-antagonist analgesic, butorphanol, is shown in Fig- ure 5. At the lowest dose of butorphanol $(0.01 \mathrm{mg} / \mathrm{kg} /$ day), cocaine self-administration decreased significantly, but food self-administration remained slightly above saline treatment levels. However, as treatment drug doses were increased, there was a parallel decline in both food and cocaine self-administration. This means that the effects of the $0.03-$ to $0.3-\mathrm{mg} / \mathrm{kg}$ dose of butorphanol were not selective for cocaine, but rather reflected a general disruption of operant behavior.

Another strategy used to evaluate selectivity is to compare the effects of the treatment drug on self-administration of the target drug of abuse and self-administration of a drug from another pharmacological class. If self-administration of the target drug is reduced and self-administration of the comparison drug is not, then it can be argued that the treatment drug is having a selective effect. An example of this approach is the evaluation of potential treatment medications on cocaine and alfentanil self-administration (Winger et al. 1992; Winger 1994). Comparisons between two or more drugs from different pharmacological classes also may clarify the mechanisms by which the treatment medication reduces drug self-administration (Winger et al. 1992). One problem in interpreting data from studies that compare medication effects on the target drug with an alternative drug or with nondrug reinforcers is whether or not each has equivalent reinforcing properties. However, determining the equivalence of reinforcers is a complex issue of continuing debate that is beyond the scope of this review. 
Although medication-induced suppression of responding maintained by other reinforcers is undesirable, the interpretation of medication effects on the self-administration of an alternative reinforcer may be complicated by the same considerations that influence interpretation of medication effects on self-administration of the target drug (i.e., the inverted U-shaped curve relating magnitude of the reinforcer to rates of self-administration behavior; see Figures 2 and 3). Furthermore, evaluating medication effects on the self-administration of alternative reinforcers addresses only one dimension of the many adverse effects that could be produced by a medication. For example, a medication that produced a nonselective suppression of operant behavior at doses that produced no other toxic effects may have clinical utility under some circumstances. Thus, an evaluation of the selectivity of a medication in decreasing drug self-administration is an important step in a more general process of characterizing that medication's adverse effects.

One final medication effect that can be directly assessed in drug self-administration studies is the reinforcing effect of the medication itself. To evaluate a medication's reinforcing effects, it is substituted for cocaine or heroin to determine the dose-range over which it maintains operant behavior leading to its self-administration. Because reinforcing effects in preclinical studies are indicative of abuse liability in humans, the ability of a drug to reinforce behavior is usually considered to be an adverse effect. However, in the clinical treatment of drug dependence, medications are self-administered by the patient and medication delivery depends on the patient's active participation and cooperation. As a result, medication-induced reinforcing effects may improve patient compliance with the treatment regimen. In addition, the relative costs associated with medication-induced reinforcing effects must be weighed against the costs of continued abuse of the target drug. Even if a medication produces reinforcing effects on its own, it may still be valuable in the treatment of drug dependence if it decreases self-administration of the target drug and produces fewer adverse effects than the target drug.

\section{Interpretation of Criteria for Medication Efficacy}

From a clinical perspective, a decrease in drug self-administration is the goal of treatment, and this is the criterion of efficacy used in inpatient evaluations of new medications (Meyer and Mirin 1979; Mello and Mendelson 1980; Mello et al. 1981; 1982). However, in preclinical studies, this criterion has not been used consistently as an index of potential medication effectiveness. Rather, many investigators have interpreted an increase in drug self-administration as evidence that the treatment medication was antagonizing the reinforcing effects of cocaine or heroin. This apparent contradiction in goals in the clinical and the preclinical treatment evaluation literature is based in part on the assumption that an effective treatment medication should make the abused drug more like saline or like a lower dose of the abused drug by antagonizing its reinforcing properties. Because substituting saline for cocaine or heroin may result in an initial increase in drug-maintained responding, a treatment that increases drug self-administration may be classified as a potentially effective antagonist. This criterion for medication effectiveness usually is applied in studies where one or more doses of the treatment drug were administered on a single occasion (acute treatment). However, an increase in drug self-administration is not a desirable outcome in studies in which the medication is administered repeatedly over days or weeks (chronic treatment). In chronic treatment studies, medication effectiveness is reflected in a sustained decrease in drug self-administration. The saline analogy remains relevant insofar as self-administration of saline also decreases over several days of exposure. Some investigators have measured the number of days required for saline-maintained responding to decrease to a low level and used this as the basis for determining how long to evaluate each dose of a treatment medication (Woolverton and Virus 1989; Kleven and Woolverton 1993).

If an initial increase in drug self-administration in acute treatment studies was usually followed by a decrease in drug self-administration over time in chronic treatment studies, then reconciliation of findings from reports of acute and chronic treatment would be less problematic. However, the inconsistencies in results obtained with the same treatment medication in the same species indicate the importance of these procedural differences. This issue is further complicated by different results obtained when cocaine or heroin doses are on the ascending or descending limb of the dose-effect curve (see Figure 4).

\section{TREATMENT MEDICATION EFFECTS ON COCAINE SELF-ADMINISTRATION}

\section{Clinical Treatment of Cocaine Abuse}

Currently there is no uniformly effective clinical treatment for cocaine abuse and dependence. Treatment is complicated by the diversity of cocaine administration patterns as well as concurrent abuse of opioids, alcohol, and other substances. Often pharmacotherapies that appeared to be effective with cocaine abusers were not effective with more severely ill persons who met DSM-III-R criteria for cocaine dependence (see Mendelson and Mello 1996 for review). Conversely, severely cocainedependent men who also were heroin dependent appeared more responsive to treatment with an opioid mixed agonist-antagonist, buprenorphine, than opioid- 
dependent patients who used cocaine occasionally (see Mello et al. 1993c for review). Although a wide range of medications, including antidepressants, dopamine agonists, antagonists and reuptake inhibitors, anticonvulsants and opioid agonists, antagonists, and mixed agonist-antagonists have been studied in clinical samples, the findings were often inconclusive (see Rawson et al. 1991; Halikas et al. 1993; Tutton and Crayton 1993; Mendelson and Mello 1996 for review). Inconsistent diagnostic criteria for cocaine abuse and cocaine dependence, as well as controversy over appropriate criteria for treatment effectiveness, contribute to the discrepant results in the clinical literature. Traditionally, total drug abstinence has been the accepted standard for success of treatment. Yet, this criterion is more stringent than is applied in other areas of medicine. The clinical reality is that most cocaine abusers and other substance abusers continue to use some drugs during maintenance treatment, but a $30 \%$ to $60 \%$ reduction in drug use may benefit the patient, as well as society (see Mello and Mendelson 1995; Mendelson and Mello 1996 for review).

\section{Cocaine Self-Administration Dose-Effect Curves}

Cocaine maintains behavior leading to its self-administration under a wide range of experimental conditions (Kelleher 1976; Spealman and Goldberg 1978; Griffiths et al. 1979a; Spealman 1985; Winger 1988; Woods et al. 1987). Under some second-order schedule conditions, monkeys responded for up to 1 hour for a single cocaine injection (Goldberg et al. 1976). As shown in Figure 2, the dose-effect curve relating cocaine dose per injection to either the number of drug injections per session or response rate has a typical inverted-U shape with intermediate doses maintaining more drug self-administration behavior than either lower or higher doses.

Cocaine usually is classified as an indirect dopamine agonist, and there is considerable evidence that cocaine's reinforcing effects are mediated in part through its blockade of dopamine reuptake at presynaptic terminals (see Dackis and Gold 1985; Ritz et al. 1987; Ritz et al. 1988; Kuhar et al. 1988, 1991; Johanson and Fischman 1989; Spealman et al. 1992; Wise et al. 1995; Woolverton and Johnson 1992 for review). A number of other structurally distinct compounds that block dopamine reuptake are also reinforcing in animals (Woolverton et al. 1984; Winger and Woods 1985; Bergman et al. 1989). Cocaine also blocks the reuptake of serotonin and norepinephrine, but these appear to be less important for its reinforcing effects.

\section{Effects of Dopamine Antagonists on Cocaine Self-Administration [Table 1]}

The effects of dopamine antagonists on cocaine self-administration have been examined by a number of inves- tigators, and the findings are often inconsistent (see Table 1). These apparent inconsistencies reflect differences in procedure and in interpretation of findings as well as variations in the receptor specificity of the dopamine antagonists studied. As appreciation of the complexity of the dopamine system increased and compounds selective for dopamine receptor subtypes became available, it became possible to study the effects of specific $D_{1}$ and $D_{2}$ dopamine receptor antagonists on cocaine self-administration.

Most of the early studies examined the effects of compounds with nonspecific dopaminergic activity such as chlorpromazine and haloperidol (Wilson and Schuster 1972; Herling and Woods 1980; de la Garza and Johanson 1982; Roberts et al. 1989). Often these mixed dopamine antagonists increased rather than decreased stimulant self-administration. These findings were interpreted as evidence for antagonism of cocaine's reinforcing properties because reducing the unit dose of a reinforcing drug or substitution of saline also results in an initial increase in rates of drug self-administration. Many of the early studies administered single acute doses of nonselective dopamine antagonists and did not evaluate treatment effects on alternative reinforcers such as food, so it was not possible to distinguish between rate altering effects of the treatment drug and the enhancement or antagonism of the reinforcing effects of cocaine (Table 1). Examples of some selected studies are described to illustrate how these research methods have evolved.

One of the first studies of the effects of a selective $D_{1}$ antagonist ( $\mathrm{SCH} 23390$ ) and a selective $\mathrm{D}_{2}$ antagonist (pimozide) on the self-administration of cocaine and piribedil (a direct $\mathrm{D}_{2}$ agonist) by rhesus monkeys was reported by Woolverton in 1986. Each dopamine antagonist was studied across a broad dose range, and the effects of single acute antagonist doses on a single reinforcing dose of cocaine or piribedil were evaluated. The traditional efficacy criterion of changes in responding similar to the effects of reducing the unit dose of cocaine was used as the basis for interpretation of the findings. Since the $D_{1}$ antagonist resulted in dose-related decreases in cocaine and piribedil self-administration, this was interpreted as a nonspecific decrease in rates of responding. The $D_{2}$ antagonist increased rates of both cocaine and piribedil self-administration, and because this effect was similar to the initial effects of substituting saline for cocaine, these data were interpreted as evidence for blockade of each drug's reinforcing effects. High doses of both dopamine antagonists produced cataleptic effects (Woolverton 1986).

Subsequently, Woolverton and Virus (1989) reevaluated the effects of the same $D_{1}$ and $D_{2}$ dopamine antagonists on self-administration of cocaine and an alternative reinforcer, food, to determine the extent to which the behavioral effects of these antagonists were specific 
to cocaine (Woolverton and Virus 1989). Each antagonist was administered for the same number of sessions (4-10) that were required for drug-maintained responding to decline after saline substitution, and data were presented for the last 3 days of each treatment condition. Each antagonist was studied over a behaviorally active but nontoxic dose range, and its effect on self-administration of a single reinforcing dose of cocaine was examined. Each session consisted of a sequence of food availability for 15 minutes, a 15 minute timeout, cocaine availability for 15 minutes, a 15 minute timeout, and food availability for 15 minutes. Cocaine and food were available under a FR30 schedule of reinforcement, and there was a 2-minute timeout after delivery of each reinforcer to minimize any direct rate-reducing effects of cocaine. Under these conditions, there was an antagonist dose-related decrease in cocaine-maintained responding. However, these effects were not specific for cocaine, because food maintained responding also decreased as the antagonist dose increased. Moreover, the initial reductions in both cocaine and food self-administration were often followed by a return to baseline levels during chronic antagonist treatment suggesting that tolerance may have developed to these dopamine antagonists (Woolverton and Virus 1989). These two pioneering studies from the same laboratory have been described in some detail because they illustrate the development of more refined methods for examining the effects of potential treatment drugs on cocaine self-administration. Although the investigators concluded that the decreases in cocaine self-administration after $D_{1}$ dopamine antagonist administration did not reflect blockade of cocaine's reinforcing effects in both studies, the methodological improvements in the second study made this conclusion less open to alternative interpretations.

The complexity of $D_{1}$ antagonist effects on cocaine's reinforcing properties was further illustrated in a study in which both selective attenuation of cocaine's reinforcing effects during SCH 23390 treatment and subsequent enhancement following treatment were observed (Kleven and Woolverton 1990b). Because SCH 23390 has a relatively short duration of action, the effects of a continuous infusion on cocaine and food-maintained responding were evaluated in rhesus monkeys under conditions similar to those in the Woolverton and Virus study (1989). A range of doses of SCH 23390 was administered chronically over 5 to 13 days, the same period of time required for responding to decrease when saline was substituted for cocaine. Baseline doses of cocaine were available for 2 weeks or more between successive treatments. SCH 23390 infusion produced a selective decrease in cocaine-maintained responding in two of the four monkeys. However, these effects diminished over the period of observation, and both cocaine and food-maintained responding returned to pretreatment baseline levels. Interestingly, after termination of
SCH 23390, there was a persistent sensitization to the reinforcing effects of cocaine that lasted for at least 2 weeks. Low doses of cocaine that did not maintain selfadministration before SCH 23390 treatment, became reinforcing, that is, the ascending limb of the cocaine dose-response curve was shifted to the left (Kleven and Woolverton 1990b).

With the development of longer-acting and more selective dopamine antagonists, there has been additional support for the hypothesis that the reinforcing properties of cocaine may be selectively reduced by antagonism of specific dopamine receptors (Bergman et al. 1990; Corrigall and Coen 1991a; Hubner and Moreton 1991; Bergman and Rosenzweig-Lipson 1992; Spealman et al. 1992; Caine and Koob 1994). Bergman and coworkers (1990) examined the effects of a long-acting $D_{1}$ dopamine antagonist, SCH 39166, and of a $\mathrm{D}_{2}$ antagonist, eticlopride, on cocaine self-administration in squirrel monkeys (Bergman et al. 1990). This study differed from many previous reports in that dopamine antagonist effects were examined on an entire cocaine dose-effect curve rather than on a single reinforcing dose of cocaine (see Table 1 ). Moreover, these $\mathrm{D}_{1}$ and $\mathrm{D}_{2}$ antagonists were examined chronically over 5 days. This procedure permitted examination of whether or not the cocaine dose-effect curve was shifted to the right, suggesting antagonism of cocaine's reinforcing effects by these dopamine antagonists (see Figure 4). Single acute doses of the $\mathrm{D}_{1}$ antagonist $\mathrm{SCH} 39166$ or the $\mathrm{D}_{2}$ antagonist eticlopride were studied at each point in the cocaine dose-response curve. Responding for cocaine was maintained on a second-order FR 30, FI 10 minute schedule of reinforcement and no alternative reinforcer was studied. As shown in Figure 6, SCH 39166 shifted the ascending limb of the cocaine self-administration dose-effect curve to the right in four of five monkeys, suggestive of surmountable antagonism of cocaine's reinforcing effects (Bergman et al. 1990). Comparable effects were obtained with eticlopride.

The authors concluded that these data were consistent with antagonism at the level of dopamine receptors (Bergman et al. 1990). However, there remains considerable disagreement as to the capacity of dopamine receptor antagonists to antagonize competitively the reinforcing effects of cocaine (Roberts and Vickers 1984; Caine and Koob 1994; Richardson et al. 1994; Winger 1994; Negus et al. 1996). In rats, low doses of the dopamine $\mathrm{D}_{1}$ receptor antagonists SCH $23390(5 \mathrm{mcg} /$ $\mathrm{kg})$ and SCH $39166(10 \mathrm{mcg} / \mathrm{kg})$, but not A69024, selectively decreased cocaine self-administration without decreasing responding for food maintained on a multiple schedule (Caine and Koob 1994). Higher doses of these $D_{1}$ antagonists decreased both cocaine- and foodmaintained responding. When only cocaine-maintained responding was examined, treatment with these three $D_{1}$ antagonists, as well as the $D_{2}$ receptor antagonists 


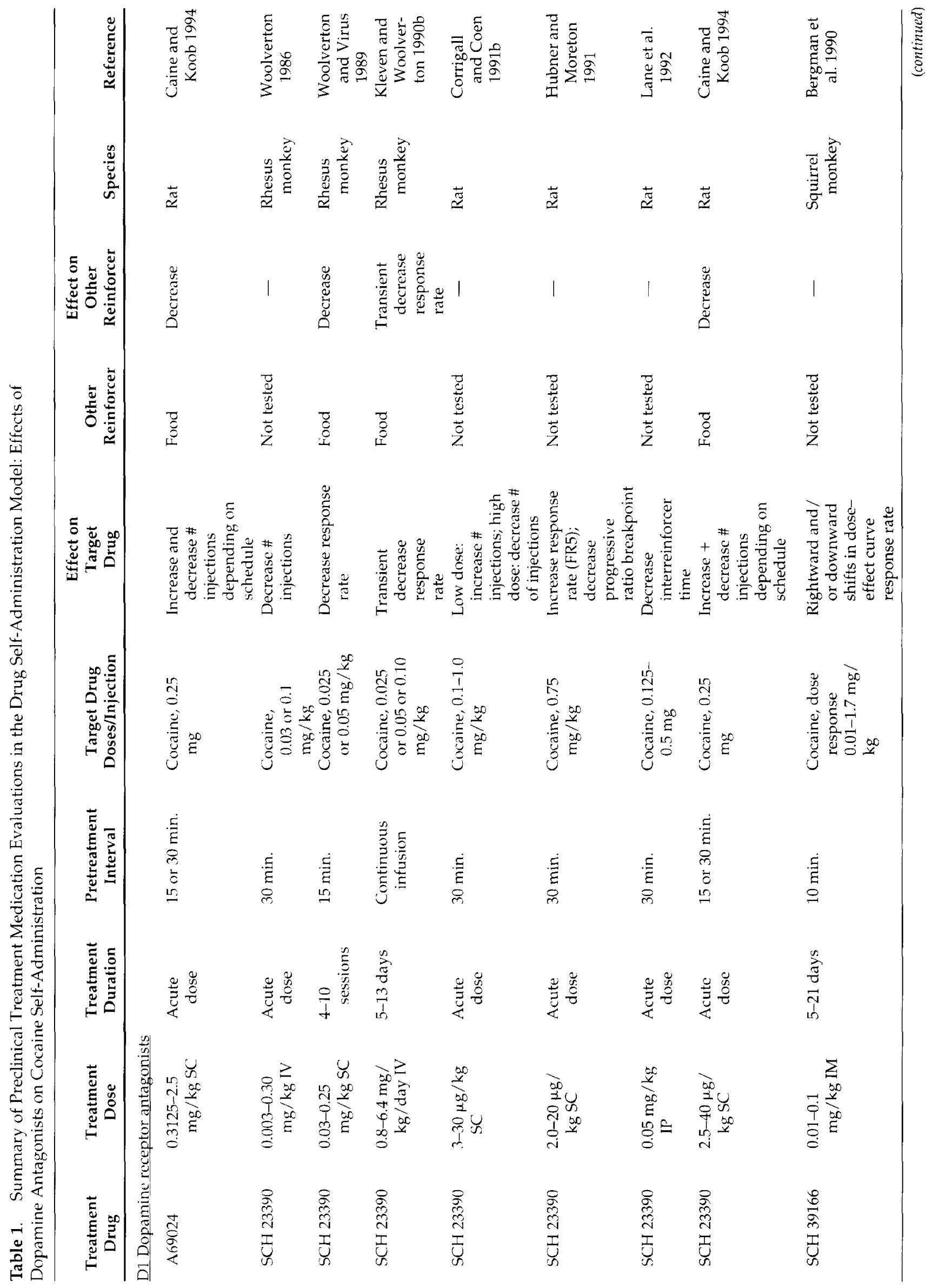




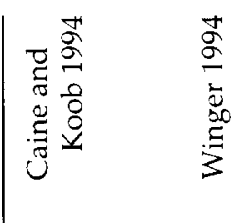

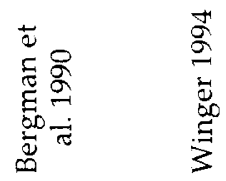

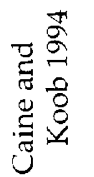

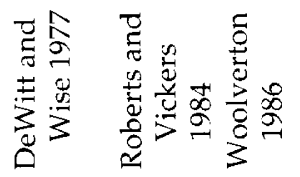

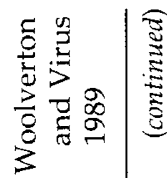

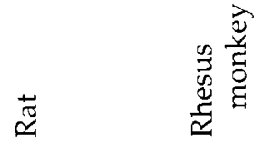

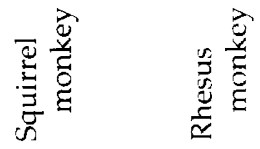

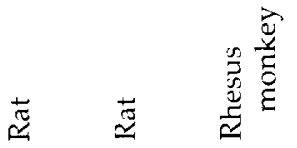

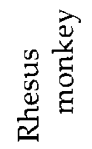

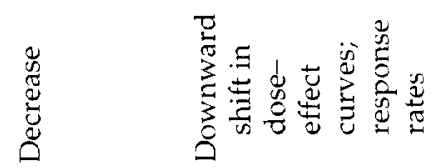

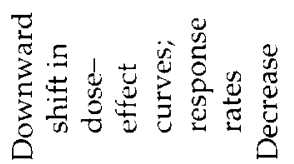

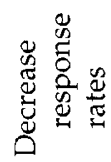

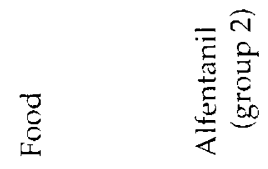

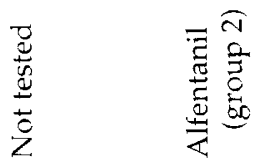

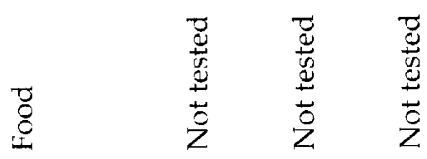
$\overline{8}$

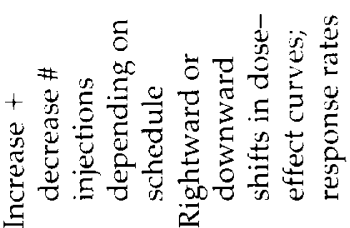

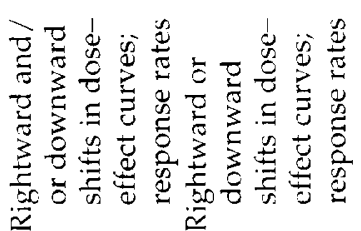

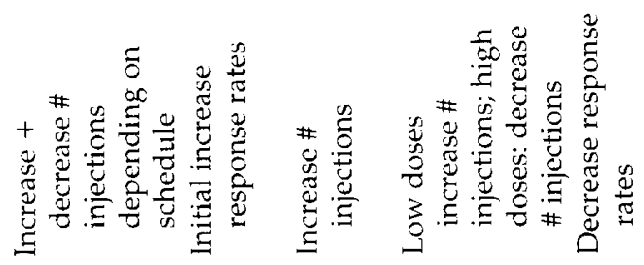

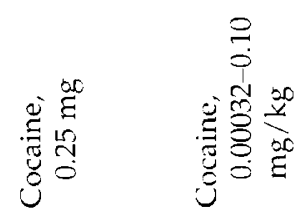

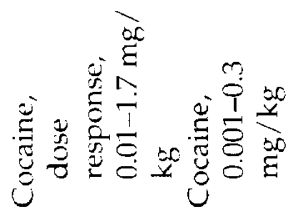

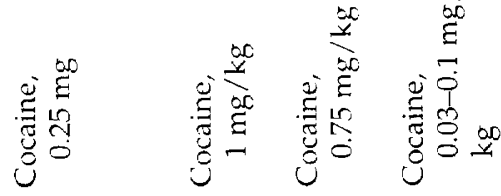

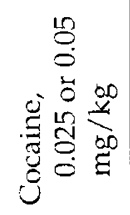

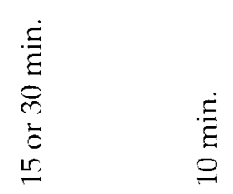

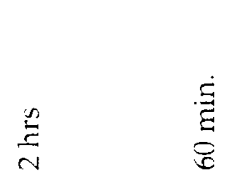

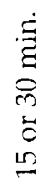
$\stackrel{n}{\frac{n}{n}} \quad \frac{\infty}{2}$

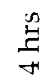

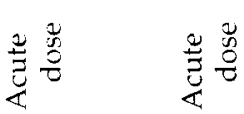

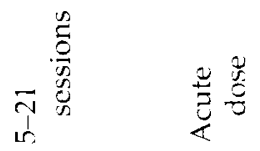

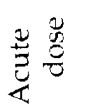

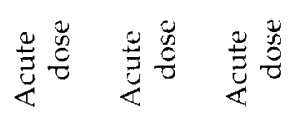
$\frac{1}{1}$
$\frac{1}{2}$
$\frac{1}{2}$
0

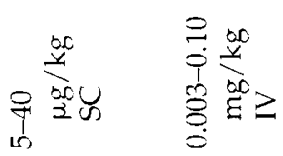

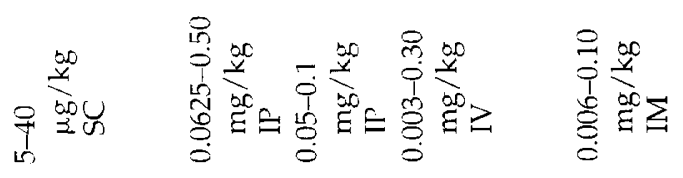

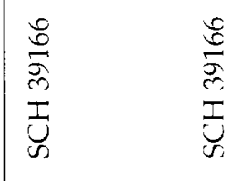

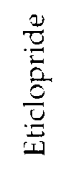

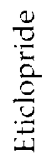

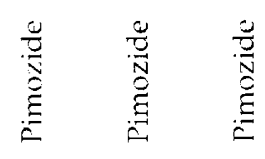

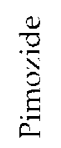




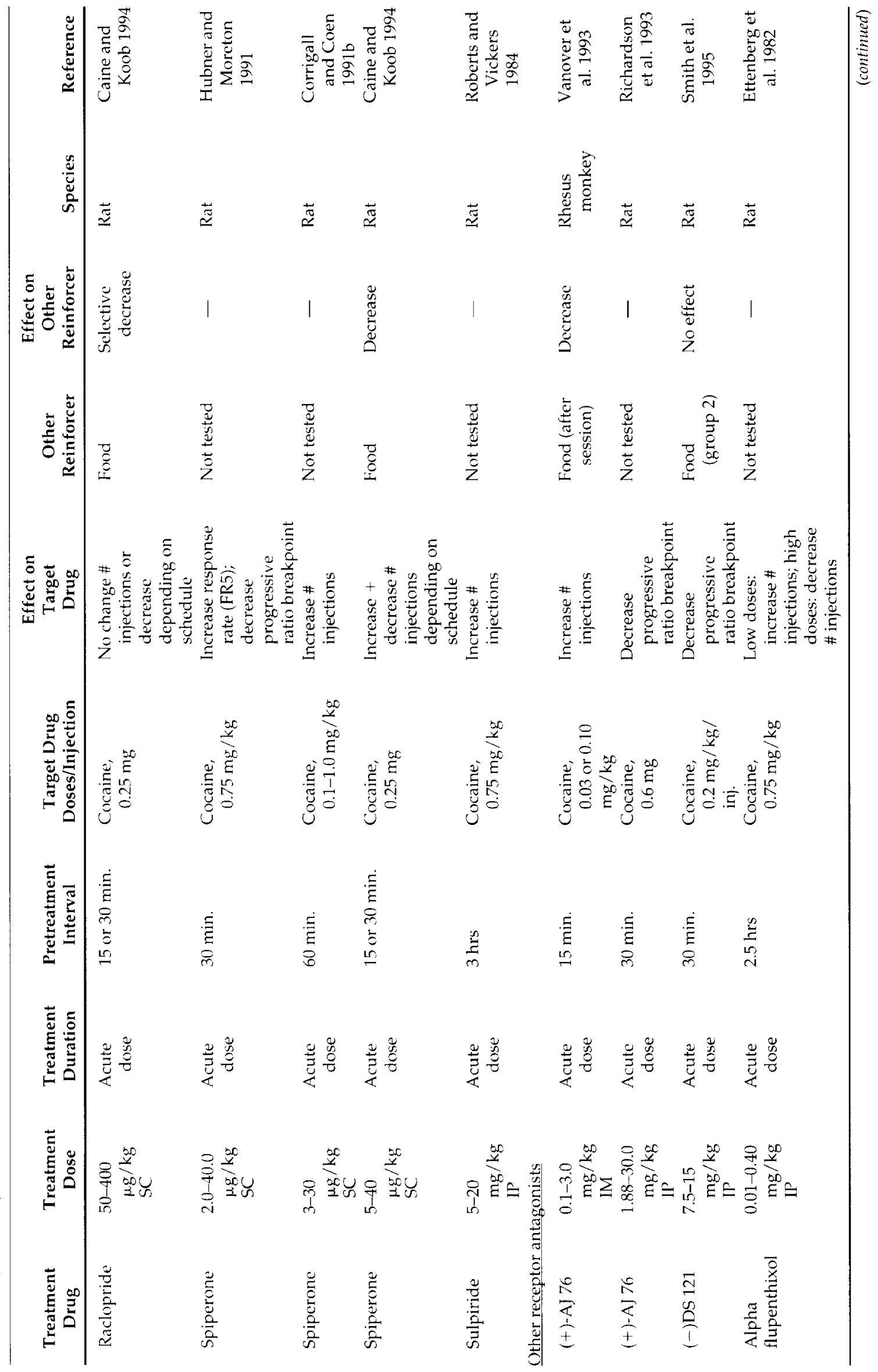




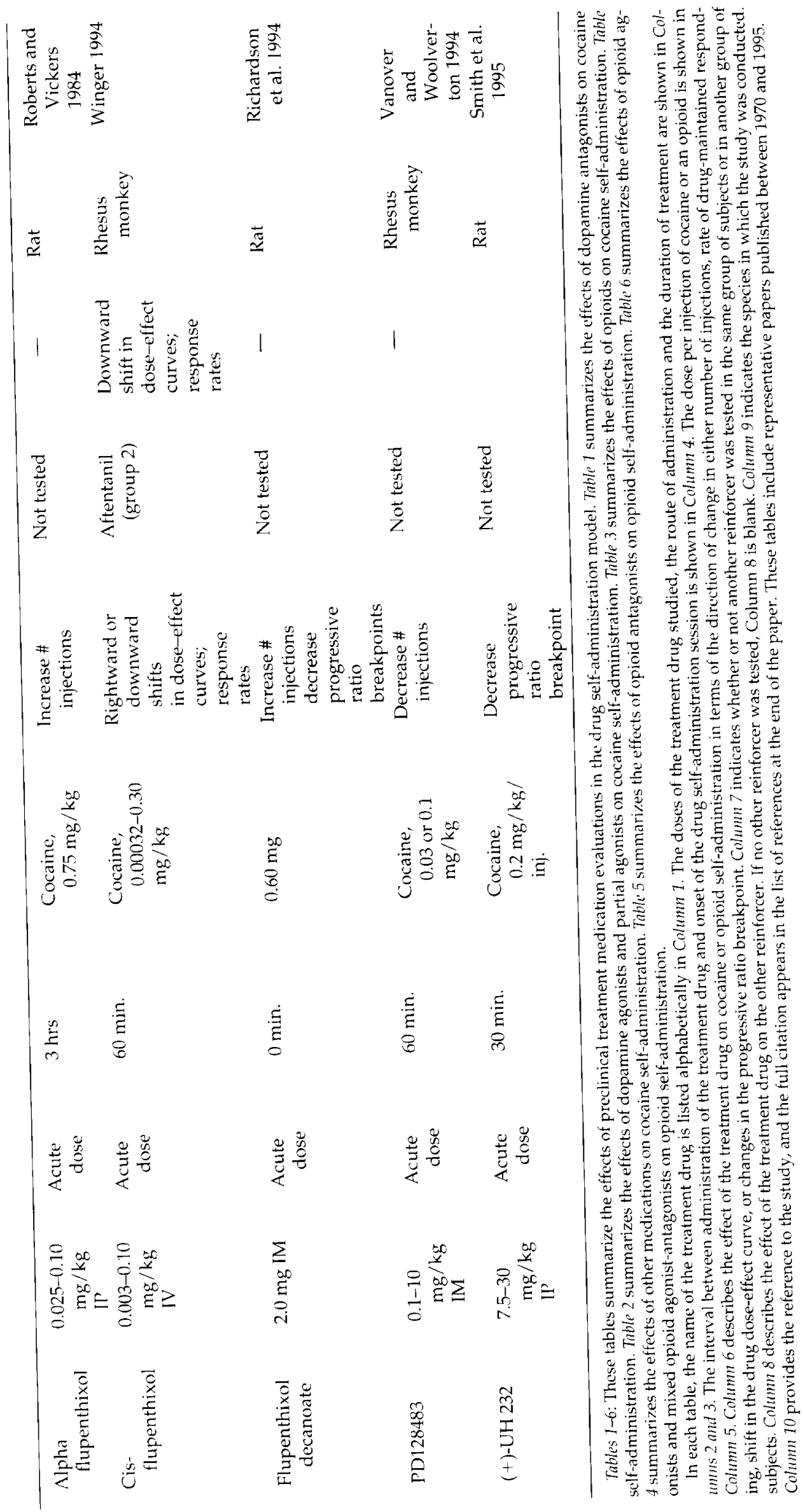




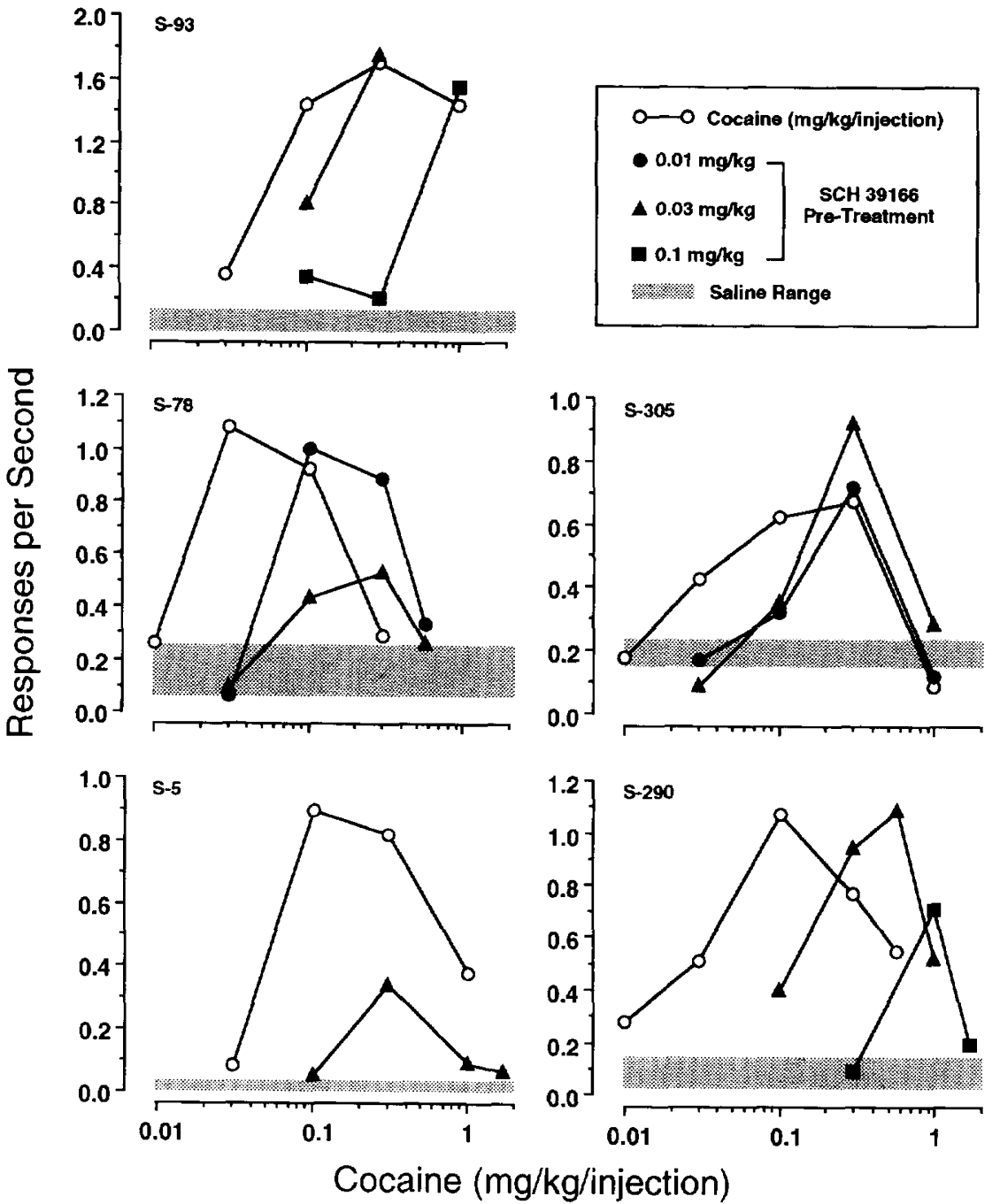

Figure 6. Antagonism of cocaine self-administration by a dopamine $D_{1}$ receptor antagonist, $\mathrm{SCH}$ 39166, in individual monkeys. Cocaine selfadministration was maintained under a second-order FR30 FI 10 minute schedule. Abscissae: cocaine dose, $\log$ scale; ordinates: rate of responding. Points are means based on the last three sessions at each dose of drug. The horizontal bar represents the mean $\pm S D$ values averaged for all periods of saline substitution in individual subjects. From Bergman I, Kamien JB, Spealman RD (1990): Antagonism of cocaine self-administered by selective $D_{1}$ and $D_{2}$ antagonists. Behav Pharmacol 1:355-363. Reprinted with permission. eticlopride and spiperone, resulted in a dose-dependent increase in cocaine self-administration. These changes in cocaine self-administration were similar to the effect of decreasing the cocaine unit dose, but response patterns were different from those observed during saline substitution. Only the $\mathrm{D}_{2}$ antagonist raclopride had no effect on cocaine self-administration under these conditions (Caine and Koob 1994). Caine and Koob concluded that "finally, it remains to be demonstrated conclusively that changes in self-administration behavior produced by dopamine antagonists can be attributed to changes in the reinforcing effects of cocaine independent of changes in other behavioral effects of cocaine (e.g., rate altering effects)" (Caine and Koob 1994, p. 217).

Similar conclusions were reached by Winger (1994) after studying the acute effects of the $D_{1}$ antagonist SCH 39166, the $D_{2}$ antagonist eticlopride, and the mixed $D_{1} / D_{2}$ antagonist cis-flupenthixol on the ascending limb of the cocaine and the alfentanil dose-effect curve in rhesus monkeys. Larger doses of these dopamine antagonists were required to suppress rates of re- sponding maintained by cocaine than by alfentanil, and this was interpreted to suggest that cocaine antagonized the rate suppressant effects of these dopamine antagonists. Winger concluded that "there is little evidence to support the notion that DA antagonists acting on either the $D_{1}$, the $D_{2}$ or both $D_{1} / D_{2}$ sites produce a competitive antagonism of the reinforcing effects of either cocaine or alfentanil" (Winger 1994, p. 139).

Flupenthixol is a $D_{1} / D_{2}$ antagonist that produces antidepressant effects clinically. Gawin and colleagues (1989) have reported that chronic treatment with low doses of flupenthixol decreases both cocaine craving and cocaine use in "crack" cocaine smokers. Chronic administration of cis-flupenthixol to rhesus monkeys over 10 days occasionally resulted in a selective decrease in cocaine self-administration in comparison to a saline treatment baseline with minimal effects on food self-administration (Negus et al. 1996). Selective decreases in cocaine self-administration occurred at relatively low doses of flupenthixol $(0.0032 \mathrm{mg} / \mathrm{kg})$; however, these effects were often transient and inconsistent 
across monkeys. Higher doses $(0.032 \mathrm{mg} / \mathrm{kg})$ tended to reduce both cocaine and food-maintained responding. Although dopamine $D_{1} / D_{2}$ receptor activity may contribute to cocaine's reinforcing effects, cis-flupenthixol's inconsistent effects on cocaine self-administration in rhesus monkeys suggest that it may have limited clinical usefulness (Negus et al. 1996). However, in rats, flupenthixol decreased progressive ratio breakpoints for cocaine (Richardson et al. 1994), suggesting an attenuation of cocaine's reinforcing effects.

$(+)$-AJ 76 is a dopamine antagonist that is reported to be selective for dopamine autoreceptors and is thought to have weak stimulant effects and to increase dopamine metabolism (Vanover et al. 1993). In rhesus monkeys, intermediate doses of (+)-AJ 76 increased cocaine self-administration with a concomitant decrease in food intake after the cocaine session. It was concluded that the changes in cocaine self-administration following acute administration of $(+)$-AJ 76 reflected at best a partial blockade of cocaine's reinforcing effects (Vanover et al. 1993). In rats, acute treatment with (+)-AJ 76 had little effect on progressive ratio breakpoints over a doserange of 1.88 to $15 \mathrm{mg} / \mathrm{kg}$, but breakpoints were significantly reduced at a high dose of $30 \mathrm{mg} / \mathrm{kg}$ (Richardson et al. 1993). Because progressive ratio breakpoints often are considered to be a sensitive measure of reinforcing efficacy, these results were consistent with the interpretation that (+)-AJ 76 antagonized cocaine's reinforcing effects. Moreover, because rats tended to increase rates of responding for the first six cocaine injections, these findings probably could not be attributed to sedation, but no alternative reinforcer was studied.

In summary, dopamine antagonists have occasionally been reported to antagonize the reinforcing effects of cocaine and shift the cocaine dose-effect curve to the right. However, these cocaine antagonist effects often are inconsistent across subjects, transient, and accompanied by unacceptable adverse side effects. Usually dopamine antagonist effects are not selective for cocaine, and behavior maintained by cocaine as well as by alternative reinforcers is decreased. Furthermore, these rightward shifts are small, and self-administration of some unit doses of cocaine is increased, as shown schematically in Figure 4. An antagonist-induced increase in cocaine self-administration is not an optimal clinical outcome. Taken together, these findings predict that dopamine antagonists may not have an ideal pharmacological profile for the treatment of cocaine abuse.

\section{Effects of Dopamine Agonists and Partial Agonists on Cocaine Self-Administration [Table 2]}

The rationale for treatment of cocaine abuse with cocaine-like drugs that have less abuse liability and fewer toxic side effects than cocaine is similar to the rationale advanced for the treatment of opioid dependence with opioid agonists and mixed agonist-antagonists. It also is possible that cocaine-like drugs could increase compliance with behavioral treatment interventions (Balster et al. 1992). A number of dopamine agonists and partial agonists have been shown to maintain responding leading to their self-administration. However, reinforcing effects of treatment medications may be problematic because these may contribute to abuse liability as well as facilitating compliance during chronic treatment.

Reinforcing Effects of Dopamine Agonists. The reinforcing effects of dopamine agonists and partial agonists appear to reflect their relative selectivity for or efficacy at dopamine receptors. For example, a partial $D_{1}$ receptor agonist (SKF 38393) failed to maintain drug self-administration by rhesus monkeys (Woolverton et al. 1984), whereas a full $D_{1}$ receptor agonist (SKF 81297) was self-administered and its reinforcing effects were attenuated by a $\mathrm{D}_{1}$ antagonist (SCH 39166) (Weed et al. 1993). Other $D_{1}$ agonists (SKF 82958) and (SKF 77434) also were self-administered by rats (Self and Stein 1992). Dopamine agonists with activity at the $D_{2}$ receptor (apomorphine, quinpirole, piribedil and bromocriptine) are usually self-administered (Spealman et al. 1992). A dopamine agonist (7-OH-DPAT) with high affinity for $D_{3}$ receptors was self-administered by cocaine-trained rats (Caine and Koob 1993) and rhesus monkeys (Nader and Mach 1996). Curiously, drug-naive monkeys could not be trained to self-administer 7-OH-DPAT under the same conditions used to train cocaine self-administration, which suggests that this $D_{3}$ agonist may have relatively low abuse liability (Nader and Mach 1996). Despite accumulating evidence of the importance of $D_{1}, D_{2}$, and $D_{3}$ receptors in cocaine's reinforcing effects, their complex interactions, coupled with the ongoing identification of additional dopamine receptor subtypes, suggest that there is unlikely to be any simple explanation of the mechanisms by which cocaine maintains behavior leading to its self-administration (see Schwartz et al. 1992; Woolverton and Johnson 1992 for review).

The reinforcing properties of structurally dissimilar drugs with mechanisms of action similar to those of cocaine also have been examined. In one illustrative study, cocaine self-administration was compared to behavior maintained by several drugs that act as indirect dopamine agonists by inhibiting dopamine reuptake (Bergman et al. 1989). Self-administration of bupropion, GBR 12909, methylphenidate, and nomifensine by squirrel monkeys was comparable to cocaine-maintained responding across the dose range studied (Bergman et al. 1989). These findings were consistent with other reports that bupropion, methylphenidate, and nomifensine were self-administered by rhesus monkeys (Johanson and Schuster 1975; Winger and Woods 1985) and that GBR 12909 was self-administered by squirrel 


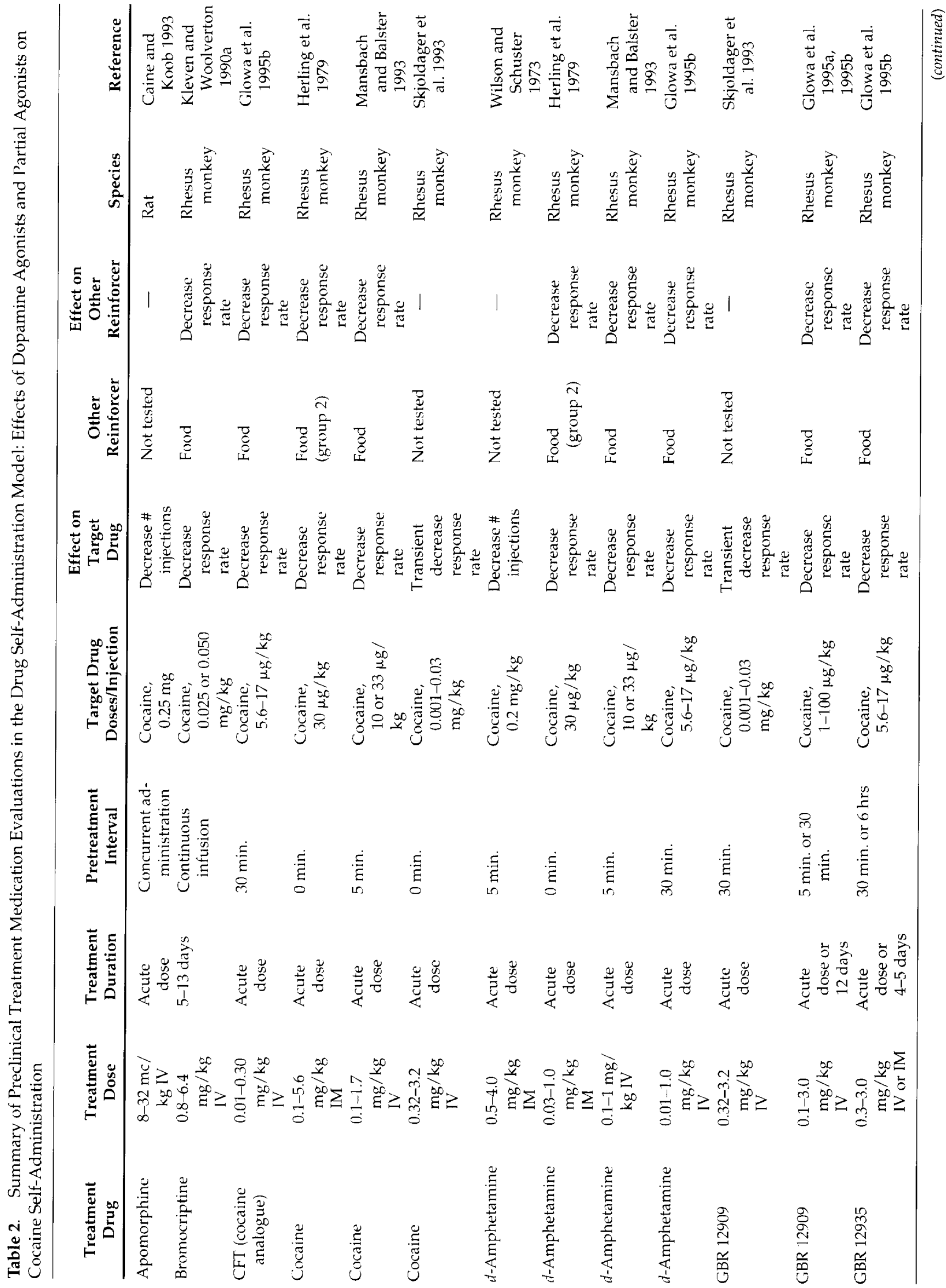




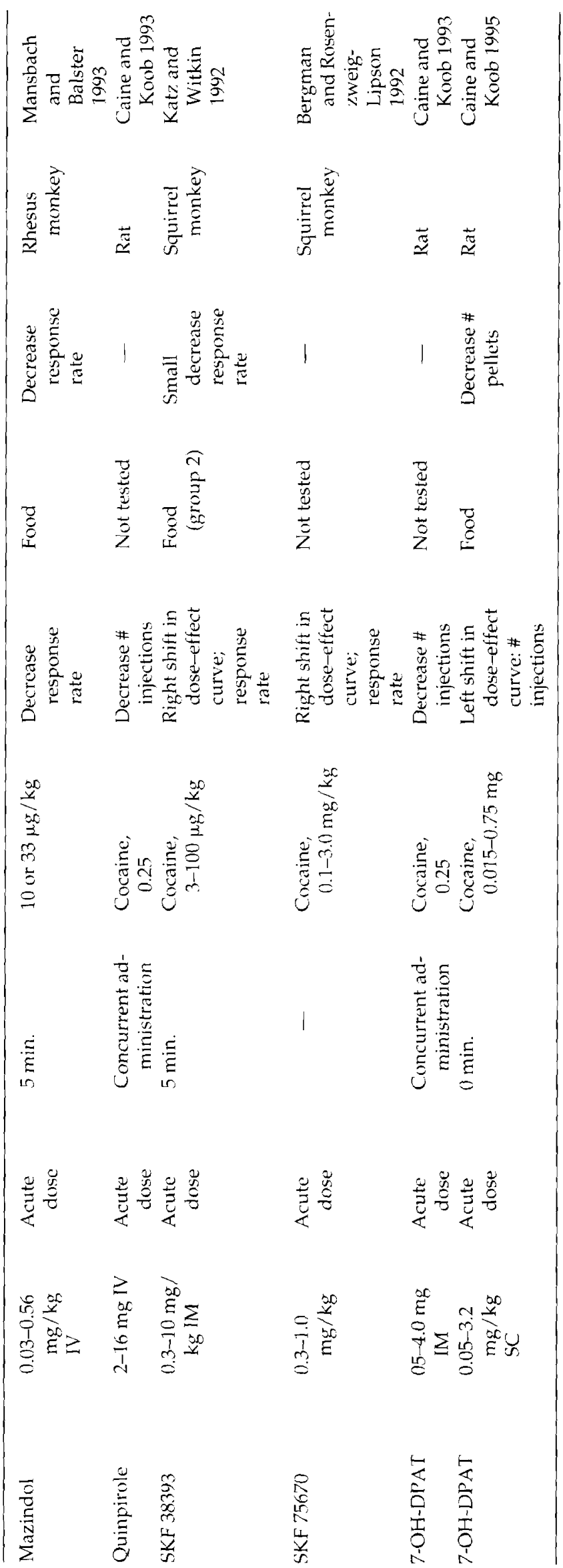

monkeys (Howell and Byrd 1991). Each drug was similar to cocaine in its rates and patterns of self-administration and yielded characteristic inverted U-shaped doseresponse curves with one exception. Mazindol was selfadministered by only half of the monkeys studied and produced a number of toxic side effects, including profuse salivation, self-mutilation, and distress calls (Bergman et al. 1989). In contrast to these findings in squirrel monkeys, mazindol was self-administered by rhesus monkeys (Wilson and Schuster 1976). A recent comparison of GBR 12909 and cocaine self-administration in rhesus monkeys found that GBR 12909 maintained lower rates of responding at higher unit doses than cocaine (Skjoldager et al. 1993).

Effects of Dopamine Agonists on Cocaine Self-Administration. Treatment with cocaine and other dopamine agonists has consistently decreased cocaine self-administration in animal models. However, these effects often were not selective for cocaine when another reinforcer was available for comparison (see Table 2). For example, the effects of mazindol, a dopamine and norepinephrine reuptake inhibitor, were compared to those of sertraline and fluoxetine, which inhibit the reuptake of serotonin (Kleven and Woolverton 1993). Cocaine and food self-administration were maintained on an FR 30 schedule. During treatment drug evaluations, each monkey was maintained on the dose of cocaine that was at or near the peak of its dose-response curve. Mazindol $(0.4-3.2 \mathrm{mg} / \mathrm{kg} / 24 \mathrm{hr})$, sertraline $(0.1-8.0$ $\mathrm{mg} / \mathrm{kg} / 24 \mathrm{hr}$ ) or fluoxetine $(0.4-3.2 \mathrm{mg} / \mathrm{kg} / 24 \mathrm{hr})$ was continuously infused through the second lumen of a double-lumen catheter for the same number of sessions required for responding to decrease after saline was substituted for cocaine. Doses of test drugs were given in an ascending order in the first monkey tested and presented in an irregular order in the other monkeys. Monkeys returned to saline-treatment baseline levels of cocaine and food-maintained responding for 1 week or more between successive doses of each treatment drug. Each drug decreased cocaine self-administration in a dose-related manner, but food self-administration also decreased over the same dose range (Kleven and Woolverton 1993). Similar findings have been reported in studies where cocaine was administered to monkeys given access to cocaine self-administration (see Table 2). The extent to which the nonselective effects of these monoamine uptake inhibitors on cocaine and food selfadministration can be attributed to enhancement of the aversive effects of cocaine or anorectic effects on foodmaintained behavior could not be determined with certainty from these data (Kleven and Woolverton 1993).

Results from studies of the selective dopamine reuptake inhibitor GBR 12909 have been inconsistent across laboratories. Pretreatment with single doses of cocaine $(0.32-3.2 \mathrm{mg} / \mathrm{kg})$ or GBR $12909(0.32-3.2 \mathrm{mg} /$ 
$\mathrm{kg}$ ) had minimal and transient effects on cocaine selfadministration by rhesus monkeys (Skjoldager et al. 1993). The greatest suppression occurred during the first 25 minutes of cocaine self-administration sessions, consistent with the relatively short duration of action of each compound. Moreover, doses that were effective in altering cocaine self-administration were just slightly below doses that had convulsant effects (Skjoldager et al. 1993). Skjoldager and coworkers concluded that GBR 12909 enhanced cocaine's rate decreasing effects but did not modify its reinforcing effects (Skjoldager et al. 1993). In contrast, GBR 12909 was reported to decrease cocaine self-administration in rhesus monkeys responding for food and cocaine under an FR 30 schedule during sessions composed of alternating cycles of food and cocaine availability (Glowa et al. 1995a). Under these conditions, intermediate doses of GBR 12909 (1-7 mg/ $\mathrm{kg}$ IV) produced a selective decrease in the self-administration of unit doses of cocaine located on the peak and descending limb of the cocaine dose-effect curve. GBR 12909 was more effective in reducing self-administration of lower rather than higher unit doses of cocaine (Glowa et al. 1995a). In subsequent studies, the effects of another dopamine reuptake inhibitor (GBR 12935) as well as CFT, a long-acting cocaine analog and $d$-amphetamine were evaluated on cocaine and food self-administration under similar conditions (Glowa et al. 1995b). Unlike GBR 12909, these compounds decreased both cocaine- and food-maintained responding. Chronic GBR $12909(1.7 \mathrm{mg} / \mathrm{kg})$ administration over 12 days resulted in a selective and sustained decrease in cocaine self-administration (Glowa et al. 1995b). Amantadine, another dopamine reuptake inhibitor, failed to decrease cocaine self-administration during chronic treatment and did not maintain self-administration behavior in baboons when substituted for cocaine (Sannerud and Griffiths 1988).

Studies by Caine and Koob $(1993,1995)$ have examined the effects of the $\mathrm{D}_{3}$ dopamine receptor-selective agonist 7-OH-DPAT in rats responding for cocaine under several schedules of reinforcement (Caine and Koob 1993, 1995). Initial studies showed that concurrent administration of cocaine and 7-OH-DPAT decreased cocaine selfadministration by rats (Caine and Koob 1993). Moreover, the pattern of this decrease was similar to the pattern produced by increasing the unit dose of cocaine. These 7-OH-DPAT-induced changes in cocaine self-administration were interpreted as evidence that 7-OH-DPAT increased the reinforcing effects of cocaine. Subsequent studies also suggested that 7-OH-DPAT pretreatment enhanced the reinforcing effects of cocaine (Caine and Koob 1995). For example, one group of rats was trained to respond for food and cocaine under a FR 5/Timeout 2-minute schedule during sessions composed of alternating food and cocaine cycles. Pretreatment with 0.4$\mathrm{mg} / \mathrm{kg}$ SC of 7-OH-DPAT produced a leftward shift in the cocaine dose-effect curve and decreased rates of responding maintained by food. In the 7-OH-DPAT pretreatment paradigm, the effects on cocaine self-administration were critically dependent on the position of the unit dose of cocaine on the cocaine dose-effect curve. 7-OH-DPAT pretreatment increased cocaine self-administration at doses on the ascending limb of the doseeffect curve and decreased cocaine self-administration at doses on the descending limb of the dose-effect curve. Food-maintained responding was uniformly decreased under both conditions (Caine and Koob, 1995).

Partial dopamine agonists, which function as antagonists at some doses, also decrease cocaine self-administration by squirrel monkeys. For example, pretreatment with single doses of the partial $D_{1}$ selective agonist SKF 38393 shifted the ascending limb of the cocaine dose-response curve to the right in comparison to saline control treatment (Katz and Witkin 1992). SKF 38393 reduced cocaine-maintained responding more than food-maintained responding in separate groups of monkeys, which suggested that the effects of this $D_{1}$ dopamine agonist were selective for cocaine (Katz and Witkin 1992). These data (Figure 7) are a model study of acute treatment drug effects insofar as the effects of SKF 38393 were examined on the complete cocaine self-administration dose-response curve, as well as on an alternative reinforcer. A dopamine $\mathrm{D}_{1}$ agonist with limited agonist efficacy, SKF 75670, also resulted in a rightward downshift (Bergman and Rosenzweig-Lipson 1992). This low-efficacy agonist was similar to the $\mathrm{D}_{1}$ antagonist SCH 39166 in reducing cocaine's behavioral effects on several measures (Bergman and Rosenzweig-Lipson 1992)

In summary, dopamine agonists and partial agonists occasionally have been reported to decrease cocaine self-administration. However, these effects may be accompanied by toxic side effects, including suppression of the self-administration of other reinforcers. In addition, many dopamine agonists have reinforcing effects that may contribute to their high abuse potential but that may also facilitate patient compliance during treatment. Finally, some dopamine agonists, such as 7-OHDPAT, may actually enhance the reinforcing effects of cocaine. Partial dopamine agonists may present the most promising profile for an effective medication with minimal side effects, because they mimic some effects of cocaine without producing the toxic effects of full dopamine agonists or antagonists.

\section{Effects of Opioid \\ Antagonists, Agonists, and \\ Mixed Agonist-Antagonists on Cocaine \\ Self-Administration [Table 3]}

Interactions between cocaine and opioids are poorly understood. Because cocaine's reinforcing and discrimi- 

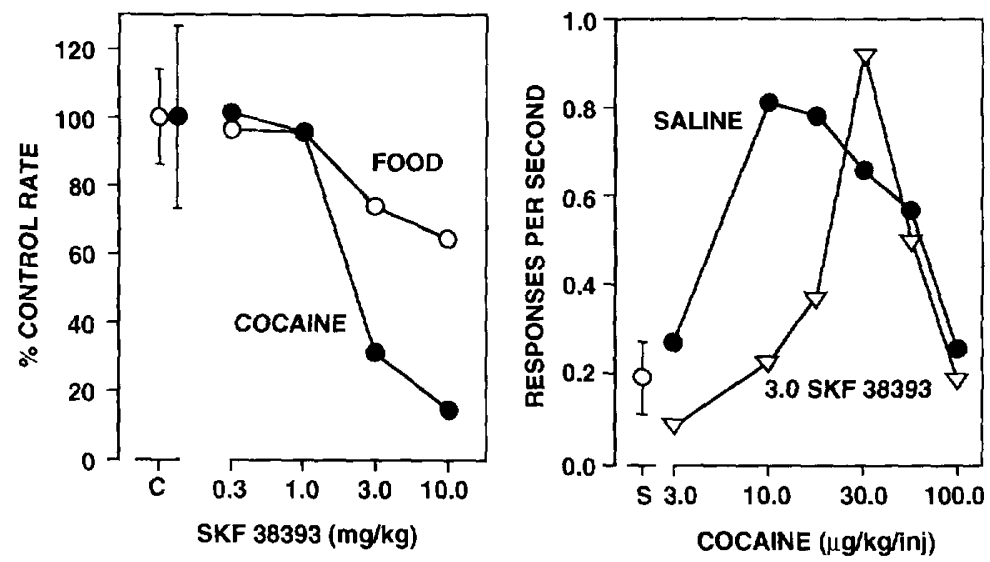

Figure 7. Effects of the partial $D_{1}$ agonist SKF 38393 on behavior maintained by cocaine in squirrel monkeys. Left panel, effects of SKF 38393 on responding maintained under a FR schedule of either cocaine injection $(17 \mu \mathrm{g} / \mathrm{kg} / \mathrm{inj}$.) or food presentation (190 mg/presentation). Solid circles, cocaine-maintained responding. Each circle is the mean of four subjects with typically two determinations at each dose. Open circles, food-maintained responding. Each point is the mean of two subjects with typically two determinations at each dose. Points above $\mathrm{C}$ represent rates of responding during the control cocaineinjection sessions that preceded test sessions for the subjects maintained on cocaine, and saline-control sessions for the subjects maintained on food. The average control rates of responding ( \pm SE) were $3.87( \pm 0.54)$ and $1.22( \pm 0.33$ ) responses per second under the schedules of food presentation or cocaine injection, respectively. Right panel, effects of pretreatment with saline or $3.0 \mathrm{mg} / \mathrm{kg}$ SK 38393 on the cocaine dose-effect curve. Cocaine doses per injection $(\mu \mathrm{g} / \mathrm{kg})$ are shown on the abscissa and responses per second are shown on the ordinate. Solid circles, effects of cocaine dose/injection following pretreatment with saline. Each point is the mean of two subjects with typically two determinations at each dose.Open triangles, effects of cocaine dose/injection following pretreatment with $3.0 \mathrm{mg} / \mathrm{kg}$ SKF 38393 . Each point is the mean of two subjects with typically two determinations at each dose. Open circle above $S$, average rate of responding maintained by saline injection. From Katz JL, Witkin JM (1992): Selective effects of the D dopamine receptor agonist, SKF 38393, on behavior maintained by cocaine injection. Psychopharmacology 109:241-244. Reprinted with permission.

native stimulus effects are modulated by dopaminergic neural systems, the effects of opioid agonists and antagonists on cocaine self-administration behavior are difficult to predict from what is known about the pharmacology of either class of drugs alone. Cocaine often is abused concurrently with opioids, and the combined effects have been described anecdotally as enhancing the positive subjective effects of opioids, and decreasing aversive agitation produced by cocaine (Kosten et al. 1986, 1987; Rosen and Kosten 1991; Tutton and Crayton 1993). One controlled clinical study suggests that morphine-cocaine combinations result in a unique profile of subjective effects that differ from those of either drug alone (Foltin and Fischman 1992). Opioid agonists, antagonists, and mixed agonist-antagonists have been used clinically to treat opioid abuse and polydrug abuse involving cocaine, often with inconsistent results (Rosen and Kosten 1991; Tutton and Crayton 1993; Mendelson and Mello 1996). Methadone, a mu-selective agonist, has not been consistently effective in reducing cocaine abuse by opioid-dependent patients, and if opioid abuse persists, cocaine abuse may increase during treatment (Kosten et al. 1986, 1987, 1989a; Cushman 1988; Chaisson et al. 1989; Dunteman et al. 1992). In early clinical trials, a mu-selective antagonist, naltrexone, appeared to be more effective than methadone in reducing concurrent cocaine abuse, but lack of compliance by opioid-dependent patients has limited naltrexone's clinical utility (National Research Council Committee on Clinical Evaluation of Narcotic Antagonists 1978; Meyer and Mirin 1979; Kosten et al. 1989b; Rosen and Kosten 1991). An opioid mixed agonist-antagonist, buprenorphine, appears to be more effective in reducing combined cocaine and opioid abuse in severely drug-dependent patients (Gastfriend et al. 1993; Mello et al. 1993c; Schottenfeld et al. 1993; Mello and Mendelson 1996).

Opioid Antagonists. Opioid antagonists have had inconsistent effects on cocaine self-administration in preclinical studies (Table 3). Naltrexone, a mu-selective opioid antagonist, has been studied with conflicting results in several species. In rats, acute pretreatment with naltrexone resulted in no change (Ettenberg et al. 1982), decreases (Corrigal and Coen 1991a), or increases (Carroll et al. 1986) in cocaine self-administration. Chronic naltrexone treatment in rhesus monkeys selectively decreased cocaine self-administration in comparison to food-maintained responding, but naltrexone's effects were not dose-related (Mello et al. 1990b). In a subsequent study, naltrexone had no effect on cocaine self-administration in rhesus monkeys studied under similar conditions (Mello et al. 1993b). The absence of robust ef- 
要

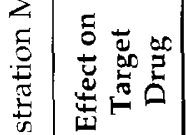

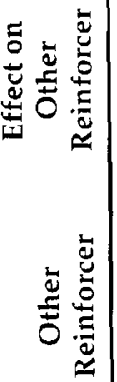

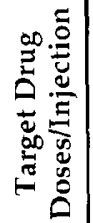

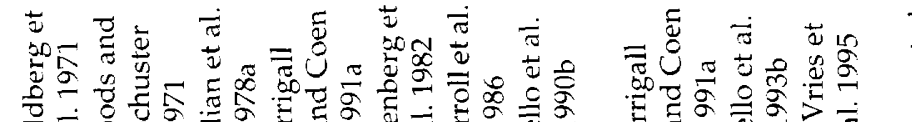

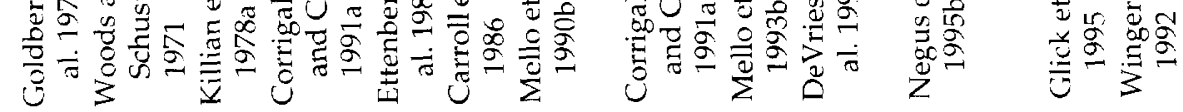

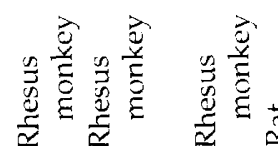

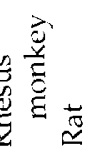

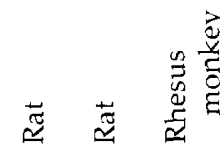

密

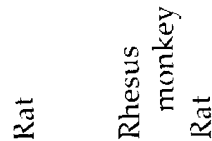

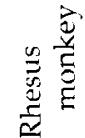

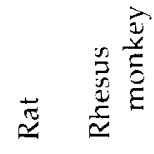

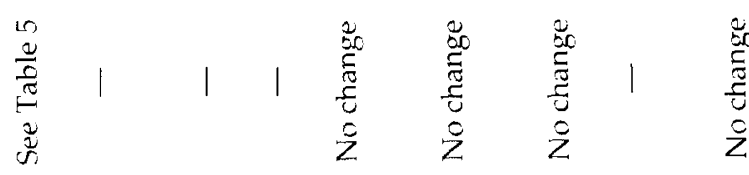

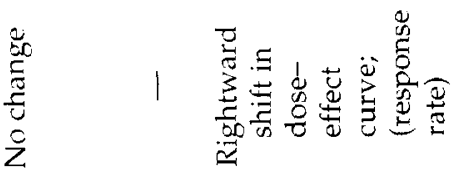

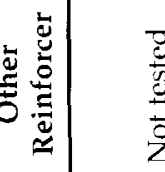

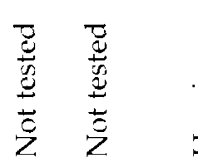

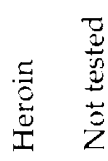

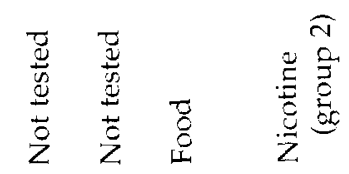

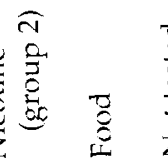

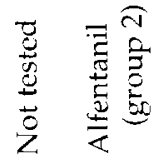

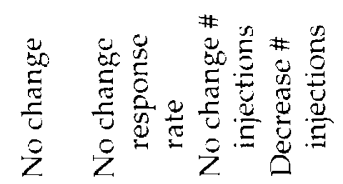

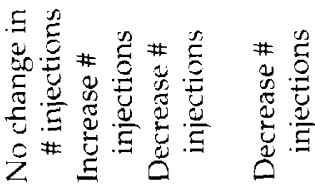

$\Xi \stackrel{\Xi}{\mathscr{c}} \cong \mathscr{\Xi}$

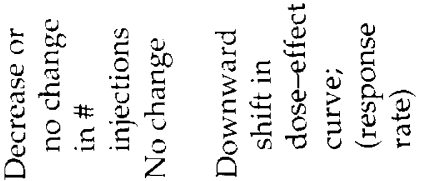

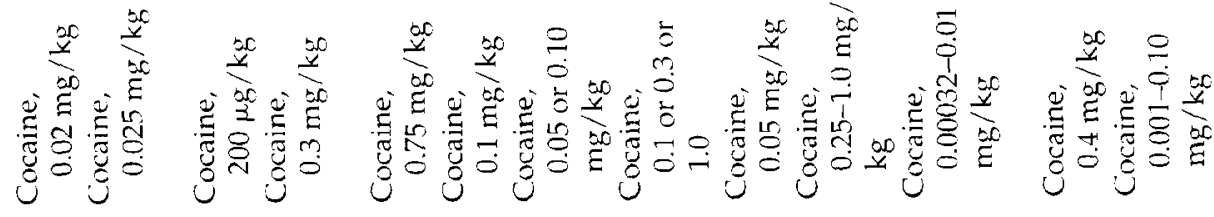

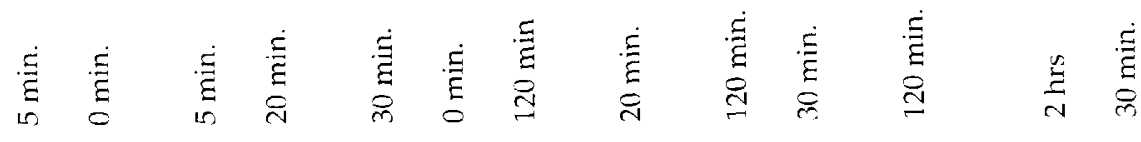

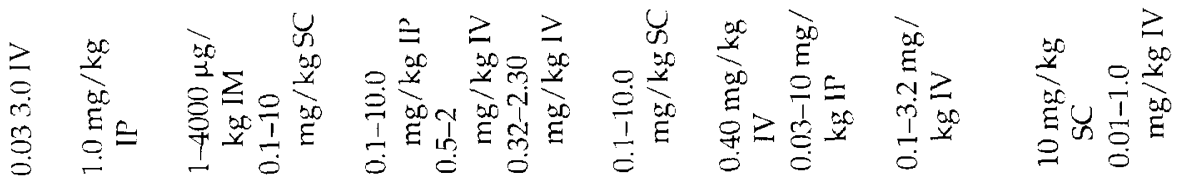




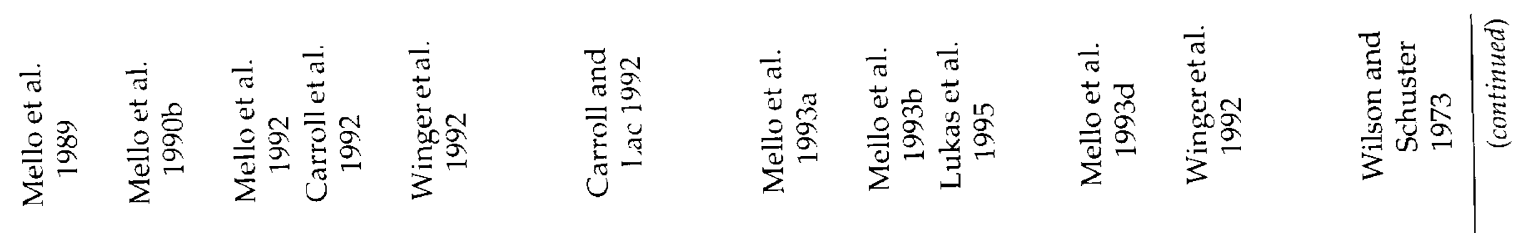

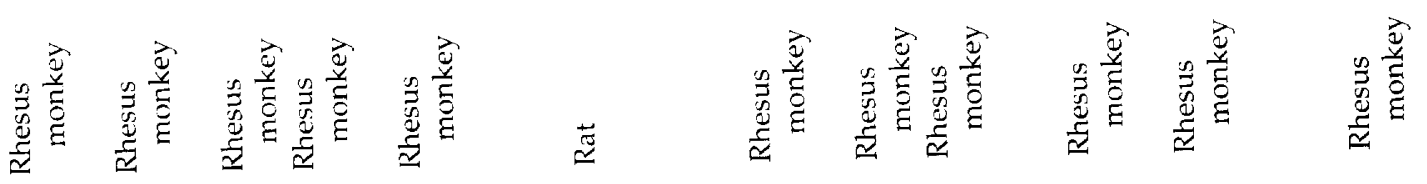

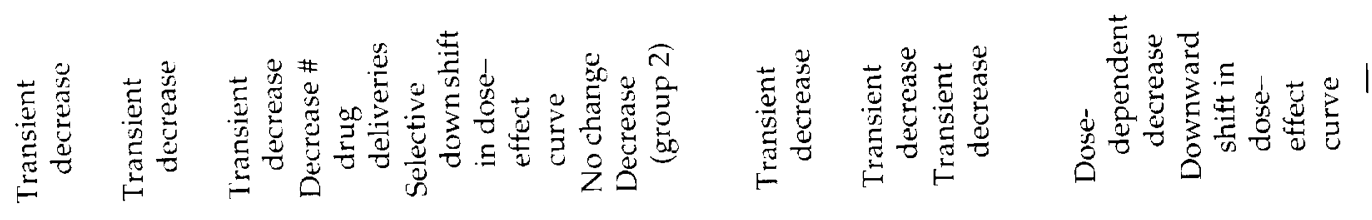

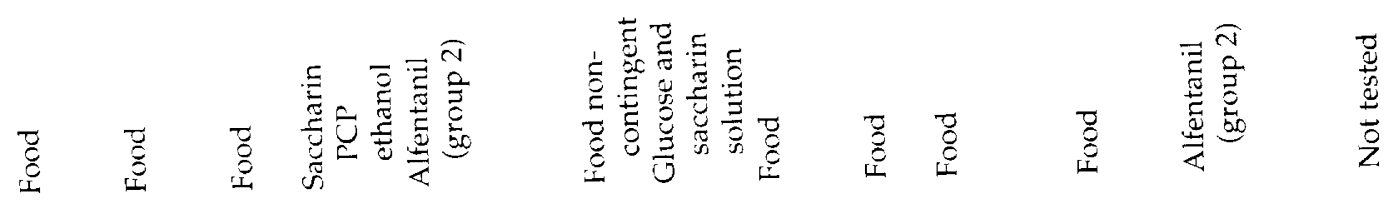

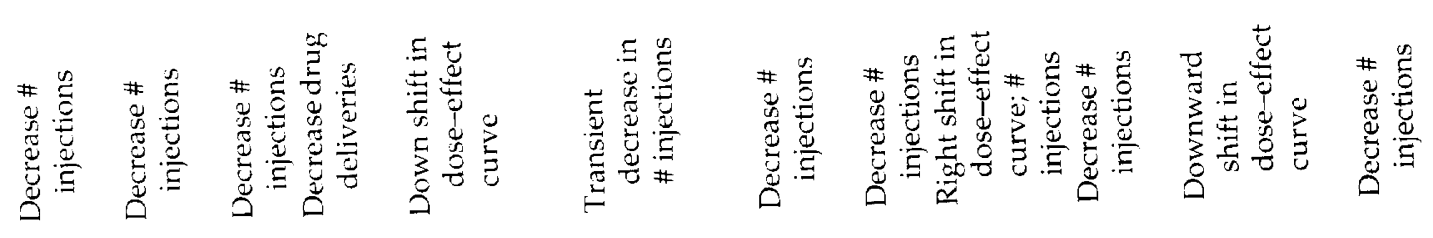

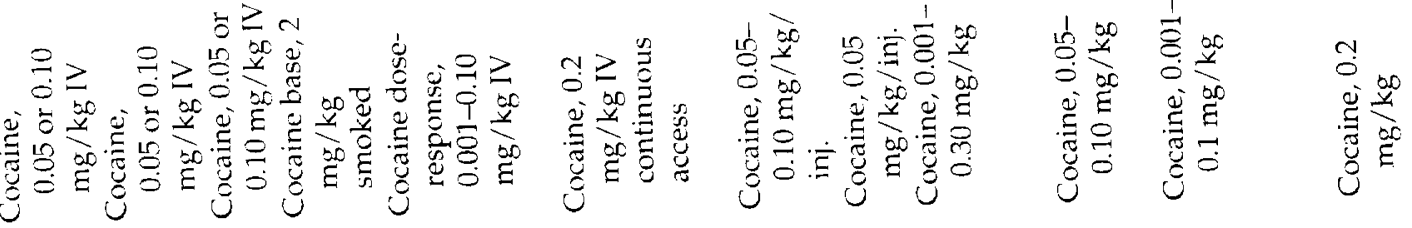

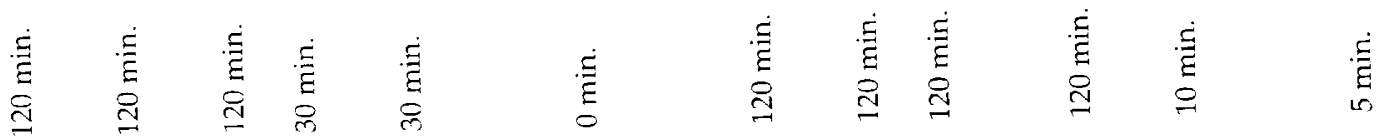

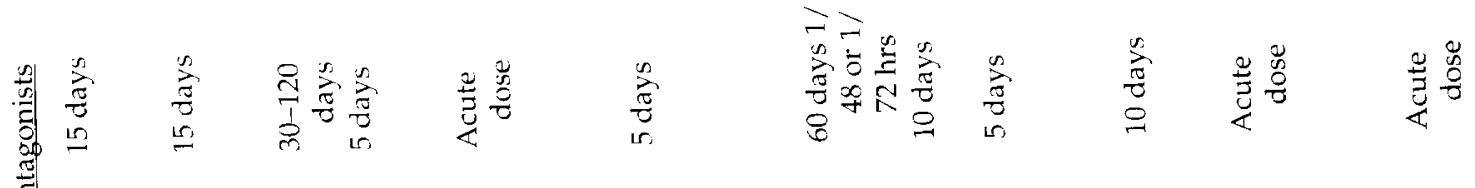

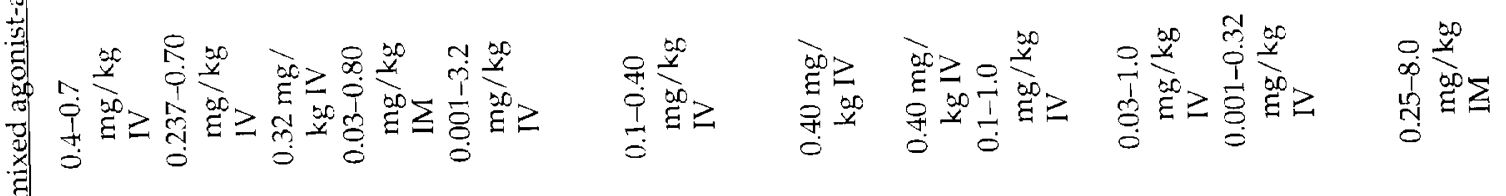

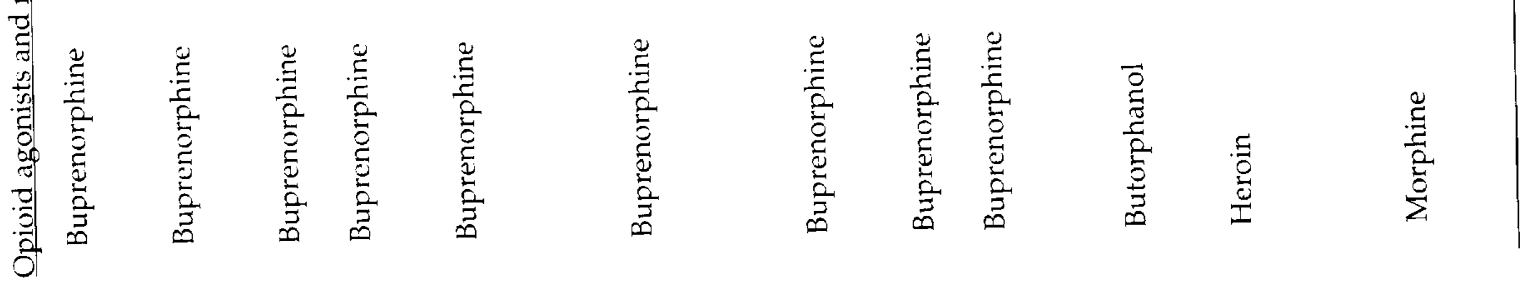




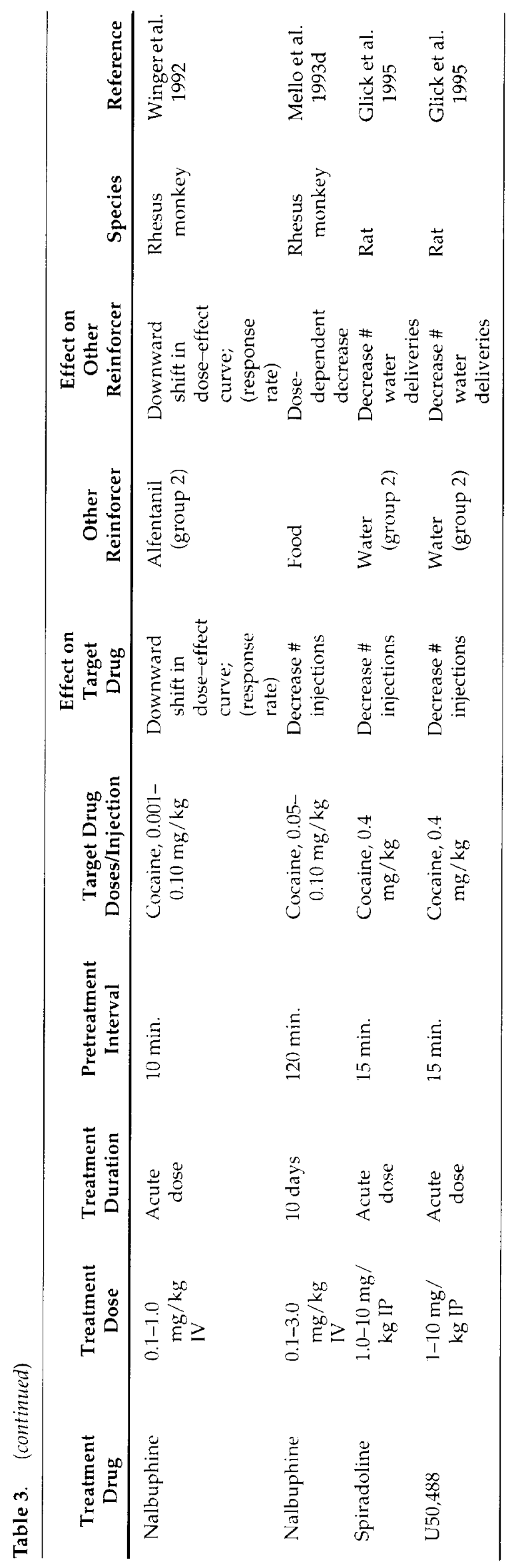

fects of naltrexone on cocaine self-administration is consistent with findings from most preclinical evaluations of mu-selective opioid antagonists. Earlier studies of pretreatment with the short-acting opioid antagonists naloxone or nalorphine also found no suppression of cocaine self-administration in rhesus monkeys (Goldberg et al. 1971; Woods and Schuster 1971; Killian et al. 1978a).

In addition to mu-receptor selective opioid antagonists, the effects of a delta receptor selective opioid antagonist, naltrindole, on cocaine self-administration have also been examined in rhesus monkeys (Negus et al. 1995b) and in rats (de Vries et al. 1995). In rats, naltrindole had no effects on cocaine self-administration (de Vries et al. 1995). In rhesus monkeys, at least one dose of naltrindole (0.1-3.2 mg/kg IV) administered over 10 days decreased self-administration of a maximally reinforcing dose of cocaine $(0.01 \mathrm{mg} / \mathrm{kg} / \mathrm{inj}$.) in three of four subjects. Food self-administration was unaffected by naltrindole, which suggested that decreases in cocaine-maintained responding did not result from a nonselective decrease in operant behavior. However, these effects did not occur at all naltrindole doses or in all monkeys. An intermediate dose of naltrindole usually was more effective than either lower or higher doses. Finally, the cocaine-antagonist actions of naltrindole were not replicable and were not monotonically related to the naltrindole dose. Although naltrindole may modulate the reinforcing effects of cocaine, these results suggest that delta opioid receptors play a minimal and inconsistent role in the reinforcing effects of cocaine in rhesus monkeys (Negus et al. 1995b).

Opioid Agonists. The effects of mu opioid agonists, including methadone, on cocaine self-administration have received relatively little attention in preclinical studies (Table 3). Both morphine and heroin reduced cocaine self-administration in rhesus monkeys, but these effects were not selective (Wilson and Schuster 1973; Winger et al. 1992). Kappa- and delta-receptor selective opioid agonists also may influence cocaine selfadministration, and there has been increasing interest in examining the effects of these opioid agonists on cocaine's reinforcing effects. Kappa- and delta-opioid agonists have opposite effects on dopamine release from the nucleus accumbens; kappa agonists decrease dopamine levels, whereas delta agonists, like mu agonists, increase extracellular dopamine release from the nucleus accumbens (DiChiara and Imperato 1988b; Spanagel et al. 1990; Longoni et al. 1991; Maisonneuve et al. 1994). The kappa agonists U50,488 and spiradoline selectively decreased cocaine self-administration without affecting water-maintained responding in rats (Glick et al. 1995). Cocaine self-administration remained significantly reduced for at least 2 days, and in some instances up to 6 days after a single kappa-agonist treatment (Glick et al. 1995). These findings indicate that kappa 
agonists can decrease cocaine's reinforcing effects, perhaps by inhibiting cocaine-related increases in extracellular dopamine (Glick et al. 1995). These drug self-administration data are consistent with evidence that kappa agonists antagonize cocaine's behavioral effects in rats (Heidbreder et al. 1993, 1995; Crawford et al. 1995) as well as cocaine's discriminative stimulus effects in squirrel monkeys (Spealman and Bergman 1992, 1994).

Delta agonists and cocaine have similar reinforcing effects in drug self-administration procedures (Jenck et al. 1987; Shippenberg et al. 1987; Devine and Wise 1994) and similar neurochemical effects on extracellular dopamine levels (Spanagel et al. 1990; Longoni et al. 1991). However, the effects of delta-receptor selective agonists on cocaine self-administration are unknown. Delta agonists may be useful as maintenance drugs for cocaine abuse, but no preclinical evaluations have been reported at this time. Currently, two systemically active delta agonists are available for study, BW373U86, which has mu and delta activity, and SNC 80, a more selective delta agonist (see Bilsky et al. 1995; Negus and Picker 1996 for review).

Opioid Mixed Agonist-Antagonists. These drugs have both opioid agonist and antagonist effects, and buprenorphine, butorphanol, and nalbuphine have been evaluated in preclinical studies of cocaine self-administration (see Table 3). Of these, only buprenorphine has selective effects on cocaine-maintained responding across a broad dose range. Buprenorphine is currently under evaluation for the clinical treatment of opioid abuse (Segal and Schuster 1995), and it combines the characteristics of mu-opioid agonists such as methadone with long-acting opioid-antagonist effects similar to those of naltrexone. This combination makes buprenorphine safer than opioid agonists alone because the risk for lethal overdose is minimized (Lewis et al. 1983, 1995). Buprenorphine antagonizes the acute subjective and physiological effects of opioids under many conditions, and its agonist properties appear to increase patient compliance (see Mello et al. 1993c; Mello and Mendelson 1995 for review).

In rhesus monkeys, daily buprenorphine treatment $(0.237-0.70 \mathrm{mg} / \mathrm{kg} /$ day $)$ significantly reduced cocaine self-administration below saline treatment baseline levels with minimal effects on food self-administration (Mello et al. 1989, 1990b). Food intake during the session immediately after buprenorphine treatment was not suppressed in comparison to saline treatment, and animals did not appear sedated. We concluded that buprenorphine treatment selectively reduced cocainemaintained responding but did not produce a generalized suppression of operant behavior (Mello et al. 1989; 1990b). These findings were subsequently confirmed and extended in other laboratories (Carroll and Lac 1992; Carroll et al. 1992; Winger et al. 1992), as well as our own (Mello et al. 1990b, 1992, 1993a, 1993b). Recent studies in rhesus monkeys indicate that buprenorphine treatment modifies cocaine self-administration on both the ascending and descending limbs of the cocaine dose-effect curve. Daily buprenorphine treatment $(0.10$ $\mathrm{mg} / \mathrm{kg} /$ day) shifted the cocaine dose-effect curve (0.001-0.30 mg $/ \mathrm{kg} / \mathrm{inj}$.) downward and approximately $1 \mathrm{log}$ unit to the right with minimal effects on foodmaintained responding (Lukas et al. 1995; see Table 3).

Because the eventual clinical application of buprenorphine for drug abuse treatment involves chronic maintenance, we subsequently asked whether tolerance developed to buprenorphine's effects on cocaine-maintained responding. We examined the effects of 30 to 120 days of buprenorphine treatment $(0.32 \mathrm{mg} / \mathrm{kg} /$ day $)$ on cocaine and food self-administration in six rhesus monkeys (Mello et al. 1992). As shown in Figure 8, during the first 15 days of buprenorphine treatment, cocaine self-administration decreased by 60 percent below the saline treatment baseline level and remained suppressed by 70 to 94 percent over the period of observation. Food-maintained responding was also significantly suppressed at the beginning of buprenorphine treatment, but it gradually returned to and significantly exceeded saline treatment baseline levels. When saline treatment was substituted for buprenorphine, cocaine self-administration resumed, and food self-administration remained above pre-buprenorphine baseline levels (Figure 8). The resumption of cocaine self-administration after buprenorphine treatment ended indicates that the significant decrease in cocaine self-administration was due to buprenorphine treatment and not to other uncontrolled variables. These data indicate that tolerance did not develop to buprenorphine's effects on cocaine self-administration by rhesus monkeys during 100 to 120 days of daily treatment (Mello et al. 1992).

One implication of the finding that buprenorphine can selectively reduce both opioid and cocaine self-administration by rhesus monkeys is that it may be useful for the treatment of polydrug abuse involving concurrent opioid and cocaine use. Recent clinical reports indicate that buprenorphine significantly reduces both cocaine and opioid abuse as well as needle use and needle sharing by polydrug abusers who meet DSM-III-R criteria for opioid and cocaine dependence (Gastfriend et al. 1993; Gastfriend et al. 1995; Schottenfeld et al. 1993; see Mello et al. 1993c; Mello and Mendelson, 1995). Moreover, in controlled clinical studies, buprenorphine reduced the positive subjective effects of speedball combinations of cocaine and morphine (Foltin and Fischman 1995). Further studies of the concordance between clinical and preclinical studies of buprenorphine's effects on polydrug abuse will be facilitated by the development of a primate model of the simultaneous self-administration of heroin and cocaine, i.e., "speedballs"; (Mello et al. 1995). Preliminary findings from ongoing studies 
suggest that buprenorphine significantly decreases lowdose cocaine and high-dose heroin combinations more effectively than it decreases speedballs containing high doses of cocaine and low or high doses of heroin (Mello et al. 1996a).

\section{Effects of Other Medications on Cocaine Self-Administration [Table 4]}

In addition to compounds with primarily dopaminergic or opioid activity, the effects on cocaine self-administration of a wide variety of other compounds with diverse mechanisms of action also have been evaluated. The effects of medications that are used for other indications on cocaine self-administration are summarized in Table 4. For the most part, these medications did not selectively reduce cocaine self-administration at doses that did not concurrently disrupt food self-administration or produce severe side effects. These data are concordant with findings from other behavioral models. The effects of a number of compounds on cocaine-induced changes in locomotor activity and schedule-induced responding as well as other behaviors have recently been reviewed (see Witkin, 1994).

As noted earlier, before the development of compounds selective for specific dopamine receptor subtypes, clinically available medications with nonspecific dopaminergic activity, used for the treatment of psychosis, were examined in cocaine self-administration models. These compounds often increased cocaine self-administration, and this was interpreted as evidence for antagonism of cocaine's reinforcing properties (Wilson and Schuster 1972; Herling and Woods 1980; Woolverton and Balster 1981; de la Garza and Johanson 1982; Roberts and Vickers 1984). More recently, the acute effects of chlorpromazine were reevaluated and compared with the effects of two anti-anxiety drugs, buspirone and gepirone. Gepirone had no effect on cocaine self-administration and decreased food self-administration (Gold and Balster 1992). Acute administration of both chlorpromazine and buspirone resulted in a dose-dependent increase in cocaine self-administration with no change in food self-administration (Gold and Balster 1992). Subsequently, the effects of chronic treatment with buspirone and gepirone were examined for 10 days. Neither buspirone nor gepirone had any consistent effects on cocaine or food self-administration during daily treatment (Gold and Balster 1992). This study illustrates the importance of comparing acute and chronic treatment regimens rather than drawing conclusions about potential therapeutic efficacy on the basis of acute medication administration.

An antidepressant, desipramine, has been used to treat cocaine abuse and related affective disorders (Gawin and Kleber 1984), but there remains considerable disagreement about the efficacy of desipramine therapy based on subsequent clinical evaluations (Weiss 1988; Fischman et al. 1990; Halikas et al. 1993; Mendelson and Mello 1996). In rhesus monkeys, continuous infusion of desipramine over 21 days or more had no effect on responding maintained by cocaine or an alter-

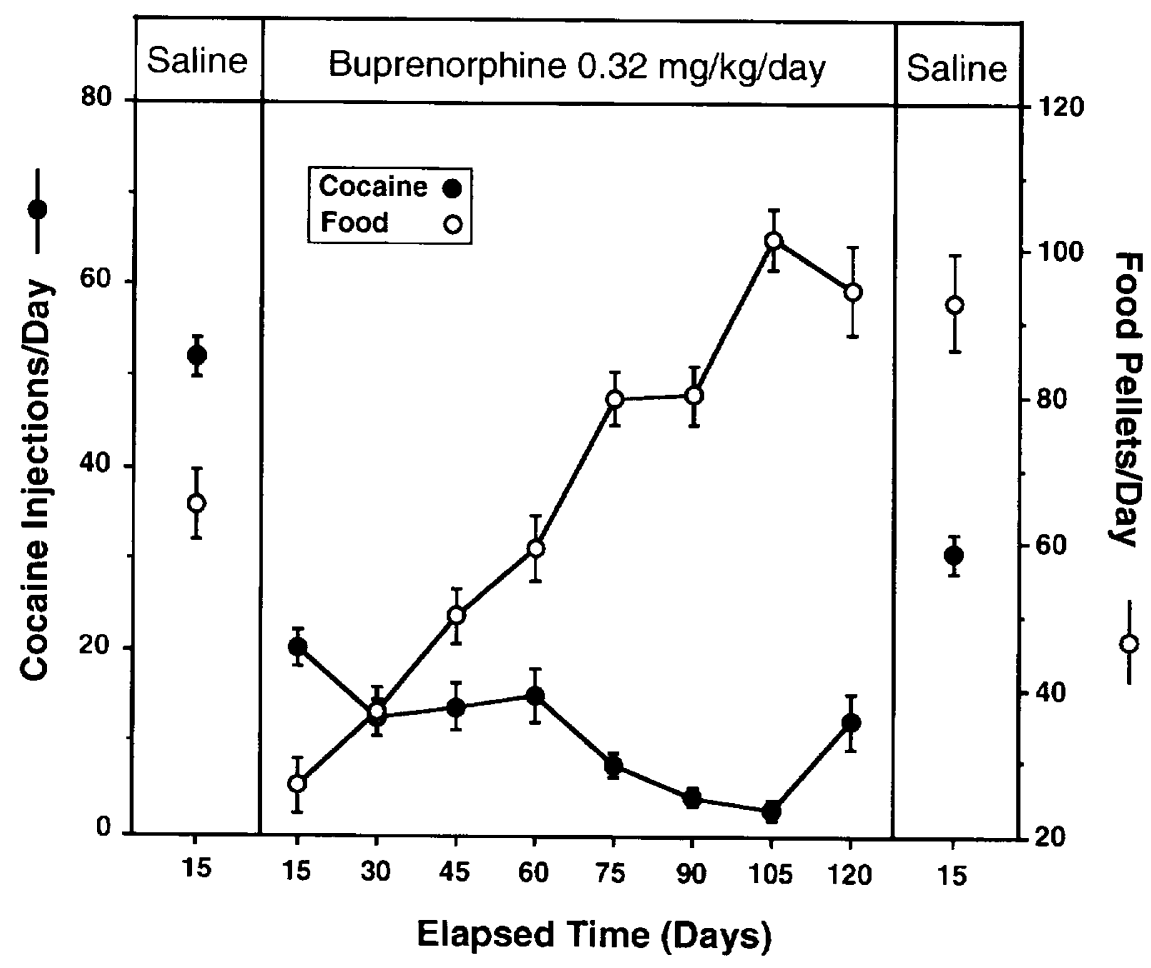

Figure 8. The effects of 30 to 120 days of daily buprenorphine treatment $(0.32 \mathrm{mg} / \mathrm{kg} /$ day $)$ on cocaine and food self-administration. Days of treatment are shown on the abscissa and cocaine injections and food pellets per day are shown on the left and right ordinates, respectively. Each data point for cocaine injections (solid circles) and food pellets (open circles) during the pre-buprenorphine saline control period is the average \pm S.E. of 4 monkeys over 15 days. The first 100 days of buprenorphine treatment are an average of data from 4 monkeys, and days 101-120 are an average of data from 3 monkeys. These data were adapted from Mello NK; Lukas SE; Kamien JB; Mendelson JH; Cone EJ (1992): The effects of chronic buprenorphine treatment on cocaine and food self-administration by rhesus monkeys. J. Pharmacol Exp Ther 260(3):1185-1193. 
native reinforcer, food, at doses up to 10 times higher than those used in clinical treatment of cocaine abuse (Kleven and Woolverton 1990b). Similar findings were obtained when daily doses of desipramine were given to rhesus monkeys for periods of 5 to 30 days (Mello et al. 1990a). Cocaine injections increased or did not change, and food injections also increased or did not change. These preclinical data are consistent with the clinical literature on desipramine treatment, where both stimulation of cocaine use and inconsistent or incomplete attenuation of cocaine abuse during desipramine maintenance have been reported (see Mello et al. 1990a for review).

The antidepressant fluoxetine also has been used clinically for the treatment of cocaine dependence in heroin abusers (Pollack and Rosenbaum 1991; Batki et al. 1993). The initially encouraging reports have not been confirmed in placebo-controlled double-blind trials (Grabowski et al. 1995). Fluoxetine selectively reduced cocaine self-administration with no change in food selfadministration in rats (Carroll et al. 1990b). Suggestive evidence that fluoxetine may decrease cocaine's reinforcing properties was shown by a progressive ratio evaluation in which fluoxetine dose-dependently decreased the number of responses rats emitted for a single dose of cocaine (Richardson and Roberts 1991).

The anticonvulsant carbamazepine has been used for the clinical treatment of cocaine abuse with primarily negative results (see Cornish et al. 1995; Kranzler et al. 1995; Montoya et al. 1995; Mendelson and Mello 1996 for review). Its clinical usefulness is limited by a number of adverse side effects ranging from dizziness, nausea, and vomiting to aplastic anemia and agranulocytosis (Mendelson and Mello 1996). The rationale for the use of an anticonvulsant to treat cocaine abuse was based on the observation that carbamazepine reduces cocaine-induced seizures in a "kindling" model in rats (Halikas et al. 1993; Post et al. 1993) and the assumption that cocaine craving and withdrawal signs and symptoms may reflect a progressive increase in neuronal sensitivity. Dietary carbamazepine over 5 days reduced cocaine self-administration as well as administration of food and a glucose saccharine solution (Carroll et al. 1990a). Seizures, convulsions, and apparent overdose deaths were observed at the highest dose of carbamazepine in combination with cocaine. It was concluded that the reduction in cocaine self-administration probably reflected the toxic and aversive effects of this compound (Carroll et al. 1990a). Similar conclusions were reached by Sharpe and coworkers in 1992. In that study, carbamazepine decreased both cocaine and food self-administration at doses that did not induce severe motor incoordination (Sharpe et al. 1992). The nonselective and toxic effects reported in these preclinical models are concordant with recent clinical evaluations (see Mendelson and Mello 1996 for review).

Clozapine, an antipsychotic medication, appears to have affinity for dopaminergic, cholinergic, serotonergic, and GABAergic receptor sites (Vanover et al. 1993). Acute administration of clozapine to rhesus monkeys increased response rates for cocaine at doses on the descending limb of the cocaine dose-response function without affecting the pattern of responding. This effect was similar to decreasing the unit dose of cocaine, but response patterns were not the same as those seen when saline was substituted for cocaine. Although an alternative reinforcer was not available, the effects of clozapine on food intake subsequent to cocaine self-administration was measured, and food intake was decreased in two of the four monkeys at doses that increased cocaine self-administration (Vanover et al. 1993). In rats, acute clozapine treatment decreased cocaine self-administration (Roberts and Vickers 1984).

Ibogaine, an hallucinogen derived from the iboga plant indigenous to Africa, is a recent addition to the list of potential pharmacotherapies for cocaine abuse. There has been considerable attention to ibogaine in the popular press, but controlled clinical trials have not been conducted, and the anecdotal results reported to date are, at best, inconclusive. In preclinical evaluations in rats, acute administration of ibogaine decreased cocaine self-administration (Cappendijk and Dzolijic 1993). However, when ibogaine's effects on cocaine-maintained responding were compared with its effects on food, there was a nonselective decrease in both food and cocaine self-administration (Dworkin et al. 1995). These investigators suggested caution in the use of ibogaine for clinical treatment of drug abuse because of its adverse motor effects and evidence of cerebellar neurotoxicity (Dworkin et al. 1995).

\section{TREATMENT MEDICATION EFFECTS ON OPIOID SELF-ADMINISTRATION}

\section{Clinical Treatment of Opioid Abuse with Opioid Antagonists}

It is reasonable to assume that a medication that antagonizes the subjective and physiological effects of opioids would reduce opioid self-administration by humans and animals. The compelling logic of this approach led to the development of naltrexone, a prototypic long-acting mu-opioid receptor antagonist (Blumberg and Dayton 1974). In controlled clinical trials, naltrexone reduced the subjective and physiologic effects of opioids in opioid-dependent men (Martin et al. 1973b). Naltrexone also reduced heroin self-administration by heroindependent men studied on a clinical research ward (Meyer and Mirin 1979; Mello et al. 1981). When naltrexone was first introduced into clinical trials, it appeared to be an ideal pharmacotherapy in terms of its safety, absence of significant side effects, and capacity to antagonize opioid effects for 24 to 48 hours (Martin et 


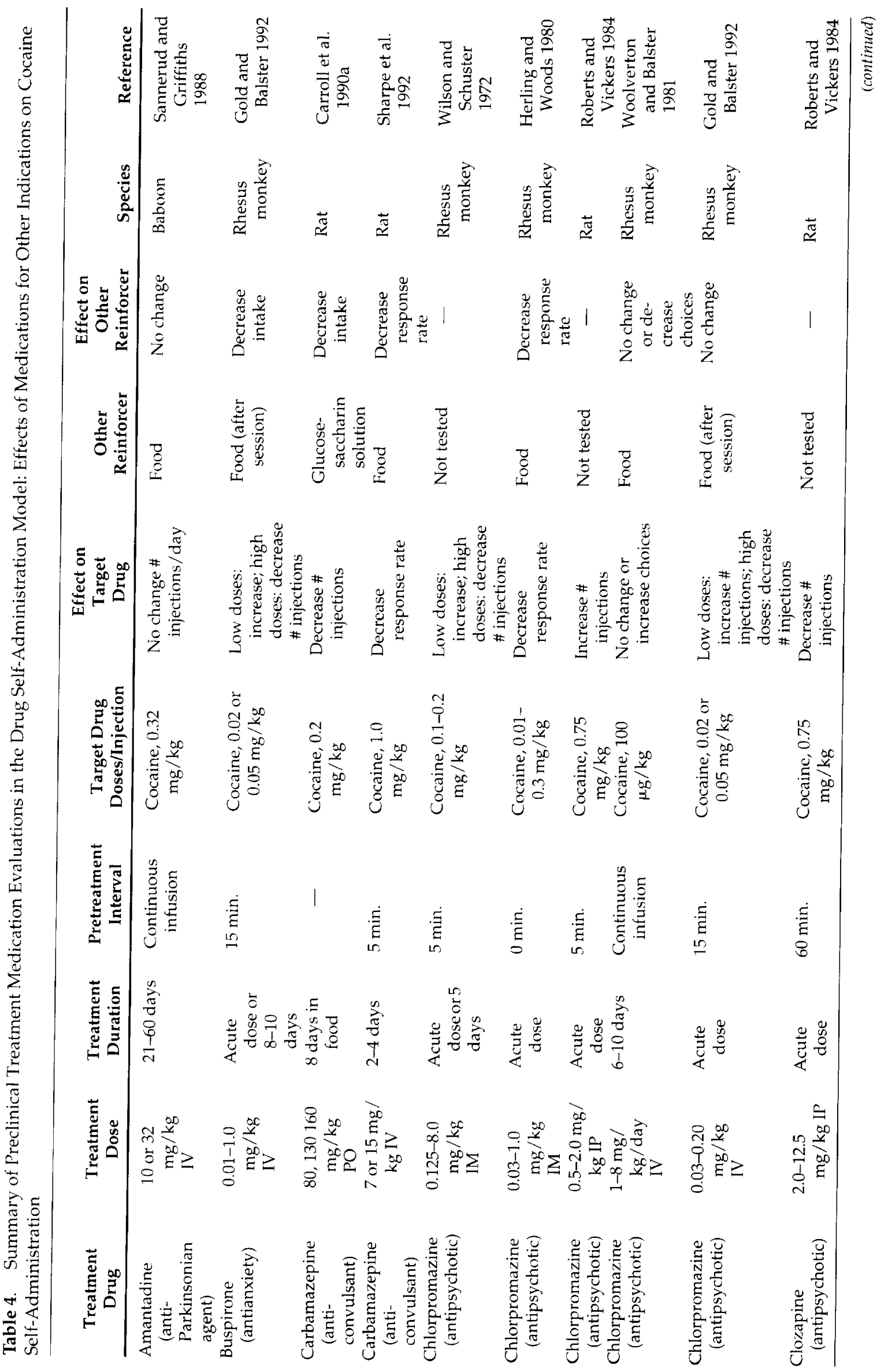




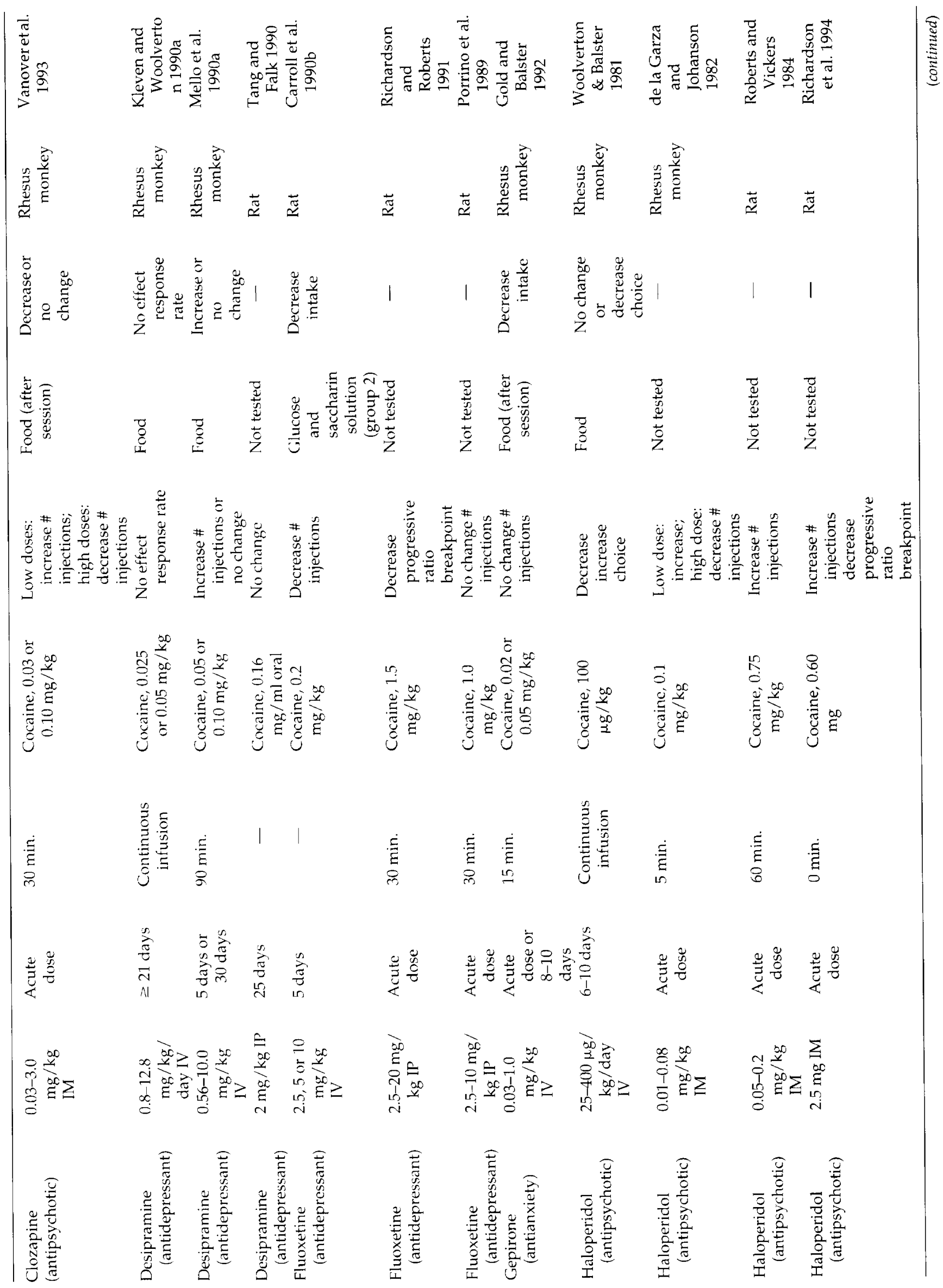




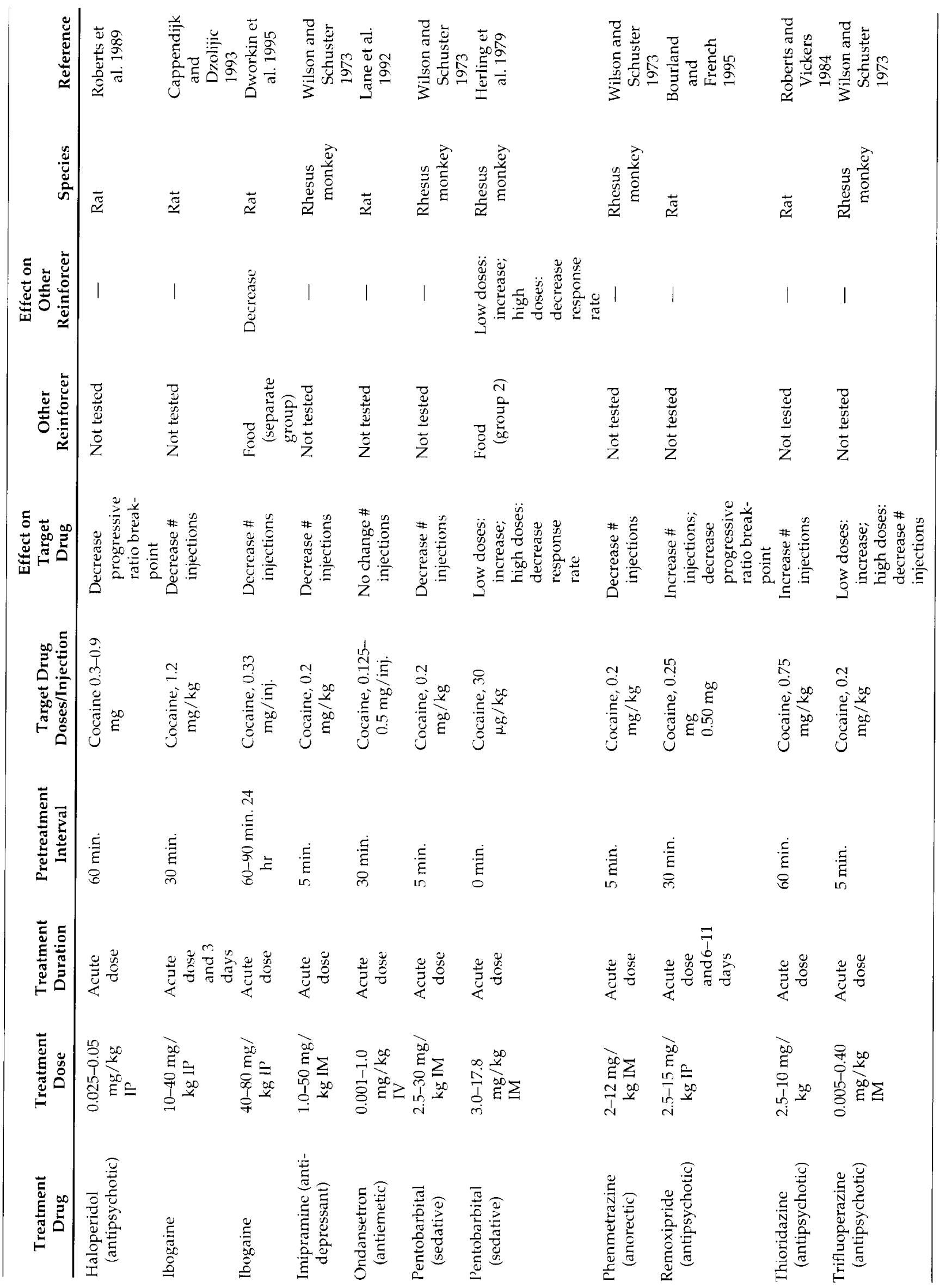


al. 1973b; Julius and Renault 1976; Verebey et al. 1976). Yet, naltrexone proved to be relatively ineffective in outpatient clinical trials, because it was difficult to retain opioid-dependent patients in naltrexone treatment programs (see National Research Council 1978; Meyer and Mirin 1979; Schecter 1980 for review). Today, naltrexone is an effective treatment for highly motivated opioid-dependent patients, usually medical professionals, who must remain opioid-free to retain clinical licensure (Jaffe and Martin 1990). The failure of naltrexone as a wide-scale treatment for opioid addiction is instructive for the development of future pharmacotherapies for drug abuse treatment. Although naltrexone antagonized opioid effects, it had no positive mood-modulating effects, and it could be abruptly discontinued without adverse consequences. It appeared that the pharmacological blockade of opioid effects, without other agonist properties, was not an effective treatment for most opioid-dependent patients, even in the context of a multimodality treatment program.

\section{Opioid Self-Administration Dose-Effect Curves}

Experimental animals will self-administer a wide range of opioid agonists, including morphine, heroin and codeine, and synthetic opioid analgesics such as alfentanil, methadone and hydromorphone (Weeks and Collins 1964; Woods and Schuster 1968; Woods and Schuster 1970; Deneau et al. 1969; Downs and Woods 1974; Jones and Prada 1977; Sanchez-Ramos and Schuster 1977; Harrigan and Downs 1978; Herling 1981; Young et al. 1981; Mello et al. 1983; Negus et al. 1993b). There are at least three major types of opioid receptors, the mu-, delta-, and kappa-opioid receptors (Martin et al. 1976; Lord et al. 1977; Mansour et al. 1987), and, for the most part, the opioid agonists that have been used to maintain opioid self-administration are selective for mu receptors. In general, the dose-effect curve relating dose per injection of these opioids to some metric of drug self-administration (i.e., response rate, injections per session) displays an inverted-U shape, with intermediate doses maintaining more self-administration behavior than either lower or higher doses (see Figure 2). As discussed earlier, the slopes of the ascending and descending limbs of the dose-effect curve, as well as the position of the dose-effect curve on the abscissa, can vary dramatically as a function of several experimental parameters, including the type of opioid serving as the reinforcer and the schedule of drug delivery. As a result, it is important to consider the underlying opioid doseeffect curve when interpreting the results produced by pretreatments with various potential treatment medications. The following discussion of test drug effects on opioid dose-effect curves considers three types of potential treatment medications: opioid antagonists, opioid agonists and nonopioids.

\section{Effects of Opioid Antagonists on Opioid Self-Administration [Table 5]}

Opioid antagonists include such compounds as naloxone, naltrexone, nalorphine, and quadazocine, and the effects of opioid antagonists on opioid self-administration have been extensively evaluated in preclinical models of opioid abuse. Most of these studies have examined only a single unit dose of the opioid agonist (Weeks and Collins 1964, 1976; Goldberg et al. 1971; Woods et al. 1975; Griffiths et al. 1976; Killian et al. 1978a, 1978b; Ettenberg et al. 1982; Koob et al. 1984; Negus et al. 1993a). However, the effect of an opioid antagonist such as naltrexone on opioid self-administration critically depends on the unit dose of opioid used to maintain responding. For example, Weeks and Collins trained morphine-dependent female rats to respond for $10-\mathrm{mg} / \mathrm{kg} /$ injection morphine under a FR 10 schedule that was in effect 24 hours/day (Weeks and Collins 1964, 1976). Initial experiments revealed that decreasing the unit dose of morphine resulted in an increase in the number of injections per day, indicating that the 10$\mathrm{mg} / \mathrm{kg} /$ injection unit dose was on the descending limb of the morphine dose-effect curve. Continuous infusion for 24 hours with the opioid antagonists nalorphine (0.006-1.0 mg/kg/hour; Weeks and Collins 1964) and naloxone $(0.056-0.56 \mathrm{mg} / \mathrm{kg} /$ day; Weeks and Collins 1976) produced a dose-dependent increase in the number of morphine injections per day, an effect that mimicked a decrease in the unit dose of morphine.

Harrigan and Downs (1978), in contrast, trained rhesus monkeys to self-administer morphine $(8.0 \mu \mathrm{g} / \mathrm{kg} /$ injection), $d$-amphetamine $(4.0 \mu \mathrm{g} / \mathrm{kg} /$ injection $)$, and saline on alternate days ( 3 days morphine, 2 days $d$-amphetamine, 2 days saline). The drug solutions were available under a FR 1 schedule of drug delivery during 15minute sessions every 4 hours ( 8 sessions per day). Under these conditions, continuous infusion with the antagonist naltrexone $(0.25-10.0 \mu \mathrm{g} / \mathrm{kg} /$ hour $)$ for 4 weeks produced a selective and dose-dependent decrease in morphine self-administration, an effect opposite to that obtained by Weeks and Collins $(1964,1976)$. However, in monkeys, the $8.0 \mu \mathrm{g} / \mathrm{kg} /$ inj. unit dose of morphine was located at the peak of the ascending limb of the morphine dose-effect curve, such that decreases in the unit dose of morphine led to a decrease in morphine self-administration (Harrigan and Downs 1978). Thus, in both studies the effects of opioid antagonist treatment on morphine self-administration mimicked the effects of decreasing the unit dose of morphine. In addition, Harrigan and Downs (1978) reported that naltrexone treatment did not alter d-amphetamine self-administration, suggesting that effects of naltrexone were selective for opioid self-administration. Other studies also have reported a selective effect of opioid antagonists on opioid self-administration (Ettenberg et al. 1982; Winger et al. 1992). 


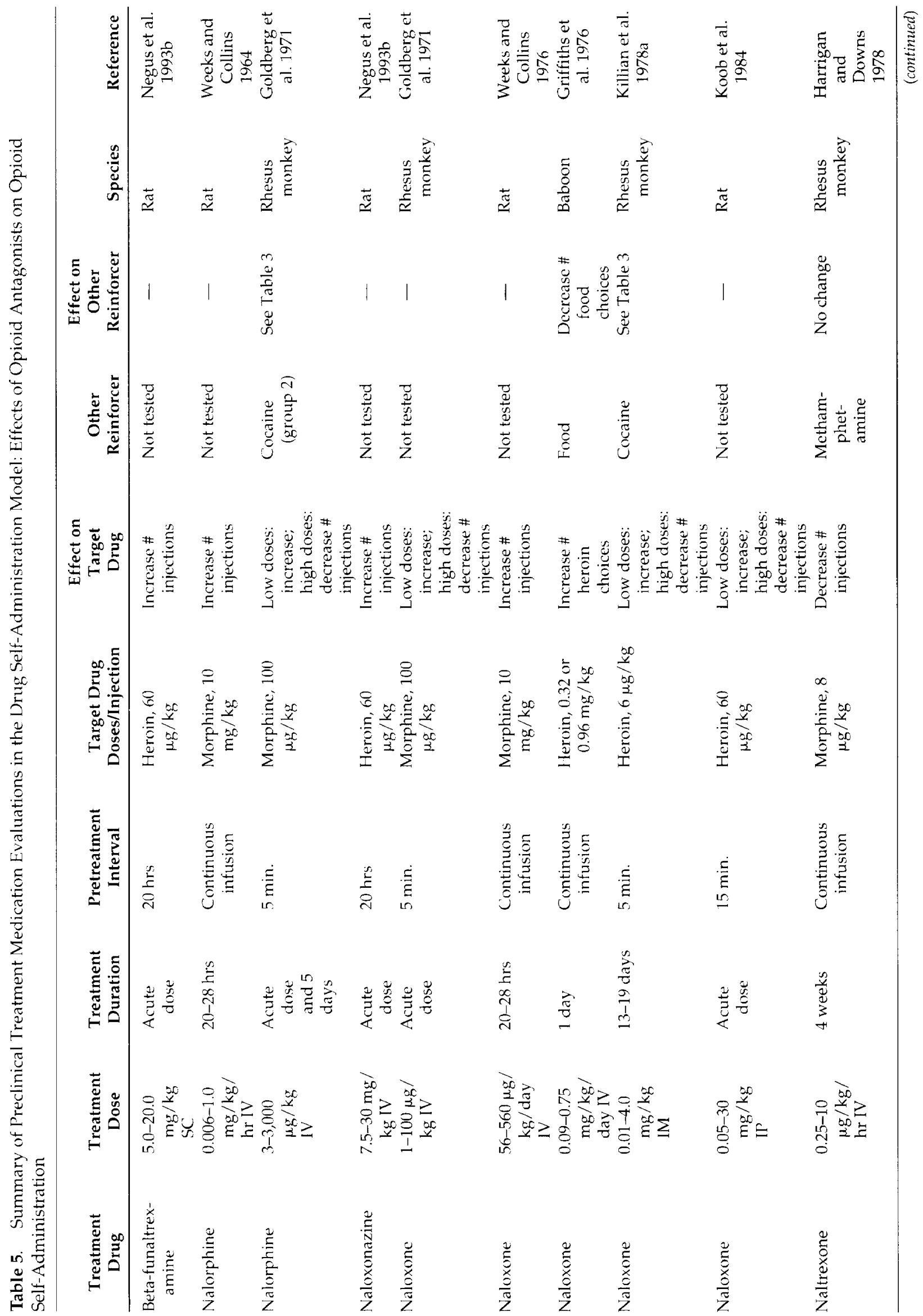




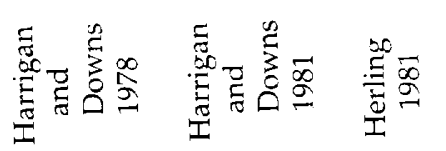

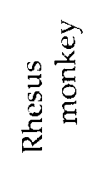

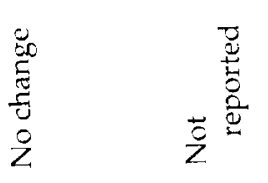

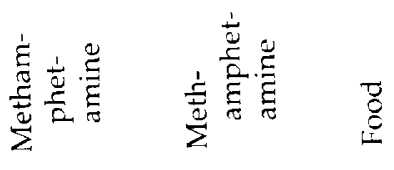

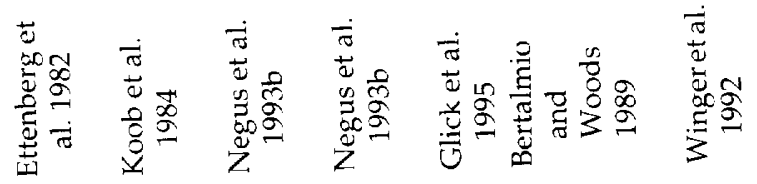

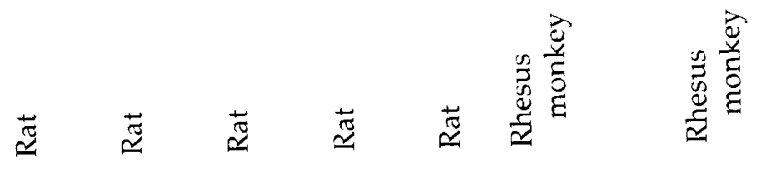

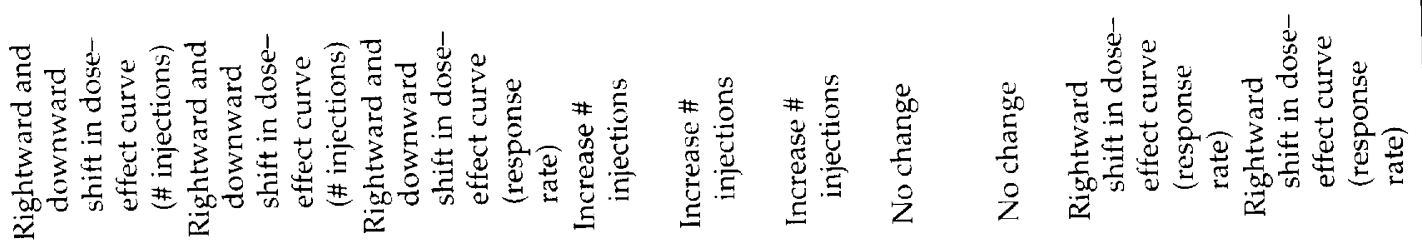

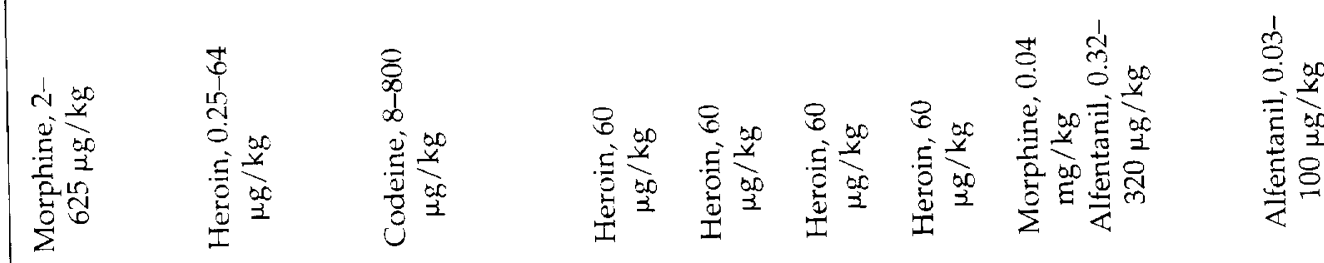

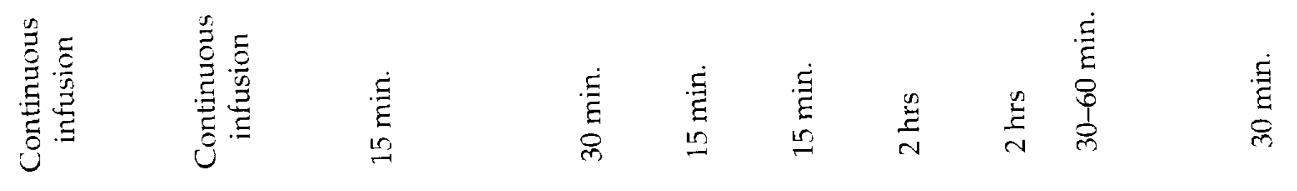

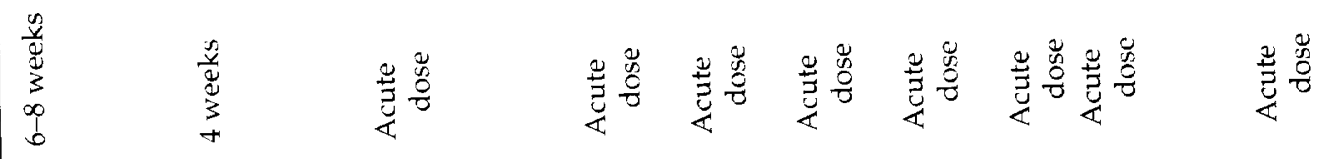

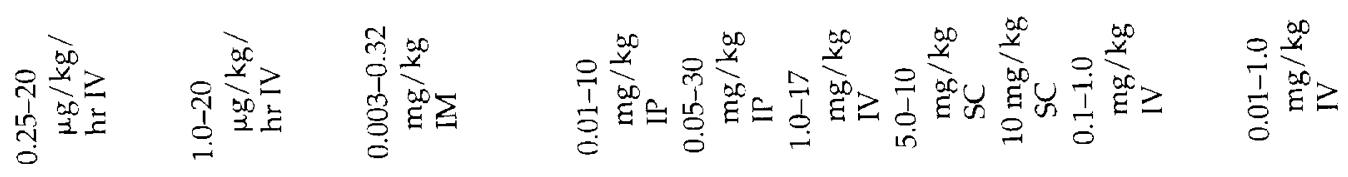


When evaluated against complete opioid agonist dose-effect curves, opioid antagonists have been reported to produce both rightward and downward shifts. Harrigan and Downs (1978) also evaluated the effects of continuous naltrexone infusion on the self-administration of a range of morphine doses (2.0-625 $\mu \mathrm{g} / \mathrm{kg} /$ injection). Chronic infusion of a relatively low dose of naltrexone ( $1 \mu \mathrm{g} / \mathrm{kg} /$ hour) produced an approximately two-fold rightward shift in the morphine dose-effect curve and a small (i.e., less than $10 \%$ ) decrease in the maximum effect. Chronic infusion of a higher dose of naltrexone (10 $\mu \mathrm{g} / \mathrm{kg} /$ hour) shifted the entire morphine curve downward so that no dose of morphine maintained rates of self-administration different from those maintained by saline. As shown in Figure 9, similar results have been obtained with chronic and continuous naltrexone infusion on the dose-effect curve for heroin self-administration in rhesus monkeys (Harrigan and Downs 1981), with low doses of naltrexone shifting the dose-effect curve to the right and higher doses of naltrexone shifting the heroin dose-effect curve rightward and downward. Finally, Herling and Woods (1980) reported that acute IM naltrexone injections produced rightward and downward shifts in the dose-effect curve for codeine self-administration in rhesus monkeys. In contrast to these effects of naltrexone, acute pretreatment with the opioid antagonist quadazocine produced only parallelrightward shifts in the dose-effect curve for the self-ad- ministration of alfentanil by rhesus monkeys (Bertalmio and Woods 1987; 1989; Winger et al. 1992). It is not clear whether these different results (i.e., rightward vs. downward shifts) reflect differences in the nature of the antagonists or differences in the procedures used to evaluate antagonist effects.

Naltrexone, quadazocine, and most antagonists that have been evaluated for their effects on opioid self-administration are selective for mu-opioid receptors. The effects of mu-, delta-, and kappa-selective antagonists on heroin self-administration were compared in rats trained to self-administer $0.06 \mathrm{mg} / \mathrm{kg} /$ injection of heroin under a FR 5 schedule during daily, 3-hour sessions (Negus et al. 1993a). Initial experiments indicated that this unit dose of heroin $(0.06 \mathrm{mg} / \mathrm{kg} / \mathrm{inj}$.) lay on the descending limb of the heroin dose-effect curve. The muselective antagonist $\beta$-funaltrexamine produced the expected, dose-dependent increases in heroin self-administration, and high doses of $\beta$-funaltrexamine produced extinction patterns of responding. These effects resembled the effects of decreasing the unit dose of heroin and suggested that $\beta$-funaltrexamine antagonized the reinforcing effects of heroin. The delta-selective antagonist naltrindole also produced a dose-dependent increase in the self-administration of $0.06 \mathrm{mg} / \mathrm{kg} / \mathrm{inj}$. of heroin; however, relatively high doses of naltrindole were required to produce these effects, suggesting that naltrindole may have increased heroin self-administra-
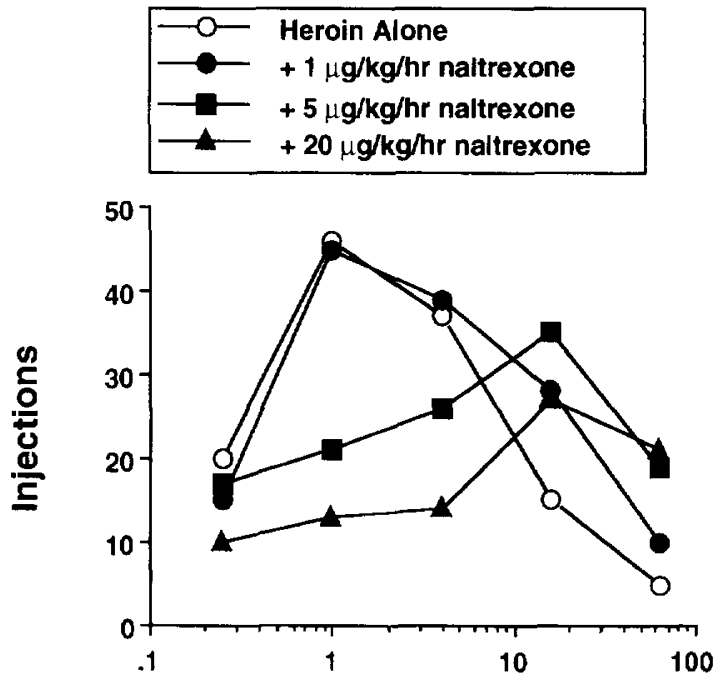
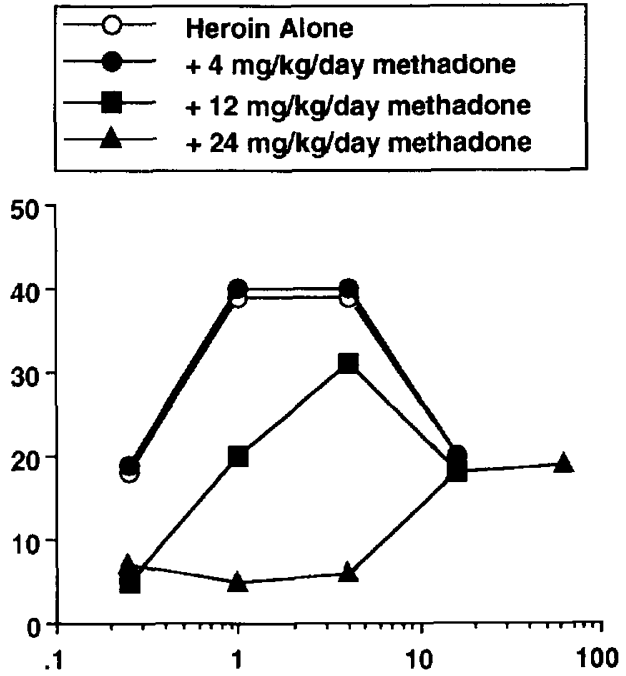

Unit Dose Heroin (mg/kg/inj)

Figure 9. Self-administration of heroin by rhesus monkeys during chronic infusion with either the opioid antagonist naltrexone (left panel) or the opioid agonist methadone (right panel). Abscissae: Unit dose in mg/kg/inj (log scale). Ordinates: Injections during each access period. Monkeys responded for drugs under a FR 1 (continuous reinforcement) schedule with 15-minute access periods occurring every 4 hours. Each point in the left panel shows mean data from four monkeys. Each point in the right panel shows data from one monkey. Adapted from Harrigan and Downs (1981): Pharmacological evaluation of narcotic antagonist delivery systems in rhesus monkeys. NIDA Research Monograph 28. Washington, DC: Government Printing Office, pp. 77-92. 
tion by acting at mu receptors. The kappa-selective antagonist nor-binaltorphimine had no effect on heroin self-administration (Negus et al. 1993b). These data suggest that the reinforcing properties of heroin are primarily mediated by mu-opioid receptors.

In summary, low doses of mu-selective opioid antagonists typically produce rightward shifts in opioid agonist dose-effect curves. Higher antagonist doses may produce further rightward shifts or may shift opioid dose-effect curves downward. When the effects of antagonists are evaluated against single unit doses of an opioid agonist, either increases or decreases in opioid self-administration may be observed depending on the position of the agonist dose along the dose-effect curve. These findings emphasize the importance of characterizing the agonist dose-effect curve as a basis for interpreting the effects of test drugs. There is no evidence to suggest that the effects of opioid antagonists on opioid self-administration change appreciably during chronic treatment, although this issue has not been examined systematically. The effects of opioid antagonists on opioid self-administration are usually selective in that opioid antagonists are more effective in altering opioid self-administration than in altering self-administration of nonopioid reinforcers. Thus, opioid antagonists appear to alter opioid self-administration while producing few other adverse effects. However, opioid antagonists may precipitate opioid withdrawal signs and symptoms in people physically dependent on opioids.

\section{Clinical Treatment of Opioid Abuse with Opioid Agonists}

Among the alternatives to opioid antagonists for treatment of opioid dependence are opioid agonists and opioid mixed agonist-antagonists. Opioid agonists such as methadone and $1-\alpha$-acetyl methadol (LAAM) produce opioid-like subjective effects and attenuate responses to heroin and other opioids (Dole and Nyswander 1965; Jaffe and Senay 1971; Jaffe et al. 1972; Martin et al. 1973a; Judson and Goldstein 1979; Jones and Prada 1975; see Jaffe and Martin 1990 for review). Methadone is the major pharmacotherapy available for drug abuse treatment, and its clinical utility is well established (Dole 1988). More recently, partial mu agonists or opioid mixed agonist-antagonists such as buprenorphine have been evaluated for treatment of opioid dependence (see Rosen and Kosten 1991; Mello et al. 1993c; Segal and Schuster 1995 for review). Buprenorphine antagonizes opioid effects but also has agonist properties that make it more acceptable to patients than an opioid antagonist such as naltrexone. Buprenorphine's opioid antagonist properties confer a greater margin of safety than opioid agonists, [i.e., overdose did not occur at 10 times the analgesic dose (Banks 1979; Lewis et al. 1983)]. Buprenorphine has potent analgesic properties with minimal capacity to induce physiological dependence in man (Jasinski et al. 1978; Houde 1979; Lewis, 1995). Assessments of buprenorphine for treatment of opioid abuse were first conducted in inpatient clinical studies and subsequently in preclinical drug self-administration models. In 1978, Jasinski and coworkers reported that buprenorphine antagonized the physiological and subjective effects of morphine $(60-120 \mathrm{mg} /$ day) for up to 29.5 hours in abstinent opioid-dependent men (Jasinski et al. 1978). Subsequent inpatient studies indicated that buprenorphine $(8 \mathrm{mg} /$ day SC) significantly reduced heroin self-administration by heroin-dependent men who had abused heroin for almost 10 years (Mello and Mendelson 1980; Mello et al. 1982).

In 1992 the first controlled outpatient comparison of buprenorphine and methadone maintenance treatment for opioid dependence was reported (Johnson et al. 1992). In a randomized, double-blind, parallel group study, it was found that buprenorphine $(8 \mathrm{mg} /$ day SL) was as effective as $60 \mathrm{mg} /$ day of methadone and superior to $20 \mathrm{mg} /$ day of methadone on two outcome measures: patient retention and opioid-free urines (Johnson et al. 1992). During the first 2 weeks of treatment, opioid-positive urines decreased more rapidly in buprenorphine-treated patients than in methadone-treated patients, but remained $47 \%$ and $56 \%$ opioid positive over the 17 weeks of treatment. A subsequent comparison of lower doses of buprenorphine ( 2 and $6 \mathrm{mg}$ ) with methadone ( 35 and $65 \mathrm{mg}$ ) found that methadone was superior in reducing opioid use and in treatment retention (Kosten et al. 1993). Currently, buprenorphine is the only opioid mixed agonist-antagonist that is being evaluated for the treatment of opioid self-administration in largescale clinical trials. A significant reduction in opioid self-administration has been reported in clinical studies as well as preclinical evaluations. Recent preclinical and clinical reports have indicated that buprenorphine also reduces cocaine self-administration by rhesus monkeys and concurrent cocaine abuse by opioid-dependent patients (Kosten et al. 1989a, 1989b; Mello et al. 1989, 1990b; Gastfriend et al. 1993; Schottenfeld et al. 1993). These findings were discussed earlier in the section on opioid effects on cocaine self-administration (see Mello et al. 1993c; Mello and Mendelson 1995 for review).

\section{Effects of Opioid Agonists on Opioid Self-Administration [Table 6]}

Many studies since the mid-1970s have evaluated the effects of opioid agonist treatments on opioid self-administration (Weeks and Collins 1964; Griffiths et al. 1976; Jones and Prada 1977; Stretch 1977; Wurster et al. 1977; Harrigan and Downs 1981; Lukas et al. 1981; Mello et al. 1983; Koob et al. 1986; Negus et al. 1992; Winger et al. 1992; see Table 6). In an early study, Weeks and Collins (1964) examined the effects of etonitazene, 


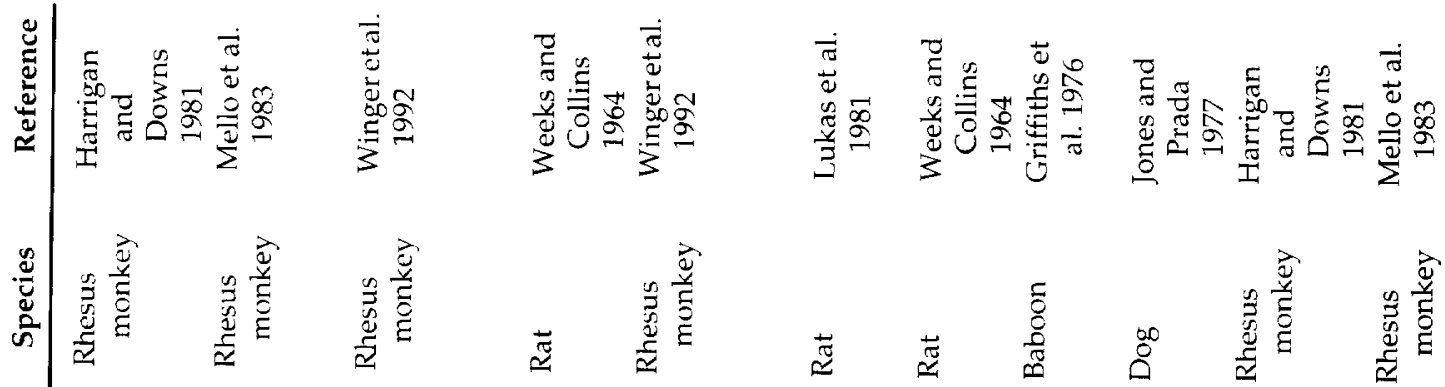

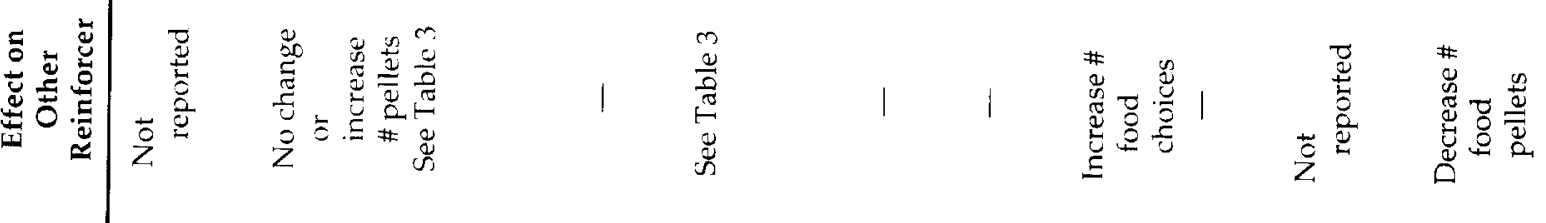

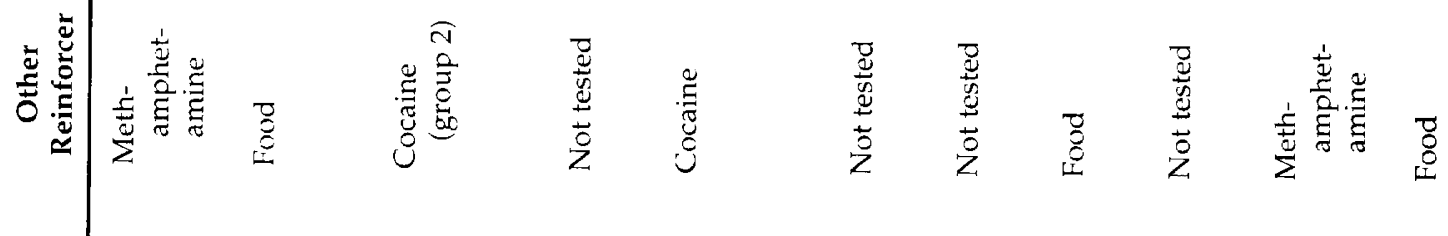

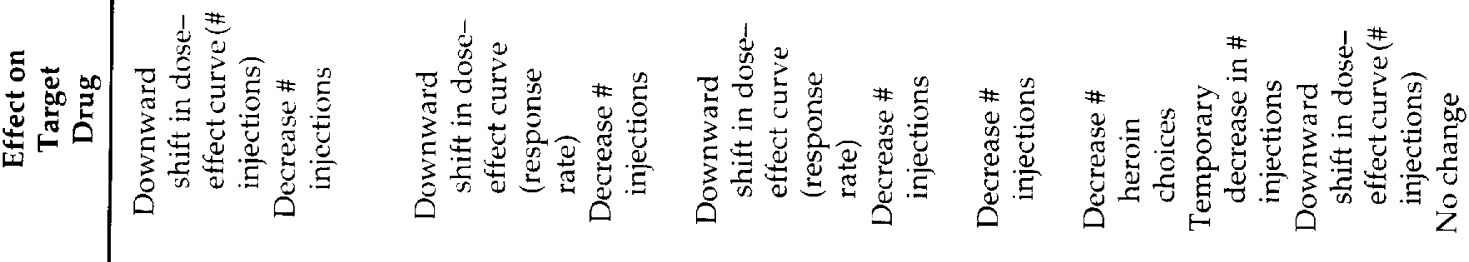

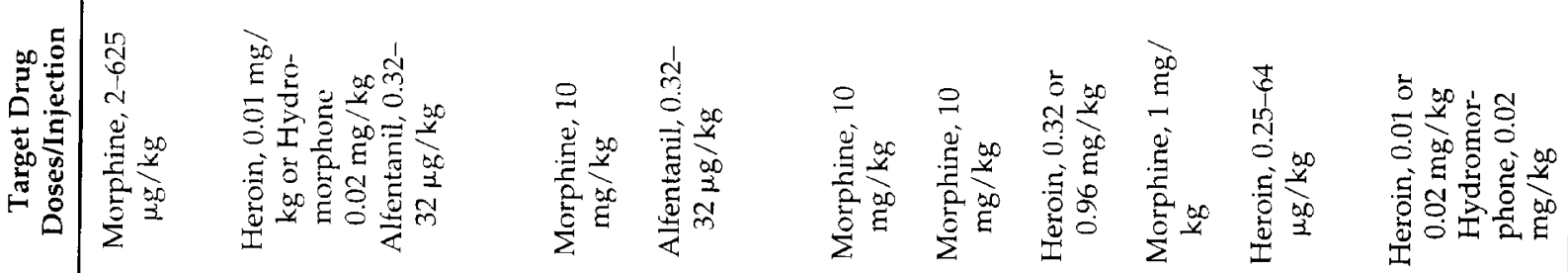

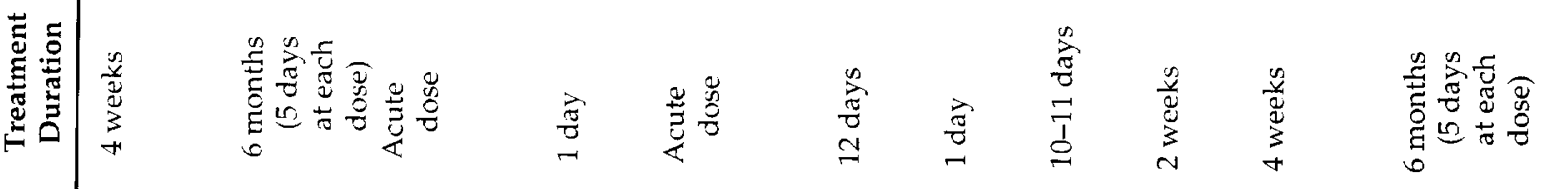

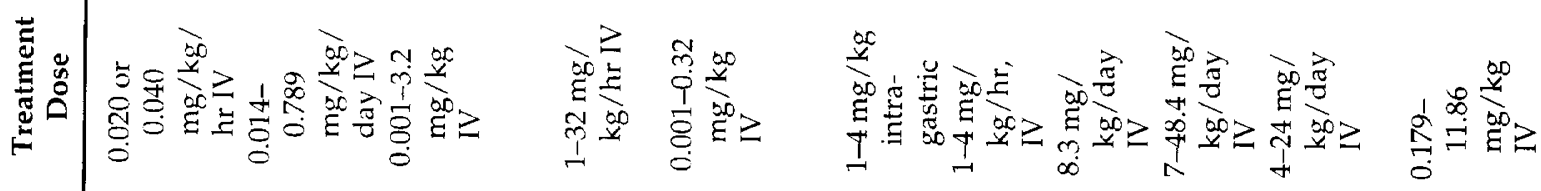

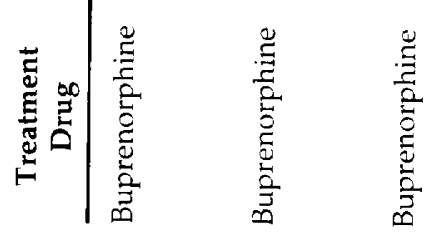

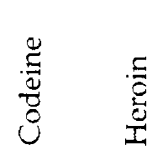

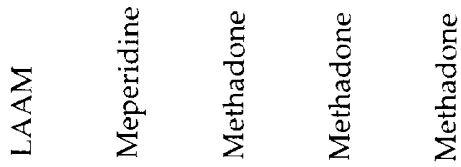




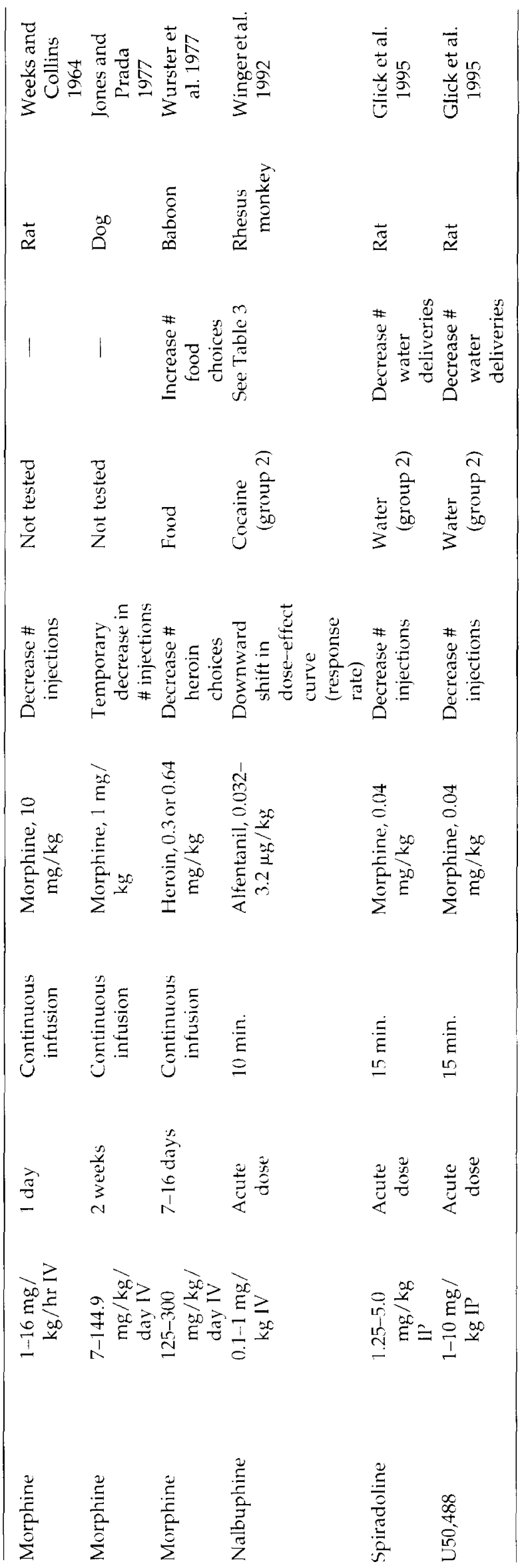

morphine, codeine, and meperidine on morphine selfadministration by rats. Morphine-dependent female rats were trained to respond to $10 \mathrm{mg} / \mathrm{kg} / \mathrm{inj}$. of morphine, a unit dose on the descending limb of the morphine dose-effect curve. Adding etonitazene $(10 \mu \mathrm{g} /$ $\mathrm{ml}$ ) to the rats' drinking water for 24 hours decreased the number of injections per day to approximately $30 \%$ of control levels. Similarly, continuous infusion of morphine, meperidine, or codeine $(1-32 \mathrm{mg} / \mathrm{kg} /$ hour $)$ for 24 hours produced a dose-dependent decrease in morphine self-administration (Weeks and Collins 1964). Although these data suggest that treatment with an opioid agonist may alter the reinforcing effects of morphine, the selectivity of these effects was not evaluated. It is also possible that the opioid agonists may have produced a nonselective disruption of behavior that impaired the subjects' ability to emit an operant response. More recent studies have addressed this issue by employing procedures that examine test drug effects on self-administration of both opioid and nonopioid reinforcers. For example, Griffiths, Brady, and colleagues (Griffiths et al. 1976, 1981; Wurster et al. 1977) developed a choice procedure in which baboons selected either food or a single heroin injection every 3 hours (total of eight daily trials). Chronic treatment with continuous infusion of 8.4 to $20 \mathrm{mg} / \mathrm{kg} / 24$ hours of morphine or $8.3 \mathrm{mg} / \mathrm{kg} / 24$ hours of methadone for up to 14 days produced a sustained decrease in the number of daily heroin choices and an increase in the number of food choices. The finding that heroin self-administration decreased while food self-administration increased indicates that the decrease in heroin self-administration did not occur because the baboons were unable to respond. Rather, these results suggest that continuous infusion with either morphine or methadone selectively decreased the reinforcing effects of heroin. Furthermore, these findings suggest that tolerance did not develop to the opioid-induced decreases in heroin self-administration during chronic opioid maintenance. This last conclusion contrasts with a study by Jones and Prada (1977) reporting that tolerance did develop within 2 weeks to opioid-induced decreases in morphine self-administration in dogs.

In a related study, the effectiveness of buprenorphine and methadone in reducing the self-administration of heroin (0.01-0.02) and dilaudid (hydromorphone; 0.02 $\mathrm{mg} / \mathrm{kg} /$ inj.) by rhesus monkeys was compared (Mello et al. 1983). Drugs and food were available in alternating daily sessions, and each drug or food delivery required an average of 64 responses under a second-order FR 4 (VR16:S) schedule. Chronic daily administration of the partial mu agonist buprenorphine $(0.014-0.79 \mathrm{mg} /$ $\mathrm{kg} /$ day) for 6 to 8 months selectively decreased self-administration of heroin and dilaudid while having little effect on food self-administration. Again, these results suggest that the decrease in opioid self-administration 
did not reflect a nonselective suppression of all behaviors, but rather a selective decrease in the reinforcing effects of the opioid agonist. Interestingly, chronic treatment with methadone $(0.179-11.86 \mathrm{mg} / \mathrm{kg} /$ day $)$ did not consistently decrease opioid self-administration in this study, although food self-administration was suppressed. The relative ineffectiveness of methadone in this study may have resulted in part from the treatment regimen in which methadone doses were gradually increased over a period of 4 months. However, other studies also have reported behavioral toxicity resulting from administration of methadone doses that were sufficient to decrease opioid self-administration (Jones and Prada 1971; Harrigan and Downs 1981; see the following sections in this review).

In all the studies discussed, the effects of opioid agonists were evaluated on a single unit dose per injection of the self-administered opioid. Other studies have examined the effects of opioid agonists on the self-administration of a range of opioid unit doses. For example, Harrigan and Downs (1981) trained rhesus monkeys to self-administer either heroin $(0.25-64 \mu \mathrm{g} / \mathrm{kg} / \mathrm{inj}$.) or morphine $(2-625 \mu \mathrm{g} / \mathrm{kg} /$ inj.) under a FR 1 schedule during 15-minute sessions occurring every 4 hours (total of eight sessions per day). Days during which an opioid was available for self-administration alternated with days during which either $d$-amphetamine or saline was available. Figure 9 shows that continuous infusion of methadone (4-24 mg/ $\mathrm{kg} /$ day for at least 3 weeks) decreased the self-administration of low to intermediate unit doses of heroin located on the ascending limb or peak of the heroin dose-effect curve; however, selfadministration of high unit doses located on the descending limb of the opioid dose-effect curve was not decreased. Similar effects were obtained in experiments examining the effects of chronic buprenorphine (0.48$0.96 \mathrm{mg} / \mathrm{kg} /$ day) on morphine self-administration. Overall, chronic treatment with methadone or buprenorphine produced a downward shift in the opioid dose-effect curves. Unfortunately, the effects of methadone and buprenorphine on $d$-amphetamine self-administration were not reported, so it is not clear whether these opioid agonists selectively decreased opioid self-administration. However, the investigators did note that doses of methadone that suppressed heroin self-administration produced "severe debilitation and depression," suggesting that the effects of methadone on heroin self-administration may have been nonselective (Harrigan and Downs 1981).

In another study examining opioid agonist effects on entire opioid dose-effect curves, Winger and coworkers (1992) trained two groups of rhesus monkeys to respond for either cocaine (1-100 $\mu \mathrm{g} / \mathrm{kg} / \mathrm{inj}$.) or alfentanil $(0.03-3 \mu \mathrm{g} / \mathrm{kg} / \mathrm{inj}$.) under a FR 30 schedule. Each of the two daily sessions was composed of four cycles, and during each cycle either saline or one of several unit doses of drug was available for self-administration. Thus, a complete dose-effect curve could be examined during each daily session. Acute pretreatment with the opioid agonists buprenorphine, heroin, and nalbuphine all produced a dose-dependent downward shift in both the alfentanil and cocaine dose-effect curves. Buprenorphine displayed a potency difference in producing these effects, with doses as low as $0.003 \mathrm{mg} / \mathrm{kg}$ effectively suppressing the alfentanil dose-effect curve, whereas a dose of $3.2 \mathrm{mg} / \mathrm{kg}$ buprenorphine was required to suppress the cocaine dose-effect curve. Thus, low doses of buprenorphine selectively decreased alfentanil self-administration. Both nalbuphine and heroin, in contrast, were equipotent and nonselective in decreasing alfentanil and cocaine self-administration. As in the study by Harrigan and Downs (1981), lower unit doses of alfentanil were sometimes more sensitive than higher unit doses of alfentanil to the effects of opioid agonist pretreatments.

For the most part, the opioid agonists that have been evaluated for their effects on opioid self-administration are selective for mu receptors, although compounds such as buprenorphine and nalbuphine also bind with high affinity to kappa- and delta-opioid receptors (e.g. Wood et al. 1981). The effect of more selective kappaand delta-opioid receptor agonists on opioid self-administration has received little attention, although relatively low doses of the kappa agonist U50,488 (Koob et al. 1986) and the delta agonist DPDPE (Negus et al. 1992) did not alter heroin self-administration in rats. High doses of kappa and delta selective agonists do suppress rates of responding maintained by other reinforcers such as food (e.g. Negus et al. 1993b), so it is reasonable to predict that they would also decrease responding maintained by opioid agonists. Recently, two kappa agonists, spiradoline and U50,488, have been reported to produce dose-related ( 2.5 to $10 \mathrm{mg} / \mathrm{kg}$ ) and selective decreases in morphine self-administration by rats (Glick et al. 1995). The effects of U50,488 on morphine-maintained responding were fully antagonized by the kappa antagonist norbinaltorphimine $(10 \mathrm{mg} /$ $\mathrm{kg}$ ) (Glick et al. 1995). A more thorough evaluation of these compounds is warranted.

In summary, opioid agonists, and particularly mu-selective opioid agonists, have generally been reported to decrease opioid self-administration and to shift opioid dose-effect curves downward. In some cases, the magnitude of these decreases in drug self-administration appears to depend on the unit dose of opioid-maintaining behavior. Specifically, opioid agonist pretreatments often are more effective in decreasing self-administration of lower unit doses located on the ascending limb or peak of the opioid dose effect-curve than in decreasing self-administration of higher unit doses located on the descending limb of the dose-effect curve. Again, these findings illustrate the importance of characterizing the 
agonist dose-effect curve as a basis for interpreting the effects of test drugs. During chronic treatment, tolerance may develop to opioid-induced decreases in opioid self-administration. In some studies, the effects of opioid agonists on opioid self-administration have been shown to be selective; in other cases, opioid agonist-induced decreases in opioid self-administration are accompanied by decreases in the self-administration of nonopioid reinforcers or by overt behavioral toxicity. Interestingly, methadone, the drug most often used clinically for the treatment of opioid dependence, has proven to be a particularly toxic drug at doses that suppress opioid self-administration in animal models. The partial mu-agonist buprenorphine, in contrast, has consistently been reported to produce a selective suppression of opioid self-administration at doses that produce few other behavioral effects.

\section{Effects of Nonopioids on Opioid Self-Administration}

Opioid agonists and antagonists presumably alter opioid self-administration by competing with the self-administered opioid for opioid receptors. Compounds that do not act directly on opioid receptors, but that may nonetheless modulate opioid activity, also have been evaluated for their effects on opioid self-administration. For example, active immunization of rhesus monkeys with a morphine/protein conjugate (morphine-6-hemisuccinate-bovine serum albumin) induces the production of antibodies that bind both morphine and heroin and selectively shift the dose-effect curve for heroin, but not for cocaine, to the right (Bonese et al. 1974). Moreover, the antibodies from immunized monkeys can be isolated and infused into non-immunized monkeys to produce similarly selective effects on heroin self-administration (Killian et al. 1978b). Presumably, these morphine antibodies function by binding morphine or heroin in plasma and preventing the drug from reaching receptors involved in self-administration. In contrast to receptor antagonists, however, antibodies display high selectivity for the antigen, and morphine antibodies would not be expected to alter self-administration of structurally distinct opioids such as methadone or alfentanil.

Other compounds that do not affect binding of the self-administered opioid to the receptor may alter the intracellular or intercellular consequences of opioid-receptor activation that culminate in reinforcement of opioid self-administration behavior. At the intracellular level, for example, activation of mu-opioid receptors has been demonstrated to inhibit the enzyme adenylate cyclase and decrease intracellular levels of the second messenger cAMP. This inhibition of adenylate cyclase is mediated by guanine nucleotide binding pro- teins ( $G$ proteins) that functionally couple the opioid receptor to the enzyme. These $G$ proteins can be inactivated by pertussis toxin, suggesting that pertussis toxin may be able to block the effects of opioid agonists. Consistent with this hypothesis, intracranial administration of pertussis toxin into the nucleus accumbens was recently reported to produce a small rightward shift in the dose-effect curves for both heroin and cocaine self-administration (Self et al. 1994). Although pertussis toxin certainly is not a candidate for the clinical treatment of opioid dependence, these preliminary findings do suggest that drugs targeted at intracellular signal transduction mechanisms may be able to alter opioid self-administration.

At an intercellular level, it has been hypothesized that the mesolimbic dopamine system forms a final common pathway for the reinforcing effects of many abused drugs, including opioids (Bozarth 1986; DiChiara and Imperato 1988a). Several studies have tested this hypothesis by examining the effects of dopamine antagonists on opioid self-administration (Glick and Cox 1975; Stretch 1977; Ettenberg et al. 1982; Van Ree and Ramsey 1987; Gerber and Wise 1989; Higgins et al. 1994; Winger 1994). In general, dopamine antagonists decrease opioid self-administration, but only at doses that also produce overt sedation and decrease behavior maintained by nonopioid reinforcers. These findings argue against a prominent role for dopamine in opioid self-administration and suggest that dopamine antagonists will not be useful in the treatment of opioid abuse.

Other compounds reported to alter opioid self-administration include the cholinergic antagonist atropine (Glick and Cox 1975), the neuropeptide oxytocin (Kovacs and Van Ree 1985), the hallucinogen ibogaine (Glick et al. 1991; Dworkin et al. 1995), the calciumchannel blockers isradipine and nimodipine (Kuzmin et al. 1992), and the indirect serotonin agonist dexfenfluramine (Higgins et al. 1993). However, these studies used only a single unit dose of the self-administered opioid. In addition, most of these studies did not demonstrate selectivity, although ibogaine (Dworkin et al. 1995) and dexfenfluramine (Wang et al. 1995) were found to produce a selective decrease in opioid self-administration relative to food self-administration. Finally, the effects of chronic treatment with these drugs are unknown, although Wang and coworkers (1995) found that dexfenfluramine produced only a transient decrease in heroin self-administration during chronic dexfenfluramine treatment. As a result, additional research is necessary to extend these provocative results and further characterize the effects of these compounds on opioid self-administration. Interestingly, the alpha adrenoreceptor agonist clonidine has not been evaluated in a preclinical model of opioid abuse, although this drug attenuates some signs of opioid withdrawal and is one of the principal pharmacotherapies em- 
ployed in the treatment of opioid dependence (Charney et al. 1986; Stine and Kosten, 1992; Gold 1993).

\section{TOWARD IMPROVED PRECLINICAL MODELS FOR MEDICATION EVALUATION}

Preclinical studies of novel compounds are an important first step in identifying potentially effective pharmacotherapies for eventual clinical evaluation and suggesting promising directions for medications development. Animal models of drug self-administration simulate one basic behavioral endpoint of human drug abuse that can be affected by pharmacotherapies. The clinical relevance of this model is suggested by the degree of concordance between clinical and preclinical studies of drugs used for the treatment of opioid dependence and polydrug abuse involving cocaine and opioid dependence described throughout this review (Mello 1991; Mello et al. 1993c). However, many of the compounds examined in preclinical studies are not approved for phase II clinical testing, and parallel clinical and preclinical studies have not been conducted. Accordingly, the cross-validation of findings from clinical and preclinical models is an ongoing process (see Figure 1). Many of the preclinical studies of pharmacological antagonists considered in this review were originally designed to investigate mechanisms of drug action rather than to predict treatment medication efficacy. The degree of similarity of data obtained under different experimental conditions has sometimes been obscured by a great diversity of study designs and basic procedures, as well as variations in criteria for interpretation of medication efficacy.

Review of this complex literature has led us to conclude that several related methodological issues should be considered in the design of future studies. An ideal preclinical evaluation of potential treatment medications should include the determination of complete dose-effect curves for the target drug of abuse and the evaluation of chronic administration of several doses of the treatment medication on several unit doses of the abused drug. It is important to recapture baseline levels of drug self-administration between each successive exposure to the treatment medication to ensure that intravenous catheters are patent and that cumulative effects of treatment drugs do not complicate the interpretation of findings. In addition, the profile of interactions between the treatment medication and the abused drug should be examined to identify possible toxic effects as well as reinforcing effects of the drug combination. Although some agonist effects appear to be important for patient acceptance of a drug abuse treatment medication (Mello et al. 1993c; Mendelson and Mello 1996), clinical usefulness may be limited if a pharmacotherapy is highly reinforcing and likely to be abused. In addi- tion to these general considerations, several procedural issues also have an important effect on the interpretation of data obtained.

\section{Selectivity of Medication Effects}

One of the challenges of preclinical medication evaluations is to design a study that permits an unambiguous assessment of the relative selectivity of medication effects on drug self-administration. Because a decrease in drug self-administration may reflect sedation or toxicity rather than a decrease in drug reinforcing efficacy, it is important to evaluate treatment drug effects on responding maintained by an alternative reinforcer such as food. Moreover, food should be available under the same conditions as drug self-administration and measures of operant response-contingent food self-administration are preferable to post-session food intake. Evaluation of treatment medication effects on drug and food self-administration in the same subject is preferable to using different groups.

\section{Treatment Medication Dose Range}

Several doses of the treatment medication should be studied to establish the range over which it is effective and to ensure that behaviorally active doses are examined. An optimal design would evaluate the effects of several doses of the treatment drug on the self-administration of several unit doses of cocaine or heroin. However, the amount of experimental time and resources required to study all these dose conditions make it impractical for an initial evaluation of new treatment medications. A pragmatic alternative is to evaluate several doses of the treatment drug in combination with one reinforcing dose of cocaine or heroin that is on the ascending limb of the dose-effect curve. If an alternative reinforcer is also studied to ensure that apparent treatment effects do not reflect sedation or toxicity, this more spartan paradigm can yield useful information. The effects of the most promising treatment medications on the complete cocaine or heroin dose-effect curve can be evaluated subsequently.

\section{Stability of Medication Effects}

Because clinical treatment of substance abuse involves chronic administration of a pharmacotherapy, it is important to evaluate the stability of medication effects over time in preclinical models of drug self-administration. Medication-induced changes in drug self-administration may not be reliably detected in a single test session. Several days of observation are necessary to determine whether treatment medication effects increase or decrease over time. There have been many reports of changes in medication effects during chronic 
administration on cocaine self-administration (Woolverton and Virus 1989; Kleven and Woolverton 1990b; Gold and Balster 1992; Negus and Picker 1996; Negus et al. 1995b) and opioid self-administration (Jones and Prada 1977; Wang et al. 1995). Moreover, when several drug self-administration sessions are run each day, changes in drug-maintained responding do not always occur during the first session after administration of the treatment drug (Negus et al. 1995a). In clinical medicine, some pharmacotherapies such as antidepressants require chronic exposure before effective reduction of symptoms occurs. Medications for drug abuse treatment may also require repeated administration over time to become fully effective. Alternatively, the development of tolerance to medication effects on drug self-administration could compromise its clinical usefulness.

It is also important to determine the degree to which medication effects persist after treatment has been discontinued. In clinical practice, an ideal therapeutic outcome would include enduring beneficial effects of the treatment medication so that the patient could eventually become drug-free. In the preclinical model, the time required for drug self-administration to return to baseline levels is one measure of the persistence of treatment medication effects. However, it is also possible that chronic exposure to the treatment medication might result in an increased sensitivity to the reinforcing effects of the abused drug (Kleven and Woolverton $1990 \mathrm{~b}$ ). Redetermination of drug dose-effect curves at the conclusion of treatment can discriminate between these alternatives.

\section{Drug Dose-Effect Curves}

The importance of evaluating medication effects on dose-effect curves for the abused drug has been emphasized throughout this review. The interpretation of findings depends, in part, on the position of the unit dose of cocaine or heroin on the drug dose-effect curve. If the unit dose of cocaine or heroin is on the ascending limb of the dose-effect curve (see Figure 4), a decrease in drug self-administration during treatment is consistent with a decrease in the drug's reinforcing properties. However, if the unit dose is on the descending limb of the dose-effect curve, a decrease in drug self-administration may reflect an interaction between the direct rate-reducing effects of the abused drug and the treatment medication. When the entire drug dose-effect curve is examined, a competitive antagonist would shift the ascending limb of the curve to the right. But, the effect of an antagonist on the descending limb of the dose-effect curve would depend on whether or not the rate-reducing effects of high doses of cocaine or heroin were antagonized (see Woods et al. 1987 for review).

\section{Criteria of Medication Effectiveness}

Careful attention to each of the issues described will determine, in part, the appropriate criteria for treatment efficacy. We have discussed the ambiguities of interpretation that may result when efficacy is defined as an increase in drug-maintained responding similar to that observed during substitution of saline or a minimally reinforcing low dose of the abused drug. However, it is important to recognize that this problem occurs primarily when the treatment drug is evaluated on only one occasion. When chronic administration of the treatment drug is evaluated, an initial increase in drugmaintained responding may not be sustained. Moreover, equating high levels of saline self-administration with drug medication efficacy ignores the fact that substitution of saline or very low doses of the abused drug do not invariably result in an increase in injection-maintained responding. For example, after an animal has been exposed to saline extinction procedures on multiple occasions, the substitution of saline for cocaine or heroin may be followed by a rapid decrease in saline self-administration. This qualification is relevant to the interpretation of findings from all acute treatment studies where increases in drug self-administration were interpreted as evidence for antagonism of the drug's reinforcing properties (see Tables 1-6).

It is intuitively obvious that a decrease in drug selfadministration is the goal of clinical treatment, but in preclinical evaluations, medications may have different effects depending on the position of the unit dose on the drug self-administration dose-effect curve. For example, antagonism of the reinforcing effects of cocaine or heroin decreases the self-administration of some drug doses (i.e., doses on the ascending limb of the dose-effect curve) while increasing self-administration of other doses (i.e., doses on the descending limb; see Figure 4, left panel). Although considerable experimental effort has been devoted to analysis of the antagonist effects of drugs, the clinical implications of the antagonist-related increases in drug self-administration are somewhat problematic. An ideal treatment medication would decrease drug self-administration across a wide range of doses on both the ascending and descending limbs of the dose-effect curve (see Figure 4, center panel). This preclinical outcome corresponds to a decrease in human drug abuse. Moreover, because human drug.abusers seldom have accurate information about the purity of illicit drugs, it is important to develop pharmacotherapies that reduce drug self-administration across a broad range of drug doses.

Awareness of the distinction between assessment of treatment medication effects on drug self-administration and analysis of the pharmacological mechanisms of drug interactions may help to reconcile some apparent inconsistencies in the preclinical literature. Often, these 
may be sequential steps in the evaluation process; for example, identification of a potentially effective treatment medication may precede analysis of its pharmacological mechanisms of action. Alternatively, analysis of pharmacological mechanisms of drug interactions may identify compounds with specific receptor antagonist or agonist activities that are promising candidates for preclinical evaluation. However, it is important not to limit the search for new treatment medications to a narrow range of predictable agonist-antagonist interactions within pharmacologically defined drug classes. Effective treatment of polydrug abuse involving drugs from several pharmacological classes probably will require less categorical approaches to medications development. The availability of animal models of polydrug self-administration should facilitate the evaluation of the next generation of treatment medications (Mello et al. 1995, 1996). Although many issues still remain to be resolved, recent advances in and collaboration among researchers in behavioral science, pharmacology, neurobiology, and medicinal chemistry provide a basis for the discovery of more effective medications for substance abuse treatment and relapse prevention.

\section{REFERENCES}

Adams EH, Durell J (1984): Cocaine: A growing public health problem. In Grabowski J (ed), Cocaine: Pharmacology, Effects, and Treatment of Abuse, NIDA Research Monograph 50. Washington DC, U.S. Government Printing Office, pp 9-14

Aigner TG, Balster RL (1978): Choice behavior in rhesus monkeys: Cocaine versus food. Science 201:534-535

Balster RL (1991): Drug abuse potential evaluation in animals. Br J Addict 86:1549-1558

Balster RL, Mansbach RS, Gold L, Harris LS (1992): Preclinical methods for the development of pharmacotherapies for cocaine abuse. In Harris LS (ed), Problems of Drug Dependence 1991, NIDA Research Monograph 119. Washington, DC, U.S. Government Printing Office, pp $161-164$

Banks CD (1979): Overdose of buprenorphine: Case report. NZ Med J 89:255-256

Batki SL, Manfredi LB, Jacob IP, Jones RT (1993): Fluoxetine for cocaine dependence in methadone maintenance: Quantitative plasma and urine cocaine/benzoylecgonine concentrations. J Clin Psychopharmacol 13:243-250

Bergman J, Rosenzweig-Lipson S (1992): Cocaine-antagonist effects of limited-efficacy $D_{1}$ agonists. In Harris LS (ed), Problems of Drug Dependence 1991, NIDA Research Monograph 119. Washington, D.C., U.S. Government Printing Office, pp 185-189

Bergman J, Madras BK, Johnson SE, Spealman RD (1989): Effects of cocaine and related drugs in nonhuman primates. III. Self-administration by squirrel monkeys. J Pharmacol Exp Ther 251:150-155
Bergman J, Kamien JB, Spealman RD (1990): Antagonism of cocaine self-administration by selective dopamine $D_{1}$ and $\mathrm{D}_{2}$ antagonists. Behav Pharmacol 1:355-363

Bertalmio AJ, Woods JH (1987): Differentiation between mu and kappa receptor-mediated effects in opioid drug discrimination: Apparent $\mathrm{PA}_{2}$ analysis. J Pharmacol Exp Ther 243:591-597

Bertalmio AJ, Woods JH (1989): Reinforcing effect of alfentanil is mediated by mu opioid receptors: Apparent $\mathrm{PA}_{2}$ analysis. J Pharmacol Exp Ther 251:455-460

Biden JR Jr (1989): Pharmacotherapy: A strategy for the 1990's. A Staff Report. Washington, DC, U.S. Government Printing Office, p 38

Bilsky EJ, Calderon SN, Wang T, Bernstein RN, Davis P, Hruby J, McNuitt RW, Rothman RB, Rice K, Porreca F (1995): SNC 80, A selective, nonpeptidic and systemically active, opioid delta agonist. J Pharmacol Exp Ther 273:359-366

Blumberg H, Dayton HB (1974): Naloxone, naltrexone, and related noroxymorphones. In Braude MC, Harris LS, May EL, Smith JP, Villarreal JE (eds), Narcotic Antagonists: Advances in Biochemical Psychopharmacology. New York, Raven Press, pp 33-43

Bonese KF, Wainer BH, Fitch FW, Rothberg RM, Schuster CR (1974): Changes in heroin self-administration by a rhesus monkey after morphine immunization. Nature 252:708-710

Bourland JA, French ED (1995): Effects of remoxipride, an atypical antipsychotic, on cocaine self-administration in the rat using fixed-and progressive-ratio schedules of reinforcement. Drug and Alcohol Dependence 40:111114

Bozarth MA (1986): Neural basis of psychomotor stimulant and opioid reward: Evidence suggesting the involvement of a common dopaminergic system. Behav Brain Res 22:107-116

Brady JV, Lukas SE (eds) (1984): Testing Drugs for Physical Dependence Potential and Abuse Liability, NIDA Research Monograph 52. Washington, DC, U.S. Government Printing Office

Brady JV, Griffiths RR, Hienz RD, Ator NA, Lukas SE, Lamb RJ (1987): Assessing drugs for abuse liability and dependence potential in laboratory primates. In Bozarth MA (ed), Methods of Assessing the Reinforcing Properties of Abused Drugs. New York, Springer Verlag, pp 45-86

Byrd LD (1981): Quantitation in behavioral pharmacology. In Thompson T, Dews PB, McKim WA (eds), Advances in Behavioral Pharmacology. New York, Academic Press, pp 75-90

Caine SB, Koob GF (1993): Modulation of cocaine selfadministration in the rat through $\mathrm{D}_{3}$ dopamine receptors. Science 260:1814-1816

Caine SB, Koob GF (1994): Effects of dopamine $D_{1}$ and $D_{2}$ antagonists on cocaine self-administration under different schedules of reinforcement in the rat. J Pharmacol Exp Ther 270:209-218

Caine SB, Koob GF (1995): Pretreatment with the dopamine agonist 7-OH-DPAT shifts the cocaine self-administration dose-effect function to the left under different schedules in the rat. Behav Pharmacol 6:333-347 
Cappendijk LT, Dzolijic MR (1993): Inhibitory effects of ibogaine on cocaine self-administration in rats. Eur J Pharmacol 241:261-265

Carroll ME, Lac ST (1992): Effects of buprenorphine on selfadministration of cocaine and a non-drug reinforcer in rats. Psychopharmacology 106:439-446

Carroll ME, Lac ST, Walker MJ, Kragh R, Newman T (1986): Effects of naltrexone on intravenous cocaine self-administration in rats during food satiation and deprivation. J Pharmacol Exp Ther 238:1-7

Carroll ME, Lac ST, Asencio M, Kragh R (1990a): Fluoxetine reduces intravenous cocaine self-administration in rats. Pharmacol Biochem Behav 35:237-244

Carroll ME, Lac ST, Asencio M, Halikas JA, Kragh R (1990b): Effects of carbamazepine on self-administration of intravenously delivered cocaine in rats. Pharmacol Biochem Behav 37:551-556

Carroll ME, Carmona GN, May SA, Buzalsky S, Larson C (1992): Buprenorphine's effects on self-administration of smoked cocaine base and orally delivered phencyclidine, ethanol and saccarin in rhesus monkeys. J Pharmacol Exp Ther 261:26-33

Centers for Disease Control and Prevention (February, 1993): Facts about Women and HIV/AIDS. Atlanta, GA, CDC

Chaisson RE, Bacchetti P, Osmond D, Brodie B, Sande MA, Moss AR (1989): Cocaine use and HIV infection in intravenous drug users in San Francisco. JAMA 261:561-565

Charney DS, Heninger GR, Kleber HD (1986): The combined use of clonidine and naltrexone as a rapid, safe and effective treatment for abrupt withdrawal from methadone. Am J Psychiatry 143:831-837

Condelli WS, Fairbank JA, Dennis ML, Rachal JV (1991): Cocaine use by clients in methadone programs: Significance, scope, and behavioral interventions. J Subst Abuse Treat 8:203-212

Cornish JW, Maany I, Fudala PJ, Neal S, Poole SA, Volpicelli P, O'Brien CP (1995): Carbamazepine treatment for cocaine dependence. Drug Alcohol Depend 38:221-227

Corrigall WA, Coen KM (1991a): Cocaine self-administration is increased by both $D_{1}$ and $D_{2}$ dopamine antagonists. Pharmacol Biochem Behav 39:799-802

Corrigall WA, Coen KM (1991b): Opiate antagonists reduce cocaine but not nicotine self-administration. Psychopharmacology 104:167-170

Crawford CA, McDougall SA, Bolanos CA, Hall S, Berger SP (1995): The effects of the kappa agonist U-50,488 on cocaine-induced conditioned and unconditioned behaviors and Fos immuoreactivity. Psychopharmacology 120:392-399

Cushman P Jr. (1988): Cocaine use in a population of drug abusers on methadone. Hosp Community Psychiatry 39:1205-1207

Dackis CA, Gold MS (1985): New concepts in cocaine addiction: The dopamine depletion hypothesis. Neurosci Biobehav Rev 9:469-477

DAWN (1993): Preliminary Estimates from the Drug Abuse Warning Network. Substance Abuse and Mental Health Services Administration Office of Applied Studies, Advance Report Number 2. US Dept of Health and Human Services de la Garza R, Johanson CE (1982): Effects of haloperidol and physostigmine on self-administration of local anesthetics. Pharmacol Biochem Behav 17:1295-1299

Deneau GA, Yanagita T, Seevers MH (1969): Self-administration of psychoactive substances by the monkey. Psychopharmacologia 61:30-48

Devine DP, Wise RA (1994): Self-administration of morphine, DAMGO and DPDPE into the ventral tegmental area of rats. J Neurosci 14:1978-1984

de Vries TJ, Babovic-Vuksanovic D, Elmer G, Shippenberg TS (1995): Lack of involvement of $\delta$-opioid receptors in mediating the rewarding effects of cocaine. Psychopharmacology 120:442-448

DeWitt H, Wise RA (1977): Blockade of cocaine reinforcement in rats with the dopamine receptor blocker pimozide, but not with the noradrenergic blockers phentolamine or phenoxybenzamine. Canad J Psychol 31:195-203

Dews PB (1958): Studies on behavior. IV. Stimulant actions of methamphetamine. J Pharmacol Exp Ther 122:137-147

Dews PB (1981): History and present status of rate-dependency investigations. In Thompson T, Dews PB, McKim WA (eds), Advances in Behavioral Pharmacology. New York, Academic Press, pp 111-118

DiChiara G, Imperato A (1988a): Drugs abused by humans preferentially increase synaptic dopamine concentrations in the mesolimbic system of freely moving rats. Proc Natl Acad Sci U S A. 85:5274-5278

DiChiara G, Imperato A (1988b): Opposite effects of mu and kappa opiate agonists on dopamine release in the nucleus accumbens and in the dorsal caudate of freely moving rats. J Pharmacol Exp Ther 244:1067-1080

Dole VP (1988): Implications of methadone maintenance for theories of narcotic addiction. JAMA 260:3025-3029

Dole VP, Nyswander M (1965): A medical treatment for diacetylmorphine (heroin) addiction: A clinical trial with methadone hydrochloride. JAMA 193:646-650

Donahoe RM, Falek A (1988): Neuroimmunomodulation by opiates and other drugs of abuse: Relationship to HIV infection and AIDS. In Bridge TP, Mirsky FA, Goodwin FK (eds), Psychological, Neuropsychiatric and Substance Abuse Aspects of AIDS. New York, Raven Press, pp 145-157

Downs DA, Woods JH (1974): Codeine- and cocaine-reinforced responding in rhesus monkeys: Effects of dose on response rates under a fixed-ratio schedule. J Pharmacol Exp Ther 191:179-188

Dunteman GH, Condelli WS, Fairbank JA (1992): Predicting cocaine use among methadone patients: Analysis of findings from a national study. Hosp Community Psychiatry 43:608-611

Dworkin SI, Gleeson S, Meloni D, Koves TR, Martin TJ (1995): Effects of ibogaine on responding maintained by food, cocaine and heroin reinforcement in rats. Psychopharmacology 117:257-261

Epidemiologic Trends in Drug Abuse (1995): Volume I: Highlights and Executive Summary NIH Publication 953990. National Institute on Drug Abuse, NIH, PHS, USDHHS

Ettenberg A, Pettit HO, Bloom FE, Koob GF (1982): Heroin and cocaine intravenous self-administration in rats: 
Mediation by separate neural systems. Psychopharmacology (Berlin) 78:204-209

Federal Strategy for Drug Abuse and Drug Traffic Prevention (1973). Washington, DC, Strategy Council on Drug Abuse

Ferster CB, Skinner BF (1957): Schedules of Reinforcement. New York, Appleton-Century-Crofts

Fischman MW, Foltin RW, Nestadt G, Pearlson GD (1990): Effects of desipramine maintenance on cocaine selfadministration by humans. J Pharmacol Exp Ther 253 $760-770$

Foltin RW, Fischman MW (1992): The cardiovascular and subjective effects of intravenous cocaine and morphine combinations in humans. J Pharmacol Exp Ther 261 623-632

Foltin RW, Fischman MW (1995): Interaction of buprenorphine with cocaine-morphine combinations. Exp Clin Psychopharmacol 3:261-269

Gastfriend DR, Mendelson JH, Mello NK, Teoh SK, Reif S (1993a): Buprenorphine pharmacotherapy for concurrent heroin and cocaine dependence. Am J Addict 2:269278

Gastfriend DR, Wapler M, Teoh SK, Reif S, Mendelson JH, Mello NK (1993b): Effects of buprenorphine on needle sharing, drug use and drug craving in men with combined heroin and cocaine dependence. In Harris LS (ed), Problems of Drug Dependence 1992, NIDA Research Monograph 132. Washington, DC, U.S. Government Printing Office, p 312

Gastfriend DR, Mendelson IH, Mello NK, Teoh SK, Reif S (1995): Long-term effects of buprenorphine for treatment of combined opiate and cocaine dependence. In Harris LS (ed), Problems of Drug Dependence 1994, NIDA Research Monograph 153. Washington, DC, U.S. Government Printing Office, $\mathrm{p} 9$

Gawin FH (1991): Cocaine addiction: Psychology and neurophysiology. Science 251:1580-1586

Gawin FH, Ellinwood EH (1988): Cocaine and other stimulants: Actions, abuse and treatment. N Engl J Med 318: 1173-1182

Gawin FH, Kleber HD (1984): Cocaine abuse treatment, open pilot trial with desipramine and lithium carbonate. Arch Gen Psychiatry 41:903-909

Gawin FH, Allen D, Humblestone B (1989): Outpatient treatment of "crack" cocaine smoking with flupenthixol decanoate. Arch Gen Psychiatry 46:322-325

Gerber GJ, Wise RA (1989): Pharmacological regulation of intravenous cocaine and heroin self-administration in rats: A variable dose paradigm. Pharmacol Biochem Behav 32:527-531

Glick SD, Cox RD (1975): Dopaminergic and cholinergic influences on morphine self-administration in rats. Res Commun Chem Pathol Pharmacol 12:17-24

Glick SD, Rossman K, Steindorf S, Maisonneuve IM, Carlson IN (1991): Effects and after effects of ibogaine on morphine self-administration in rats. Eur J Pharmacol 195:341-345

Glick SD, Maisonneuve IM, Raucci J, Archer S (1995): Kappa opioid inhibition of morphine and cocaine self-administration in rats. Brain Res 681:147-152
Glowa JR, Wojnicki FHE, Matecka D, Bacher JD, Mansbach RS, Balster RL, Rice K (1995a): Effects of dopamine reuptake inhibitors on food- and cocaine-maintained responding: I. dependence on unit dose of cocaine. Exp Clin Psychopharmacol 3:219-231

Glowa JR, Wojnicki FHE, Matecka D, Rice K, Rothman RB (1995b): Effects of dopamine reuptake inhibitors on food- and cocaine-maintained responding: II. Comparisons with other drugs and repeated administrations. Exp Clin Psychopharmacol 3:232-239

Gold LH, Balster RL (1992): Effects of buspirone and gepirone on i.v. cocaine self-administration in rhesus monkeys. Psychopharmacology (Berl) 108:289-294

Gold MS (1993): Opiate addiction and the locus coeruleus. The clinical utility of clonidine, naltrexone, methadone and buprenorphine. Psychiatr Clin North Am 16:61-73

Goldberg SR, Woods JH, Schuster CR (1971): Nalorphineinduced changes in morphine self-administration in rhesus monkeys. Pharmacol Exp Ther 176:464-471

Goldberg SR, Morse WH, Goldberg DM (1976): Behavior maintained under a second order schedule by intramuscular injection of morphine or cocaine in rhesus monkeys. J Pharmacol Exp Ther 199:278-286

Grabowski J, Rhoades H, Elk R, Schmitz J, Davis C, Creson D, Kirby K (1995): Fluoxetine is ineffective for treatment of cocaine dependence or concurrent opiate and cocaine dependence: Two placebo-controlled, double-blind trials. J Clin Psychopharmacol 15:163-174

Griffiths RR, Balster RL (1979): Opioids: Similarity between evaluations of subjective effects and animal self-administration results. Clin Pharmacol Ther 25:611-617

Griffiths RR, Brady J, Bradford L (1979a): Predicting the abuse liability of drugs with animal drug self-administration procedure: Psychomotor stimulants and hallucinogens. In Thompson T, Dews PB (eds), Advances in Behavioral Pharmacology. New York, Academic Press, pp 163-208

Griffiths RR, Bradford LD, Brady IV (1979b): Progressive ratio and fixed-ratio schedules of cocaine-maintained responding in baboons. Psychopharmacology 65:125-136

Griffiths RR, Wurster RM, Brady JV (1976): Discrete-trial choice procedure: Effects of naloxone and methadone on choice between food and heroin. Pharmacol Rev 27: 357-365

Griffiths RR, Bigelow G, Henningfield J (1980): Similarities in animal and human drug taking behavior. In Mello NK (ed), Advances in Substance Abuse, Behavioral and Biological Research. Greenwich, CT, JAI Press, pp 1-90

Griffiths RR, Wurster RM, Brady JV (1981): Choice between food and heroin: effects of morphine, naloxone and secobarbital. J Exp Anal Behav 35:335-351

Halikas J, Nurgent S, Crosby R, Carlson G (1993): Survey of pharmacotherapies used in the treatment of cocaine abuse. J Addictive Dis 12:129-139

Harrigan SE, Downs DA (1978): Continuous intravenous naltrexone effects on morphine self-administration in rhesus monkeys. J Pharmacol Exp Ther 204:481-486

Harrigan SE, Downs DA (1981): Pharmacological evaluation of narcotic antagonist delivery systems in rhesus monkeys. In Willette RE, Barnett G (eds), Narcotic Antago- 
nists: Naltrexone Pharmacochemistry and SustainedRelease Preparations, NIDA Research Monograph 28. Washington, DC, U.S. Government Printing Office, pp $77-92$

Heidbreder CA, Goldberg SR, Shippenberg TS (1993): The kappa-opioid receptor agonist U-69593 attenuates cocaine-induced behavioral sensitization in the rat. Brain Res 616:335-338

Heidbreder CA, Babovic-Vuksanovic D, Shoaib M, Shippenberg T (1995): Development of behavioral sensitization to cocaine: Influence of kappa opioid receptor agonists. J Pharmacol Exp Ther 275:150-163

Herling S (1981): Naltrexone effects on food and codeinemaintained responding in rhesus monkeys. Eur I Pharmacol 73:41-49

Herling S, Woods JH (1980): Chlorpromazine effects on cocaine-reinforced responding in rhesus monkeys: Reciprocal modification of rate-altering effects of drugs. J Pharmacol Exp Ther 214:354-361

Herling S, Downs DA, Woods JH (1979): Cocaine, d-amphetamine, and pentobarbital effects on responding maintained by food or cocaine in rhesus monkeys. Psychopharmacology 64:261-269

Higgins GA, Wang Y, Sellers EM (1993): Preliminary findings with the indirect 5-HT agonist dexfenfluramine on heroin discrimination and self-administration in rats. Pharmacol Biochem Behav 45:963-966

Higgins GA, Joharchi N, Wang Y, Corrigall WA, Sellers EM (1994): The CCKA receptor antagonist devazepide does not modify opioid self-administration or drug discrimination: Comparison with the dopamine antagonist haloperidol. Brain Res 640:246-254

Houde RW (1979): Analgesic effectiveness of the narcotic agonist-antagonists. Br J Clin Pharmacol 7 (suppl 3): 297-308

Howell LL, Byrd LD (1991): Characterization of the effects of cocaine and GBR 12909, a dopamine uptake inhibitor, on behavior in the squirrel monkey. J Pharmacol Exp Ther 258:178-185

Hubner CB, Moreton JE (1991): Effects of selective $D_{1}$ and $D_{2}$ dopamine antagonists on cocaine self-administration in the rat. Psychopharmacology 105:151-156

Jaffe JH, Martin WR (1990): Opioid analgesics and antagonists. In Gilman AG, Rall TW, Nies AS, Taylor P (eds), The Pharmacological Basis of Therapeutics. New York, Pergamon Press, pp 485-521

Jaffe JH, Senay EC (1971): Methadone and 1-methadyl acetate: Use in management of narcotic addicts. JAMA 216:1303-1305

Jaffe JH, Senay EC, Schuster CR, Renault PR, Smith B, DiMenza S (1972): Methadyl acetate vs methadone. A double-blind study in heroin users. JAMA 222:437-442

Jasinski DR, Pevnick JS, Griffith JD (1978): Human pharmacology and abuse potential of the analgesic buprenorphine. Arch Gen Psychiatry 35:601-616

Jenck F, Gratton A, Wise RA (1987): Opioid receptor subtypes associated with ventral tegmental facilitation of lateral hypothalamic brain stimulation reward. Brain Res 423:34-38

Johanson CE, Schuster CR (1975): A choice procedure for drug reinforcers: Cocaine and methylphenidate in the rhesus monkey. J Pharmacol Exp Ther 193:676-688

Johanson CE, Fischman MW (1989): The pharmacology of cocaine related to its abuse. Pharmacol Rev 41:3-52

Johnson RE, Jaffe JH, Fudala PJ (1992): A controlled trial of buprenorphine treatment for opioid dependence. JAMA 267:2750-2755

Jones BE, Prada JA (1975): Drug seeking behavior during methadone maintenance. Psychopharmacologia (Berl) 41:7-10

Jones BE, Prada JA (1977): Effects of methadone and morphine maintenance on drug-seeking behavior in the dog. Psychopharmacology 54:109-112

Judson BA, Goldstein A (1979): Levo-alpha-acetyl-methadol (LAAM) in the treatment of heroin addicts. I. Dosage schedule for induction and stabilization. Drug Alcohol Depend 4:461-466

Julius D, Renault P (eds) (1976): Narcotic Antagonists: Naltrexone Progress Report, NIDA Research Monograph 9. Washington, DC, U.S. Government Printing Office

Katz JL, Witkin JM (1992): Selective effects of the $D_{1}$ dopamine receptor agonist, SKF 38393, on behavior maintained by cocaine injection. Psychopharmacology 109:241-244

Kelleher RT (1976): Characteristics of behavior controlled by scheduled injections of drugs. In Kelleher RT, Goldberg SR, Krasnegor NA (eds), Control of Drug Taking Behavior by Schedules of Reinforcement. Baltimore, Williams \& Wilkins, pp 307-323

Kelleher RT, Morse WH (1968): Determinants of the specificity of behavioral effects of drugs. Ergeb Physiologie 60:1-56

Killian AK, Bonese K, Schuster CR (1978a): The effects of naloxone on behavior maintained by cocaine and heroin injections in the rhesus monkey. Drug Alcohol Depend $3: 243-251$

Killian A, Bonese K, Rothberg RM, Wainer BH, Schuster CR (1978b): Effects of passive immunization against morphine on heroin self-administration. Pharmacol Biochem Behav 9:347-352

Kleven MS, Woolverton WL (1990a): Effects of bromocriptine and desipramine on behavior maintained by cocaine or food presentation in rhesus monkeys. Psychopharmacology (Berl) 101:208-13

Kleven MS, Woolverton WL (1990b): Effects of continuous infusions of SCH 23390 on cocaine- or food-maintained behavior in rhesus monkeys. Behav Pharmacol 1:365-374

Kleven MS, Woolverton WL (1993): Effects of three monoamine uptake inhibitors on behavior maintained by cocaine or food presentation in rhesus monkeys. Drug Alcohol Depend 31:149-158

Koob GF, Pettit HO, Ettenberg A, Bloom FE (1984): Effects of opiate antagonists and their quaternary derivatives on heroin self-administration in the rat. J Pharmacol Exp Ther 229:481-486

Koob GF, Vaccarino FJ, Amalric M, Bloom FE (1986): Neurochemical substrates for opioid reinforcement. In Brown RM, Clouet DH, Friedman DP (eds), Opioid Receptor Subtypes and Brain Function, NIDA Research Monograph 71. Washington, DC, U.S. Government Printing Office, pp 147-164 
Kosten TR, Rounsaville BJ, Gawin FH, Kleber HD (1986): Cocaine abuse among opioid addicts: Demographic and diagnostic factors in treatment. Am J Drug Alcohol Abuse 12:1-16

Kosten TR, Schumann B, Wright D, Carney MK, Gawin FH (1987): A preliminary study of desipramine in the treatment of cocaine abuse in methadone maintenance patients. J Clin Psychiatry 48:442-444

Kosten TR, Kleber HD, Morgan C (1989a): Treatment of cocaine abuse with buprenorphine. Biol Psychiatry 26:170-172

Kosten TR, Kleber HD, Morgan C (1989b): Role of opioid antagonists in treating intravenous cocaine abuse. Life Sci 44:887-892

Kosten TR, Shottenfeld R, Ziedonis D, Falcioni J (1993): Buprenorphine versus methadone maintenance for opioid dependence. J Nerv Ment Dis 18:358-364

Kovacs CL, Van Ree JM (1985): Behaviorally active oxytocin fragments simultaneously attenuate heroin self-administration and tolerance in rats. Life Sci 37:1895-1900

Kozel NJ, Adams EH (1986): Epidemiology of drug abuse: An overview. Science 34:970-974

Kranzler HR, Bauer DH, Klinghoffer V (1995): Carbamazepine treatment of cocaine dependence: A placebocontrolled trial. Drug Alcohol Depend 38:203-211

Kreek MJ (1987): Multiple drug abuse patterns and medical consequences. In Meltzer H (ed), Psychopharmacology, the Third Generation of Progress. New York, Raven Press, pp 1597-1604

Kuhar MJ, Ritz MC, Sharkey J (1988): Cocaine receptors on dopamine transporters mediate cocaine reinforced behavior. In Clouet D, Asghar K, Brown R (eds), Mechanisms of Cocaine Abuse and Toxicity, NIDA Research Monograph 88. Washington, DC, U.S. Government Printing Office, pp 14-22

Kuhar MJ, Ritz MC, Boja JW (1991): The dopamine hypothesis of the reinforcing properties of cocaine. Trends Neurosci 14:299--302

Kuzmin A, Zvartau E, Gessa GL, Martellotta MC, Fratta W (1992): Calcium antagonists isradipine and nimodipine suppress cocaine and morphine intravenous self-administration in drug-naive mice. Pharmacol Biochem Behav 41:497-500

Lamb RJ, Preston KL, Schindler CW, Meisch RA, Davis F, Katz JL, Henningfield JE, Goldberg SR (1991): The reinforcing and subjective effects of morphine in postaddicts: A dose-response study. J Pharmacol Exp Ther 259:1165-1173

Lane JD, Pickering CL, Hooper ML, Fagan K, Tyers MB, Emmett-Oglesby MW (1992): Failure of ondansetron to block the discriminative or reinforcing stimulus effects of cocaine in the rat. Drug Alcohol Depend 30:151-162

Lewis JW (1974): Ring C-Bridged derivatives of thebaine and oripavine. In Braude MC, Harris LS, May EL, Smith JP, Villarreal JE (eds), Narcotic Antagonists. Advances in Biochemical Psychopharmacology. New York, Raven Press, pp 123-136

Lewis JW (1995): Clinical pharmacology of buprenorphine in relation to its use as an analgesic. In Cowan A, Lewis JW (eds), Buprenorphine: Combatting Drug Abuse with a Unique Opioid. New York, Wiley-Liss, pp 151-163

Lewis JW, Rance MJ, Sanger DJ (1983): The pharmacology and abuse potential of buprenorphine: A new antagonist analgesic. In Mello NK (ed), Advances in Substance Abuse: Behavioral and Biological Research. Greenwich, CT, JAI Press, pp 103-154

Longoni R, Spina L, Mulas A, Carboni E, Garau L, Melchiorri P, DiChiara G (1991): [D-Ala ${ }^{2}$ ]Deltorphin II: $D_{1}$-dependent stereotypes and stimulation of dopamine release in nucleus accumbens. Neuroscience 11:1565-1576

Lord JAH, Waterfield AA, Hughes J, Kosterlitz HW (1977): Endogenous opioid peptides: Multiple agonists and receptors. Nature 267:495-499

Lukas SE, Moreton JD, Khazan N (1981): Effects of levoalpha-acetylmethadol (LAAM) on morphine self-administration in the rat. Psychopharmacology 73:12-16

Lukas SE, Mello NK, Drieze JM, Mendelson JH (1995): Buprenorphine-induced alterations of cocaine's reinforcing properties in rhesus monkey: A dose-response analysis. Drug Alcohol Depend 40:87-98

Madras BK, Fahey MA, Bergman J, Canfield DR, Spealman RD (1989): Effects of cocaine and related drugs in nonhuman primates. I. $\left[{ }^{3} \mathrm{H}\right]$ cocaine binding sites in caudate-putamen. J Pharmacol Exp Ther 251:131-141

Maisonneuve IM, Archer S, Glick SD (1994): U50,488 a K opioid receptor agonist, attenuates cocaine-induced increases in extracellular dopamine in the nucleus accumbens of rats. Neurosci Lett 181:57-60

Mansbach RS, Balster RL (1993): Effects of mazindol on behavior maintained or occasioned by cocaine. Drug Alcohol Depend 31:183-191

Mansour A, Khachaturian H, Lewis ME, Akil H, Watson SJ (1987): Autoradiographic differentiation of $\mathrm{mu}$, delta and kappa opioid receptors in rat forebrain and midbrain. J Neurosci 7:2445-2464

Martin WR, Jasinski DR (1977): Assessment of the abuse potential of narcotic analgesics in animals. In Martin WR (ed), Drug Addiction I: Handbook of Experimental Pharmacology. Berlin, Springer-Verlag, pp 159-196

Martin WR, Eades CG, Thompson JA, Huppler RE, Gilbert PE (1976): The effects of morphine- and nalorphine-like drugs in the non-dependent and morphine-dependent dog. J Pharmacol Exp Ther 197:517-532

Martin WR, Jasinski DR, Haertzen CA, Kay DC, Jones BE, Mansky PA, Carpenter RW (1973a): Methadone-A reevaluation. Arch Gen Psychiatry 28:286-295

Martin WR, Jasinski DR, Mansky PA (1973b): Naltrexone, an antagonist for the treatment of heroin dependence effects in man. Arch Gen Psychiatry 28:784-791

Mello NK (1979): Animal models of alcoholism: Progress and prospects. In Davidson R (ed), Modification of Pathological Behavior, Experimental Analysis of Etiology and Therapy. New York, Gardner Press, pp 273-333

Mello NK (1991): Pre-clinical evaluation of the effects of buprenorphine, naltrexone and desipramine on cocaine self-administration. In Harris LS (ed), Problems of Drug Dependence 1990, NIDA Research Monograph No. 105, DHHS Publ. No. (ADM)91-1753. Washington, DC, U.S. Government Printing Office, pp 189-195 
Mello NK (1992): Behavioral strategies for the evaluation of new pharmacotherapies for drug abuse treatment. In Harris LS (ed), Problems of Drug Dependence 1991, NIDA Research Monograph No. 119, DHHS (ADM) 921888. Washington, DC, U.S. Government Printing Office, pp 150-154

Mello NK, Mendelson JH (1980): Buprenorphine suppresses heroin use by heroin addicts. Science 27:657-659

Mello NK, Mendelson JH (1992): Primate studies of the behavioral pharmacology of buprenorphine. In Blaine JD, Snyder M (eds), Buprenorphine: An Alternative Treatment for Opioid Dependence, NIDA Research Monograph No. 121, DHHS (ADM)92-1912. Washington, DC, U. S. Government Printing Office, pp 61-100

Mello NK, Mendelson JH (1995): Buprenorphine treatment of cocaine and heroin abuse. In Cowan A, Lewis JW (eds), Buprenorphine: Combatting Drug Abuse with a Unique Opioid. New York, Wiley-Liss, pp 241-287

Mello NK, Mendelson JH, Bree MP (1981): Naltrexone effects on morphine and food self-administration in morphinedependent rhesus monkeys. J Pharmacol Exp Ther 218:550-557

Mello NK, Mendelson JH, Kuehnle JC (1982): Buprenorphine effects on human heroin self-administration. J Pharmacol Exp Ther 223:30-39

Mello NK, Bree MP, Mendelson JH (1983): Comparison of buprenorphine and methadone effects on opiate selfadministration in primates. I Pharmacol Exp Ther 225:378-386

Mello NK, Mendelson JH, Bree MP, Lukas SE (1989): Buprenorphine suppresses cocaine self-administration by rhesus monkeys. Science 245:859-862

Mello NK, Lukas SE, Bree MP, Mendelson JH (1990a): Desipramine effects on cocaine self-administration by rhesus monkeys. Drug Alcohol Depend 26:103-116

Mello NK, Mendelson JH, Bree MP, Lukas SE (1990b): Buprenorphine and naltrexone effects on cocaine selfadministration by rhesus monkey. J Pharmacol Exp Ther 254:926-939

Mello NK, Lukas SE, Kamien JB, Mendelson JH, Drieze J, Cone EJ (1992): The effects of chronic buprenorphine treatment on cocaine and food self-administration by rhesus monkeys. J Pharmacol Exp Ther 260:1185-1193

Mello NK, Kamien JB, Lukas SE, Mendelson JH, Drieze JM, Sholar JW (1993a): Effects of intermittent buprenorphine administration on cocaine self-administration by rhesus monkeys. J Pharmacol Exp Ther 264:530-541

Mello NK, Lukas SE, Mendelson JH, Drieze J (1993b): Naltrexone-buprenorphine interactions: Effects on cocaine self-administration. Neuropsychopharmacology 9:211224

Mello NK, Mendelson JH, Lukas SE, Gastfriend D, Teoh SK, Holman BL (1993c): Buprenorphine treatment of opiate and cocaine abuse: Clinical and preclinical studies. Harvard Rev Psychiatry 1:168-183

Mello NK, Kamien JB, Lukas SE, Drieze J, Mendelson JH (1993d): The effects of nalbuphine and butorphanol treatment on cocaine and food self-administration by rhesus monkeys. Neuropsychopharmacology 8:45-55

Mello NK, Sarnyai Z, Mendelson JH, Drieze JM, Kelly M (1993d): Acute effects of cocaine on anterior pituitary hormones in male and female rhesus monkeys. J Pharmacol Exp Ther 266:804-811

Mello NK, Negus SS, Lamas X, Lukas SE, Mendelson JH (1996): Buprenorphine's effects on "speedball" combinations of cocaine and heroin. In Harris LS (ed), Problems of Drug Dependence 1995, NIDA Research Monograph No. 162, NIH Pub. No. 96-4116. Rockville, MD, NIDA, DHHS, p. 170

Mello NK, Negus SS, Lukas SE, Mendelson JH, Sholar JW, Drieze J (1995): A primate model of polydrug abuse: Cocaine and heroin combinations. J Pharmacol Exp Ther 274:1325-1337

Mendelson JH, Mello NK (1994): Cocaine and other commonly abused drugs. In Isselbacher $\mathrm{KH}$, Braunwald $\mathrm{E}$, Wilson JD, Martin JB, Fauci AS, Kasper DL (eds), Harrison's Principles of Internal Medicine, ed 13, New York, McGraw-Hill, pp 2429-2433

Mendelson JH, Mello NK (1996): Management of cocaine abuse and dependence. N Eng J Med 334:965-972

Meyer RE, Mirin SM (1979): The Heroin Stimulus. New York, Plenum Press

Montoya ID, Levin FR, Fudala PJ, Gorelick DA (1995): Double-blind comparison of carbamazepine and placebo for treatment of cocaine dependence. Drug Alcohol Depend 28:213-219

Musto DF (1973): The American Disease: Origins of Narcotic Control. New Haven, Yale University Press

Nader MA, Mach RH (in press): Self-administration of the dopamine $\mathrm{D}_{3}$ agonist 7-OH-DPAT in rhesus monkeys is modified by previous cocaine exposure. Psychopharmacology

National Commission on Acquired Immune Deficiency Syndrome (1991): Fifth Interim Report to the President and the Congress: The Twin Epidemics of Substance Use and HIV. Washington, DC, National Commission on AIDS.

National Research Council Committee on Clinical Evaluation of Narcotic Antagonists (1978): Clinical evaluation of naltrexone treatment of opioid-dependent individuals. Arch Gen Psychiatry 35:335-340

Negus SS, Mello NK, Lamas X, Mendelson JH (1996): Acute and chronic effects of flupenthixol on the discriminative stimulus and reinforcing effects of cocaine in rhesus monkeys. J Pharmacol Exp Ther (in press)

Negus SS, Picker MJ (1996): BW37U86: A non-peptidic, systemically-active delta opioid agonist. CNS Drug Reviews 2:68-90

Negus SS, Weinger MB, Henriksen SJ, Koob GF (1992): Effect of $\mathrm{mu}$, delta and kappa opioid agonists on heroin-maintained responding in the rat. In Harris LS (ed), Problems of Drug Dependence 1991, NIDA Research Monograph No. 119, DHHS Pub. No. (ADM) 92-1888. Rockville, MD, U.S. Government Printing Office, p 410

Negus SS, Burke TF, Medzihradsky F, Woods JH (1993a): Effects of opioid agonists selective for mu, kappa and delta opioid receptors on schedule-controlled responding in rhesus monkeys: Antagonism by quadazocine. J Pharmacol Exp Ther 267:896-903

Negus SS, Henriksen SI, Mattox A, Pasternak GW, Portoghese PS, Takemori AE, Weinger MB, Koob GF (1993b): 
Effect of opioid agonists selective for mu, delta and kappa opioid receptors on the reinforcing effects of heroin in rats. J Pharmacol Exp Ther 265:1245-1252

Negus SS, Butelman ER, Chang KJ, DeCosta BR, Winger G, Woods JH (1994): Behavioral effects of the systemically active delta opioid agonist BW373U86 in rhesus monkeys. J Pharmacol Exp Ther 270:1025-1034

Negus SS, Mello NK, Lukas SE, Mendelson JH (1995a): Diurnal patterns of cocaine and heroin self-administration in rhesus monkeys responding under a schedule of multiple daily sessions. Behav Pharmacol 6:763-765.

Negus SS, Mello NK, Portoghese PS, Lukas SE, Mendelson $\mathrm{JH}(1995 \mathrm{~b})$ : Role of delta opioid receptors in the reinforcing and discriminative stimulus effects of cocaine in rhesus monkeys. J Pharmacol Exp Ther 273:1245-1256

Pillai R, Nair BS, Watson RR (1991): AIDS, drugs of abuse and the immune system: A complex immunotoxicological network. Arch Toxicol 65:609-617

Pollack MH, Rosenbaum JF (1991): Fluoxetine treatment of cocaine abuse in heroin addicts. J Clin Psychiatry 52:31-33

Porrino LJ, Ritz MC, Goodman NL, Sharpe LG, Kuhar MJ, Goldberg SR (1989): Differential effects of the pharmacological manipulation of serotonin systems of cocaine and amphetamine self-administration in rats. Life Sci 45:1529-1535

Post RM, Weiss SRB, Aigner TG (1993): Carbamazepine in the treament of cocaine abuse. In Korenman S, Barchas J (eds), Biological Basis of Substance Abuse. New York, Oxford University Press, pp 443-462

Rawson RA, Obert JL, McCann MJ, Castro FG, Ling W (1991): Cocaine abuse treatment: A review of current strategies. J Subst Abuse 3:457-491

Richardson NR, Roberts DCS (1991): Fluoxetine pretreatment reduces breaking points on a progressive ratio schedule reinforced by intravenous cocaine self-administration in the rat. Life Sci 49:833-840

Richardson NR, Piercey MF, Svensson K, Collins RJ, Myers JE, Roberts DCS (1993): Antagonism of cocaine selfadministration by the preferential dopamine autoreceptor antagonist (+) - AI 76. Brain Res 619:15-21

Richardson NR, Smith AM, Roberts DCS (1994): A single injection of either flupenthixol decanoate or haloperidol decanoate produces long-term changes in cocaine selfadministration in rats. Drug Alcohol Depend 36:23-25

Ritz MC, Lamb RJ, Goldberg SR, Kuhar MJ (1987): Cocaine receptors on dopamine transporters are related to selfadministration of cocaine. Science 237:1219-1223

Ritz MC, Lamb RJ, Goldberg SR, Kuhar MJ (1988): Cocaine self-administration appears to be mediated by dopamine uptake inhibition. Prog Neuropsychopharmacol Biol Psychiatry 12:233-239

Roberts DCS, Vickers G (1984): Atypical neuroleptics increase self-administration of cocaine: An evaluation of a behavioural screen for antipsychotic activity. Psychopharmacology 82:135-139

Roberts DCS, Loh EA, Vickers G (1989): Self-administration of cocaine on a progressive ratio schedule in rats: Doseresponse relationship and effect of haloperidol pretreatment. Psychopharmacology 97:535-538

Rosen MI, Kosten TR (1991): Buprenorphine: Beyond methadone? Hosp Community Psychiatry 42:347-349
Sanchez-Ramos JR, Schuster CR (1977): Second-order schedules of intravenous drug self-administration in rhesus monkeys. Pharmacol Biochem Behav 7:443-450

Sannerud CA, Griffiths RR (1988): Amantadine: Evaluation of reinforcing properties and effect on cocaine selfadministration in baboons. Drug Alcohol Depend 21:195-202

Schecter A (1980): The role of narcotic antagonists in the rehabilitation of opiate addicts: A review of naltrexone. Am J Drug Alcohol Abuse 7:1-18

Schottenfeld RS, Pakes J, Ziedonis D, Kosten TR (1993): Buprenorphine: Dose-related effects on cocaine and opioid use in cocaine-abusing opioid-dependent humans. Biol Psychiatry 3:66-74

Schuster CR, Johanson CE (1974): The use of animal models for the study of drug abuse. In Gibbons RJ et al. (eds), Research Advances in Alcohol and Drug Problems. New York, Wiley, pp 1-31

Schwartz JC, Giros B, Martres MP, Sokoloff P (1992): The dopamine receptor family: Molecular biology and pharmacology. Semin Neurosci 4:99-108

Segal DL, Schuster CR (1995): Buprenorphine: What interests the National Institute on Drug Abuse? In Cowan A, Lewis JW (eds), Buprenorphine: Combatting Drug Abuse with a Unique Opioid. New York, Wiley-Liss, pp 309-320

Seiden LS, Balster RL (1985): Behavioral Pharmacology: The Current Status. New York, Alan R. Liss

Self DW, Stein L (1992): The D agonists SKF 82958 and SKF 77434 are self-administered by rats. Brain Res 582:349-352

Self DW, Nestler EJ, Stein L (1994): Role of G-proteins in heroin and cocaine reinforcement. J Neurosci 14:6239-6247

Sharpe LG, Jaffe JH, Katz JL (1992): Carbamazepine produces nonspecific effects on cocaine self-administration in rats. Life Sci 51:PL13-18

Shippenberg TS, Bals-Kubik R, Herz A (1987): Motivational properties of opioids: Evidence that an activation of $\delta$-receptors mediates reinforcement properties. Brain Res 436:234-239

Skjoldager P, Winger G, Woods JH (1991): Analysis of fixedratio behavior maintained by drug reinforcers. J Exp Anal Behav 56:331-343

Skjoldager P, Winger G, Woods JH (1993): Effects of GBR 12909 and cocaine on cocaine-maintained behavior in rhesus monkeys. Drug Alcohol Depend 33:31-39

Smith A, Piercey M, Roberts DCS (1995): Effects of (-)-DS 121 and (+)-UH 232 on cocaine self-administration in rats. Psychopharmacology 120:93-98

Spanagel R, Herz A, Shippenberg TS (1990): The effects of opioid peptides on dopamine release in the nucleus accumbens: An in vivo microdialysis study. J Neurochem 55:1734

Spealman RD (1985): Environmental factors determining the control of behavior by drugs. In Seiden LS, Balster RL (eds), Behavioral Pharmacology: The Current Status. New York, Alan R. Liss, pp 23-38

Spealman RD (1992): Use of cocaine-discrimination techniques for preclinical evaluation of candidate therapeutics for cocaine dependence. In Harris LS (ed), Problems of Drug Dependence 1991, NIDA Research Monograph 
No. 119, DHHS Publ. No. (ADM) 92-1888. Washington, DC, U.S. Government Printing Office, pp 175-179

Spealman RD, Goldberg SR (1978): Drug self-administration by laboratory animals: Control by schedules of reinforcement. Annu Rev Pharmacol Toxicol 18:313-339

Spealman RD, Bergman J (1992): Modulation of the discriminative-stimulus effects of cocaine by mu and kappa opioids. J Pharmacol Exp Ther 261:607-615

Spealman RD, Bergman J (1994): Opioid modulation of the discriminative stimulus effects of cocaine: Comparison of $\mu, \kappa$ and $\delta$ agonists in squirrel monkeys discriminating low doses of cocaine. Behav Pharmacol 5:21-31

Spealman RD, Bergman J, Madras BK, Kamien JB, Melia KF (1992): Role of $D_{1}$ and $D_{2}$ dopamine receptors in the behavioral effects of cocaine. Neurochem Int 20:147S$152 S$

Stine SM, Kosten TR (1992): Use of drug combinations in treatment of opioid withdrawal. J Clin Psychopharmacol 12:203-209

Stretch R (1977): Discrete-trial control of cocaine self-injection behaviour in squirrel monkeys: Effects of morphine, naloxone and chlorpromazine. Can J Physiol Pharmacol 55:778-790

Tang M, Falk JL (1990): Schedule-induced oral self-administration of cocaine and ethanol solutions: Lack of effect of chronic desipramine. Drug Alcohol Depend 25:21-25

Thompson T, Schuster CR (1964): Morphine self-administration, food reinforced, and avoidance behaviors in rhesus monkeys. Psychopharmacologia 5:87-94

Thompson T, Unna KR (1977): Predicting Dependence Liability of Stimulant and Depressant Drugs. Baltimore, University Park Press

Tutton CS, Crayton JW (1993): Current pharmacotherapies for cocaine abuse: A review. J Addict Dis 12:109-127

Van Ree JM, Ramsey N (1987): The dopamine hypothesis of opiate reward challenged. Eur J Pharmacol 134:239-243

Vanover KE, Woolverton WL (1994): Behavioral effects of the dopamine autoreceptor agonist PD 128483 alone and in combination with cocaine. J Pharmacol Exp Ther 270: 1049-1056

Vanover KE, Piercey MF, Woolverton WL (1993): Evaluation of the reinforcing and discriminative stimulus effects of cocaine in combination with (+) -AJ76 or clozapine. J Pharmacol Exp Ther 266:780-789

Verebey K, Volavka J, Mule SJ, Resnick RB (1976): Naltrexone: Disposition, metabolism and effects after acute and chronic dosing. Clin Pharmacol Ther 20:315-328

Wang Y, Joharchi N, Fletcher PJ, Sellers EM, Higgins GA (1995): Further studies to examine the nature of dexfenfluramine-induced suppression of heroin self-administration. Psychopharmacology 120:134-141

Weed MR, Vanover KE, Woolverton WL (1993): Reinforcing effect of the $D_{1}$ dopamine agonist SKF 81297 in rhesus monkeys. Psychopharmacology 113:51-52

Weeks JR (1962): Experimental morphine addiction: Method for automatic intravenous injection in unrestrained rats. Science 138:143-144

Weeks JR, Collins RJ (1964): Factors affecting voluntary morphine intake in self-maintained addicted rats. Psychopharmacologia 6:267-279
Weeks JR, Collins RJ (1976): Changes in morphine selfadministration in rats induced by prostaglandin E1 and naloxone. Prostaglandins 12:11-19

Weiss RD (1988): Relapse to cocaine abuse after initiating desipramine treatment. JAMA 260:2545-2546

Wilson MC, Schuster CR (1972): The effects of chlorpromazine on psychomotor stimulant self-administration in the rhesus monkey. Psychopharmacologia 26:115-126

Wilson MC, Schuster CR (1973): The effects of stimulants and depressants on cocaine self-administration behavior in the rhesus monkey. Psychopharmacologia 31:291-304

Wilson MC, Schuster CR (1976): Mazindol self-administration in the rhesus monkey. Pharmacol Biochem Behav $4: 207-210$

Winger G (1988): Pharmacological modifications of cocaine and opioid self-administration. In Clouet DH, Asghar K, Brown RM (eds), Mechanisms of Cocaine Abuse and Toxicity, NIDA Research Monograph No. 88. Washington, DC, U.S. Government Printing Office, pp 125-136

Winger G (1994): Dopamine antagonist effects on behavior maintained by cocaine and alfentanil in rhesus monkeys. Behav Pharmacol 5:141-152

Winger G, Woods JH (1985): Comparison of fixed-ratio and progressive-ratio schedules on maintenance of stimulant drug-reinforced responding. Drug Alcohol Depend 15:123-130

Winger G, Skjoldager P, Woods JH (1992): Effects of buprenorphine and other opioid agonists and antagonists on alfentanil- and cocaine-reinforced responding in rhesus monkeys. J Pharmacol Exp Ther 261:311-317

Wise RA, Newton P, Leeb K, Burnette B, Pocock D, Justice J Jr (1995): Fluctuations in nucleus accumbens dopamine concentration during intravenous cocaine self-administration in rats. Psychopharmacology 120:10-20

Witkin JM (1994): Pharmacotherapy of cocaine abuse: Preclinical development. Neurosci Biobehav Rev 18:121142

Wood PL, Charleson SE, Lane E, Hudgin RL (1981): Multiple opioid receptors: Differential binding of $\mu, \kappa$ and $\delta$ agonists. Neuropharmacolog 20:1215-1220

Woods JH, Schuster CR (1968): Reinforcement properties of morphine, cocaine and SPA as a function of unit dose Internat J Addict 3:231-237

Woods JH, Schuster CR (1970): Regulation of drug selfadministration. In Harris RT, McIsaac WM, Schuster CR (eds), Advances in Mental Science II. Drug Dependence. Austin, TX, Texas Research Institute of Mental Sciences, pp 158-169

Woods JH, Schuster CR (1971): Opiates as reinforcing stimuli. In Thompson T, Pickens R (eds), Stimulus Properties of Drugs. New York, Apple-Century-Crofts, pp 163-175

Woods JH, Downs DA, Carney J (1975): Behavioral functions of narcotic antagonists: Response drug contingencies. Fed Proc 34:1777-1784

Woods JH, Winger G, France CF (1987): Reinforcing and discriminative stimulus effects of cocaine: Analysis of pharmacological mechanisms. In Fisher S, Raskin A, Uhlenhuth $\mathrm{EH}$ (eds), Cocaine: Clinical and Behavioral Aspects. New York, Oxford University Press, pp 21-65

Woolverton WL (1986): Effects of a $D_{1}$ and $D_{2}$ dopamine 
antagonist in the self-administration of cocaine and piribedil by rhesus monkeys. Pharmacol Biochem Behav 24:351-535

Woolverton WL, Balster RL (1981): Effects of antipsychotic compounds in rhesus monkeys given a choice between cocaine and food. Drug Alcohol Depend 8:69-78

Woolverton WL, Kleven MS (1988): Evidence for cocaine dependence in monkeys following a prolonged period of exposure. Psychopharmacology (Berl) 94:288-291

Woolverton WL, Johnson KM (1992): Neurobiology of cocaine abuse. Trends Pharmacol Sci 13:193-200

Woolverton WL, Kleven MS (1992): Assessment of new medications for stimulant abuse treatment. In Harris LS (ed), Problems of Drug Dependence 1991, NIDA Research Monograph No. 119, DHHS (ADM) 92-1888. Washington, DC, U.S. Government Printing Office, pp 155-159

Woolverton WL, Virus RM (1989): The effects of a $D_{1}$ and a
$\mathrm{D}_{2}$ dopamine antagonist on behavior maintained by cocaine or food. Pharmacol Biochem Behav 32:691-697

Woolverton WL, Goldberg LI, Ginos JZ (1984): Intravenous self-administration of dopamine receptor agonists by rhesus monkeys. J Pharmacol Exp Ther 230:678-683

Wurster RM, Griffiths RR, Findley JD, Brady JG (1977): Reduction of heroin self-administration in baboons by manipulation of behavioral and pharmacological conditions. Pharmacol Biochem Behav 7:519-528

Yanagita T, Deneau GA, Seevers MH (1965): A technique for chronic intravenous programmed or self-administration of drugs to monkeys. Proc Int Union of Physiol Sci $87: 453-457$

Young AM, Swain HH, Woods JH (1981): Comparison of opioid agonists in maintaining responding and in suppressing morphine withdrawal in rhesus monkeys. Psychopharmacology (Berl) 74:329-335 